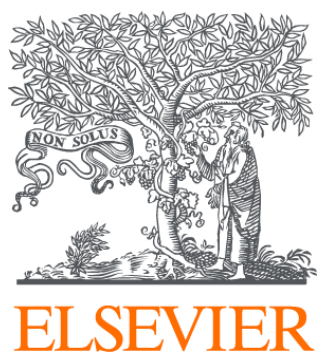

Since January 2020 Elsevier has created a COVID-19 resource centre with free information in English and Mandarin on the novel coronavirus COVID-

19. The COVID-19 resource centre is hosted on Elsevier Connect, the company's public news and information website.

Elsevier hereby grants permission to make all its COVID-19-related research that is available on the COVID-19 resource centre - including this research content - immediately available in PubMed Central and other publicly funded repositories, such as the WHO COVID database with rights for unrestricted research re-use and analyses in any form or by any means with acknowledgement of the original source. These permissions are granted for free by Elsevier for as long as the COVID-19 resource centre remains active. 


\section{Baricitinib therapy in COVID-19: A pilot study on safety and clinical impact}

\section{Dear Editor,}

As discussed in the Journal recently ${ }^{1}$ the SARS-CoV-2, a new $\beta$ Coronavirus, uses the Angiotensin Converting Enzyme-2 Receptor to enter airway cells. Viral endocytosis is mediated by several factors, including clathrin, the adaptor protein-2 complex (AP2) and the adaptor-associated kinase-1 (AAK1). ${ }^{2}$

According to a recent report, ${ }^{3}$ COVID-19, the disease caused by SARS-CoV-2, is characterized by three clinical patterns: no symptoms, mild to moderate disease, severe pneumonia requiring admission to Intensive Care Unit (ICU) in up to $31 \%$ of the patients. ${ }^{3}$

Thus far, there is no specific therapy for COVID-19 infection. No benefit of lopinavir-ritonavir treatment resulted in a recent trial. ${ }^{4}$ Hydroxychloroquine, currently used in view of its "in vitro" observed effect of reduction of viral replication, seems unsatisfactory. ${ }^{5}$

Elevated proinflammatory cytokine/chemokine responses seem associated with respiratory failure. ${ }^{3}$ Recently, tocilizumab, an interleukin-6 inhibitor, was reported as effective in patients with severe COVID-19 pneumonia. $^{6}$

Baricitinib, another inhibitor of cytokine-release, seems an interesting anti-inflammatory drug. It is a Janus kinase inhibitor (anti-JAK) licensed for the treatment of rheumatoid arthritis (RA) with good efficacy and safety records. ${ }^{7}$ Moreover it seems to have anti-viral effects by its affinity for AP2-associated protein AAK1, reducing SARS-CoV-2 endocytosis. ${ }^{8}$

On this basis, we assessed the safety of baricitinib therapy combined with lopinavir-ritonavir in moderate COVID-19 pneumonia patients and we evaluated its clinical impact.

All consecutive hospitalized patients (March 16th -30th) with moderate COVID-19 pneumonia, older than 18 years, were treated for 2 weeks with baricitinib tablets $4 \mathrm{mg} /$ day added to ritonavir-lopinavir therapy. The last consecutive patients with moderate COVID-19 pneumonia receiving standard of care therapy (lopinavir/ritonavir tablets $250 \mathrm{mg}$ /bid and hydroxychloroquine $400 \mathrm{mg} /$ day/orally for 2 weeks) admitted before the date of the first baricitinib-treated patient served as controls. Antibiotics were scheduled only in the case of suspected bacterial infection.
Inclusion criteria were: a. SARS-Co-V2 positivity in the nasal/oral swabs; b. presence of at least 3 of the following symptoms: fever, cough, myalgia, fatigue; c. evidence of radiological pneumonia. After discharge, patients treated with baricitinib were planned to be followed for additional 6 weeks. Exclusion criteria: history of thrombophlebitis (TP), latent tuberculosis infection (QuantiFERON Plus-test positivity, Qiagen, Germany ${ }^{9}$ ), pregnancy and lactation.

Mild to moderate COVID-19 disease definition: presence of bilateral pneumonia with or without ground glass opacity and in absence of consolidation, not requiring intubation at enrollment; arterial oxygen saturation $(\mathrm{SpO} 2)>92 \%$ at room-air, and ratio arterial oxygen partial pressure/fractional inspired oxygen ( $\mathrm{PaO} 2 / \mathrm{FiO} 2)$ 100-300 mmHg. Parameters daily accessed were: fever, pulmonary function, Modified Early Warning Score (MEWS), ${ }^{10}$ pulse rate, blood pressure. After the initial execution, radiology imaging was performed on demand. Laboratory investigations included blood cell counts with differential counts, tests for liver and kidney functions, erythrocyte sedimentation rate (ESR), C-reactive protein (CRP), and procalcitonin.

The trial was approved by the Azienda-USL Toscana Centro Committee for off-label use of drugs. All patients signed a written informed consent to participate to the study.

Descriptive statistics, presented as median and interquartile range (IQR), were calculated using Microsoft ${ }^{\circledR}$ Office Excel for Windows and (C2019 Minitab, LLC for Windows. Mann-Whitney $U$ test was used for pairwise comparisons, Wilcoxon-test for paired data, Fisher's exact test for categorical variables comparisons. P values $\leq 0.05$ were considered statistically significant.

Twelve patients, 10 males and 2 females, with a median age of 63.5 (IQR: 57.7-72.2) years were enrolled in the hospitals in Prato and Alessandria. Clinical characteristics are shown in Table 1. Comorbidities were similar in the two groups.

Baricitinib-treatment was well tolerated with no serious adverse events (AEs). Therapy was withdrawn in 1 patient after 10 days of treatment due to consistent transaminases elevation (AST: $267 \mathrm{U} / \mathrm{L} ;$ ALT: $298 \mathrm{U} / \mathrm{L}$ ), probably due to the antiviral therapy rather than to the baricitinib treatment, which is mainly renalmetabolized. In addition, no bacterial or opportunistic infections, trombo-flebitis or hematologic toxicity were observed. 
Table 1

Baseline demographic, clinical, and laboratory characteristics of COVID-19 patients treated with either baricitinib or with standard COVID-19 therapy.

\begin{tabular}{|c|c|c|c|}
\hline Feature & Baricitinib group & Standard COVID-19 therapy & $\mathrm{P}$ value \\
\hline Patient number, $\mathrm{N}(\%)$ & $12(100)$ & $12(100)$ & \\
\hline Male/female, $\mathrm{N}(\%)$ & $10 / 2(83 / 17)$ & $10 / 2(83 / 17)$ & 1 \\
\hline Age years, median (IQR) & $63.5(57.7-72.2)$ & $63(55.5-69.5)$ & 0.707 \\
\hline Days interval from symptoms onset and therapy starting, days $\mathrm{N}$ & $6(4-6.25)$ & $4.5(4-5.25)$ & 0.204 \\
\hline Cough $\mathrm{N}(\%)$ & $10(83)$ & $12(100)$ & 0.478 \\
\hline Dyspnea N (\%) & $10(83)$ & $9(75)$ & 1.000 \\
\hline Sputum production $\mathrm{N}(\%)$ & $4(33)$ & $3(25)$ & 1.000 \\
\hline Headache N (\%) & $5(42)$ & $4(33)$ & 1.000 \\
\hline Diarrhea N (\%) & $2(17)$ & $1(8)$ & 1.000 \\
\hline Ageusia/Anosmia N (\%) & $6(50)$ & $5(42)$ & 1.000 \\
\hline Hypertension N (\%) & $3(25)$ & $2(17)$ & 1.000 \\
\hline Diabetes N (\%) & $3(25)$ & $4(33)$ & 1.000 \\
\hline COPD N (\%) & $2(17)$ & $3(25)$ & 1.000 \\
\hline CVD N (\%) & $2(17)$ & 2 17) & 1.000 \\
\hline Malignancy & $0(0)$ & $1(8)$ & 1.000 \\
\hline Fever ${ }^{\circ} \mathrm{C}$, median (IQR) & $38(37.4-38.2)$ & $38.1(37.7-38.7)$ & 0.356 \\
\hline Breath rate $\mathrm{N} / \mathrm{min}$, median (IQR), & $23(19.5-24.2)$ & $22(19.7-24)$ & 0.665 \\
\hline SpO2 (\%),median (IQR) & $91(90-92.5)$ & $92(91.2-93)$ & 0.157 \\
\hline $\mathrm{PaO} 2 / \mathrm{FiO} 2$, median (IQR) & $290(199.2-292.2)$ & $268.6(264.4-295)$ & 0.603 \\
\hline Pulse rate, median (IQR) & $82(73-88.3)$ & $90(87.2-94.5)$ & 0.069 \\
\hline SBP mm/Hg, median (IQR) & $120(110-131.2)$ & $105(100-111.25)$ & 0.003 \\
\hline DBP mm/Hg, median (IQR) & $70(60-80)$ & $62.5(60-66.25)$ & 0.094 \\
\hline WBC $\left(x 10^{9} / \mathrm{L}\right)$, median $(\mathrm{IQR})$ & $7.8(5.8-10.8)$ & $8.2(7.3-8.8)$ & 0.908 \\
\hline Neutrophils $\left(\mathrm{x} 10^{9} / \mathrm{L}\right)$, median (IQR) & $6,5(4.5-7.7)$ & $6.9(6.4-7.6)$ & 0.707 \\
\hline Lymphocytes $\left(\times 10^{9} / \mathrm{L}\right)$, median (IQR) & $0.7(0.7-1.2)$ & $0.89(0.7-0.9)$ & 1.000 \\
\hline Hemoglobin $(\mathrm{g} / \mathrm{L})$, median (IQR) & $118(102-134.2)$ & $125(108-134)$ & 0.568 \\
\hline Platelets (x109/L), median (IQR) & $203(174-227)$ & $366(340-407)$ & 0.000 \\
\hline ALT (U/L), median (IQR) & $28.5(23.5-52)$ & $44(37-50)$ & 0.157 \\
\hline AST (U/L), median (IQR) & $34(26.2-48)$ & $44(34.7-47)$ & 0.525 \\
\hline Creatinine (mg/dl), median (IQR) & $1.0(0.9-1.1)$ & $1.00(0.9-1)$ & 0.583 \\
\hline CRP (mg/dl), median (IQR) & $8.2(5.8-14.5)$ & $3(1.5-3.2)$ & 0.002 \\
\hline Procalcitonin ng/ml, median (IQR) & $0.7(0.4-1.1)$ & $1.2(0.8-2.1)$ & 0.902 \\
\hline MEWS, median (IQR) & $3(2-3.25)$ & $3(3-4)$ & 0.544 \\
\hline
\end{tabular}

Abbreviations and symbols: $N=$ number; $\%=$ percentage; ${ }^{\circ} \mathrm{C}$ : grade Celsius; $\min =$ minute; SpO2 = peripheral capillary oxygen saturation; $\mathrm{PaO} 2 / \mathrm{FiO} 2=$ ratio of arterial oxygen partial pressure to fractional inspired oxygen; $\mathrm{SBP}=$ systolic blood pressure; $\mathrm{DBP}=\mathrm{di}-$ astolic blood pressure; WBC $=$ white blood cells; AST = serum glutamic oxaloacetic transaminase; ALT = serum alanine aminotransferase; MEWS = Modified Early Warning Score; IQR: Interquartile range.

Results are summarized in Table 2. Overall, in the baricitinibtreated group, all clinical characteristics and respiratory function parameters significantly improved both at week 1 and week 2 compared to baseline. CRP values significantly decreased at the same timeframes. In the control-group, no significant changes were recorded at week 2 compared to baseline.

Fever, SpO2, PaO2/FiO2, CRP, and MEWS significantly improved in the baricitinib-treated group compared with controls (p: 0.000 ; $0.000 ; 0.017 ; 0.023 ; 0.016$, respectively). ICU transfer was requested in $33 \%(4 / 12)$ of controls and in none of the baricitinibtreated patients $(p=0.093)$. Discharge at week 2 occurred in $58 \%$ $(7 / 12)$ of the baricitinib-treated patients vs $8 \%(1 / 12)$ of controls $(p=0.027)$. At discharge, $57 \%(4 / 7)$ had negative viral nasal/oral swabs.

These preliminary results on 12 patients with moderate COVID19 pneumonia confirmed the safety of baricitinib therapy in a clinical context different from RA. ${ }^{7}$ No infections, cardiovascular and hematologic AEs occurred after 2 weeks treatment. The short-term drug exposure may probably explain the absence of the supposed AEs. To confirm the long-term safety, the patients will be followed- up for further 6 weeks, but the restricted time of treatment and the short half-life of the drug $(12.5 \mathrm{~h})$ suggest as unlikely the later AEs occurrence.

Remarkably, both at week 1 and week 2, baricitinib therapy significantly improved the clinical and laboratory parameters, none of the patients required ICU support, and the majority of the patients were discharged. These results were likely due to the rapid action of the drug and the short median interval of 6 days from symptoms-onset and therapy starting,

The major limitations of this pilot study were its open-label design with no randomization and the low number of treated patients. A proper control group was missing and this is indeed required to formally demonstrate the efficacy of the therapy.

The use of baritinicib therapy may limit the cytokine-release syndrome associated with COVID-19 and it may be useful because it acts against a wide-range of cytokines. Although our results cannot be generalized to all COVID-19 patients, we believe that these data are encouraging in terms of safety, improvement of clinical impact and reduction of severity progression, and it may be the first-step for future controlled, larger studies. 
Table 2

Clinical, laboratory and respiratory parameters of COVID-19 patients after 1- or 2-week treatment in the baricitinib-treated group and in the standard-treated group: comparison within the same treatment group and between the 2 different treatment groups.

\begin{tabular}{|c|c|c|c|c|c|c|c|c|c|}
\hline \multirow[b]{2}{*}{ Clinical, laboratory, respiratory parameters } & \multicolumn{4}{|c|}{ Baricitinib-treated } & \multicolumn{4}{|c|}{ Standard therapy } & \multirow{2}{*}{$\begin{array}{l}\text { Baricitinib vs Standard therapy } \\
\text { P value } \\
\text { Week } 1^{*} \text { comparisons or Week } \\
2 \dagger \text { comparisons }\end{array}$} \\
\hline & Baseline & Week 1 & Week 2 & $\begin{array}{l}\text { P value } \\
\text { Baseline values vs Week } \\
1^{*} \text { or vs Week } 2 \dagger \text { values }\end{array}$ & Baseline & Week 1 & Week 2 & $\begin{array}{l}\text { P value } \\
\text { Baseline values vs Week } \\
1^{*} \text { or vs Week } 2 \dagger \text { values }\end{array}$ & \\
\hline Cough $\mathbf{N}(\%)$ & $10(83)$ & $8(66)$ & 0 & $\begin{array}{l}0.640 * \\
0.000 \dagger\end{array}$ & $12(100)$ & $10(83)$ & $9(75)$ & $\begin{array}{l}0.478 * \\
0.217 \dagger\end{array}$ & $\begin{array}{l}0.640 * \\
\mathbf{0 . 0 0 0} \dagger\end{array}$ \\
\hline Dyspnea N (\%) & $10(83)$ & $1(8)$ & 0 & $\begin{array}{l}0.001 \\
0.000 \dagger\end{array}$ & $9(75)$ & $8(67)$ & $8(67)$ & $\begin{array}{l}1.000^{*} \\
1.000 \dagger\end{array}$ & $\begin{array}{l}0.001 * \\
0.001 \dagger\end{array}$ \\
\hline Sputum production $\mathbf{N}(\%)$ & $4(33)$ & $1(8)$ & $1(8)$ & $\begin{array}{l}0.317 * \\
0.317 \dagger\end{array}$ & $3(25)$ & $3(25)$ & $3(25)$ & $\begin{array}{l}1.000^{*} \\
1.00 \dagger^{\prime}\end{array}$ & $\begin{array}{l}0.590 * \\
0.217 \dagger\end{array}$ \\
\hline Headache $N(\%)$ & $5(42)$ & 0 & 0 & $\begin{array}{l}0.037 * \\
0.037 \dagger\end{array}$ & $4(33)$ & $2(17)$ & $3(25)$ & $\begin{array}{l}0.640^{*} \\
1.000 \dagger\end{array}$ & $\begin{array}{l}0.478 * \\
0.217 \dagger\end{array}$ \\
\hline Diarrhea N (\%) & $2(17)$ & 0 & 0 & $\begin{array}{l}0.478 * \\
0.478 \dagger\end{array}$ & $1(8)$ & $1(8)$ & 0 & $\begin{array}{l}1.000^{*} \\
1.000 \dagger\end{array}$ & $\begin{array}{l}1.000^{\prime} \\
\mathrm{NA} \dagger\end{array}$ \\
\hline Ageusia/Anosmia N (\%) & $6(50)$ & $3(25)$ & $2(17)$ & $\begin{array}{l}0.400 * \\
0.193 \dagger\end{array}$ & $5(42)$ & $4(33)$ & $3(25)$ & $\begin{array}{l}1.000^{*} \\
0.667 \dagger\end{array}$ & $\begin{array}{l}1.000^{*} \\
1.000 \dagger\end{array}$ \\
\hline Fever, ${ }^{\circ} \mathrm{C}$ median $(\mathrm{IQR})$ & $\begin{array}{l}38 \\
(37.4-38.2)\end{array}$ & $\begin{array}{l}36.1 \\
(36-36.4)\end{array}$ & $\begin{array}{l}36 \\
(36-36.1)\end{array}$ & $\begin{array}{l}0.001 \\
0.001 \dagger\end{array}$ & $\begin{array}{l}38.1 \\
(37.7-38.7)\end{array}$ & $\begin{array}{l}37.7 \\
(37.1-38.2)\end{array}$ & $\begin{array}{l}37.8 \\
(37.4-38.1)\end{array}$ & $\begin{array}{l}0.123 * \\
0.285 \dagger\end{array}$ & $\begin{array}{l}0.000 \\
0.000 \dagger\end{array}$ \\
\hline Breath, N/min median (IQR) & $\begin{array}{l}23 \\
(19.5-24.2)\end{array}$ & $\begin{array}{l}18 \\
(14-20.2)\end{array}$ & $\begin{array}{l}16 \\
(16-18)\end{array}$ & $\begin{array}{l}0 \bullet 004 \text { * } \\
0.010{ }^{\dagger}\end{array}$ & $\begin{array}{l}22 \\
(19.7-24)\end{array}$ & $\begin{array}{l}19 \\
(17.5-21.7)\end{array}$ & $\begin{array}{l}18 \\
(16-22.7)\end{array}$ & $\begin{array}{l}0.063 * \\
0.885 \dagger\end{array}$ & $\begin{array}{l}0.603 * \\
0.094 \dagger\end{array}$ \\
\hline Sp02,\% median (IQR) & $\begin{array}{l}91 \\
(90-92.5)\end{array}$ & $\begin{array}{l}96 \\
(96-98.2)\end{array}$ & $\begin{array}{l}97 \\
(95.7-98)\end{array}$ & $\begin{array}{l}0.000 * \\
0.002 \dagger\end{array}$ & $\begin{array}{l}92 \\
(91.2-93)\end{array}$ & $\begin{array}{l}93.6 \\
(90.8-94.1)\end{array}$ & $\begin{array}{l}93.1 \\
(86.5-94.2)\end{array}$ & $\begin{array}{l}0.289 * \\
0.544 \dagger\end{array}$ & $\begin{array}{l}0.000 * \\
0.000 \dagger\end{array}$ \\
\hline Pa02/FiO2 value median (IQR) & $\begin{array}{l}290 \\
(199.2-292.2)\end{array}$ & $\begin{array}{l}410 \\
(315.7-452)\end{array}$ & $\begin{array}{l}421.5 \\
(308.6-456)\end{array}$ & $\begin{array}{l}0 \bullet 000 * \\
0.001 \dagger\end{array}$ & $\begin{array}{l}268.6 \\
(264.4-295)\end{array}$ & $\begin{array}{l}302.2 \\
(240.1-405.7)\end{array}$ & $\begin{array}{l}267.6 \\
(144.2-350.5)\end{array}$ & $\begin{array}{l}0.106 * \\
0.862 \dagger\end{array}$ & $\begin{array}{l}0.237 * \\
\mathbf{0 . 0 1 7} \dagger\end{array}$ \\
\hline Pulse rate, $\mathrm{N} /$ minute median (IQR) & $\begin{array}{l}82 \\
(73-88.3)\end{array}$ & $\begin{array}{l}70 \\
(68-76)\end{array}$ & $\begin{array}{l}67 \\
(63.2-71.7)\end{array}$ & $\begin{array}{l}\text { 0•050 * } \\
0.077 \dagger\end{array}$ & $\begin{array}{l}90 \\
(87.2-94.5)\end{array}$ & $\begin{array}{l}85.5 \\
(77.5-93.5)\end{array}$ & $\begin{array}{l}89 \\
(84.5-104.5)\end{array}$ & $\begin{array}{l}0.433 * \\
1.000 \dagger\end{array}$ & $\begin{array}{l}0.002 * \\
0.000 \dagger\end{array}$ \\
\hline WBC, $\times 10^{9} / \mathrm{L}$ median (IQR) & $\begin{array}{l}7.8 \\
(5.8-10.8)\end{array}$ & $\begin{array}{l}7.3 \\
(6.2-9)\end{array}$ & $\begin{array}{l}7.2 \\
(6.3-9.3)\end{array}$ & $\begin{array}{l}0 \bullet 581 \text { * } \\
0.122 \dagger\end{array}$ & $\begin{array}{l}8.2 \\
(7.3-8.8)\end{array}$ & $\begin{array}{l}6.9 \\
(6.5-7.4)\end{array}$ & $\begin{array}{l}8 \\
(7.4-8.3)\end{array}$ & $\begin{array}{l}0.013 * \\
0.931 \dagger\end{array}$ & $\begin{array}{l}0.389 * \\
0.634 \dagger\end{array}$ \\
\hline Neutrophils, $x^{10} / \mathrm{L}$ median (IQR) & $\begin{array}{l}6.5 \\
(4.5-7.7)\end{array}$ & $\begin{array}{l}5.2 \\
(4.8-6.9)\end{array}$ & $\begin{array}{l}4.8 \\
(4-7.1)\end{array}$ & $\begin{array}{l}0 \bullet 351 * \\
0.201 \dagger\end{array}$ & $\begin{array}{l}6.9 \\
(6.4-7.6)\end{array}$ & $\begin{array}{l}5.9 \\
(5.2-6.4)\end{array}$ & $\begin{array}{l}6.8 \\
(6.1-7.2)\end{array}$ & $\begin{array}{l}0.026 * \\
1.000 \dagger\end{array}$ & $\begin{array}{c}0.436 * \\
0.201 \dagger\end{array}$ \\
\hline
\end{tabular}


Table 2 (continued)

\begin{tabular}{|c|c|c|c|c|c|c|c|c|c|}
\hline \multirow[b]{2}{*}{ Clinical, laboratory, respiratory parameters } & \multicolumn{4}{|c|}{ Baricitinib-treated } & \multicolumn{4}{|c|}{ Standard therapy } & \multirow{2}{*}{$\begin{array}{l}\text { Baricitinib vs Standard therapy } \\
\text { P value } \\
\text { Week } 1^{*} \text { comparisons or Week } \\
2 \dagger \text { comparisons }\end{array}$} \\
\hline & Baseline & Week 1 & Week 2 & $\begin{array}{l}\text { P value } \\
\text { Baseline values vs Week } \\
1^{*} \text { or vs Week } 2 \dagger \text { values }\end{array}$ & Baseline & Week 1 & Week 2 & $\begin{array}{l}\text { P value } \\
\text { Baseline values vs Week } \\
1^{*} \text { or vs Week } 2 \dagger \text { values }\end{array}$ & \\
\hline 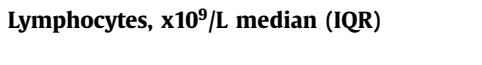 & $\begin{array}{l}0.7 \\
(0.7-1.2)\end{array}$ & $\begin{array}{l}1.14 \\
(0.9-1.6)\end{array}$ & $\begin{array}{l}1.3 \\
(1.1-1.6)\end{array}$ & $\begin{array}{l}0 \bullet 147 * \\
0.038 \dagger\end{array}$ & $\begin{array}{l}0.89 \\
(0.7-0.9)\end{array}$ & $\begin{array}{l}0.9 \\
(0.7-1)\end{array}$ & $\begin{array}{l}0.9 \\
(0.7-0.9)\end{array}$ & $\begin{array}{l}0.624 * \\
0.817 \dagger\end{array}$ & $\begin{array}{l}0.187 * \\
0.092 \dagger\end{array}$ \\
\hline Hb, g/L median (IQR) & $\begin{array}{l}118 \\
(102-134.2)\end{array}$ & $\begin{array}{l}122 \\
(104-128.1)\end{array}$ & $\begin{array}{l}128 \\
(119-129)\end{array}$ & $\begin{array}{l}0 \bullet 411 * \\
0.451 \dagger\end{array}$ & $\begin{array}{l}125 \\
(108-134)\end{array}$ & $\begin{array}{l}123 \\
(112-127.2)\end{array}$ & $\begin{array}{l}121 \\
(114-130)\end{array}$ & $\begin{array}{l}0.702 * \\
0.689 \dagger\end{array}$ & $\begin{array}{l}0.607 * \\
0.191 \dagger\end{array}$ \\
\hline Platelets, $x^{10} / \mathbf{L}$ median $(\mathrm{IQR})$ & $\begin{array}{l}203 \\
(174-227)\end{array}$ & $\begin{array}{l}312 \\
(233-358)\end{array}$ & $\begin{array}{l}354 \\
(65-512)\end{array}$ & $\begin{array}{l}0 \bullet 121 * \\
0.018 \dagger\end{array}$ & $\begin{array}{l}366 \\
(340-407)\end{array}$ & $\begin{array}{l}358(321- \\
461)\end{array}$ & $\begin{array}{l}389 \\
(315-430)\end{array}$ & $\begin{array}{l}0.468 * \\
0.624 \dagger\end{array}$ & $\begin{array}{l}0.315^{*} \\
0.468 \dagger\end{array}$ \\
\hline ALT, U/L median (IQR) & $\begin{array}{l}28.5 \\
(23.5-52)\end{array}$ & $\begin{array}{l}49 \\
(43.2-57.2)\end{array}$ & $\begin{array}{l}78 \\
(43-83.7)\end{array}$ & $\begin{array}{l}0 \bullet 712 \text { * } \\
0.838 \dagger\end{array}$ & $\begin{array}{l}44 \\
(37-50)\end{array}$ & $\begin{array}{l}56.5 \\
(36-67.2)\end{array}$ & $\begin{array}{l}44.5 \\
(39.5-54.5)\end{array}$ & $\begin{array}{l}0.094 \text { * } \\
0.419\end{array}$ & $\begin{array}{l}0.624^{*} \\
0.141 \dagger\end{array}$ \\
\hline AST, U/L median (IQR) & $\begin{array}{l}34 \\
(26.2-48)\end{array}$ & $\begin{array}{l}41 \\
(37-54)\end{array}$ & $\begin{array}{l}48.5 \\
(38-58.5)\end{array}$ & $\begin{array}{l}0.542 * \\
0.080 \dagger\end{array}$ & $\begin{array}{l}44 \\
(34.7-47)\end{array}$ & $\begin{array}{l}44.5 \\
(41.7-51.5)\end{array}$ & $\begin{array}{l}42.5 \\
(35-55.2)\end{array}$ & $0.624 \dagger$ & $\begin{array}{l}0.665 * \\
0.453 \dagger\end{array}$ \\
\hline Creatinine, $\mathrm{mg} / \mathrm{dl}$ median (IQR) & $\begin{array}{l}1.0 \\
(0.9-11)\end{array}$ & $\begin{array}{l}0 \bullet 92 \\
(0.8-1)\end{array}$ & $\begin{array}{l}0.88 \\
(0.7-0.9)\end{array}$ & $\begin{array}{l}0 \bullet 478 * \\
0.238 \dagger\end{array}$ & $\begin{array}{l}1.00 \\
(0.9-1)\end{array}$ & $\begin{array}{l}1.0 \\
(0.9-11)\end{array}$ & $\begin{array}{l}1.1 \\
(1-12)\end{array}$ & $\begin{array}{l}0.347 * \\
0.214 \dagger\end{array}$ & $\begin{array}{l}0.572 * \\
0.165 \dagger\end{array}$ \\
\hline CRP, mg/dl median (IQR) & $\begin{array}{l}8.2 \\
(5.8-14.5)\end{array}$ & $\begin{array}{l}2.26 \\
(0.9-4.8)\end{array}$ & $\begin{array}{l}1.07 \\
(0.7-3.4)\end{array}$ & $\begin{array}{l}0.003 \text { * } \\
0.001 \dagger\end{array}$ & $\begin{array}{l}3 \\
(1.5-3.2)\end{array}$ & $\begin{array}{l}1.7 \\
(1.1-8.5)\end{array}$ & $\begin{array}{l}3.2 \\
(2.1-9.2)\end{array}$ & $\begin{array}{l}0.171^{*} \\
0.225 \dagger\end{array}$ & $\begin{array}{l}0.862 * \\
\mathbf{0 . 0 2 3}\end{array}$ \\
\hline Procalcitonine, $\mathrm{ng} / \mathrm{ml}$ median (IQR) & $\begin{array}{l}0.7 \\
(0.4-1.1)\end{array}$ & $\begin{array}{l}0.8 \\
(0.6-1.3)\end{array}$ & $\begin{array}{l}0.8(0.7- \\
1.5)\end{array}$ & $\begin{array}{l}0.625 * \\
0.567 \dagger\end{array}$ & $\begin{array}{l}1.2 \\
(0.8-2.1)\end{array}$ & $\begin{array}{l}1.4 \\
(07-1.6)\end{array}$ & $\begin{array}{l}1.2 \\
(0.6-1.3)\end{array}$ & $\begin{array}{l}0.268 * \\
0.782 \dagger\end{array}$ & $\begin{array}{l}0.256 * \\
0.189 \dagger\end{array}$ \\
\hline MEWS median (IQR) & $\begin{array}{l}3 \\
(2-3.25)\end{array}$ & $\begin{array}{l}1 \\
(1-1)\end{array}$ & $\begin{array}{l}0 \\
(0-1)\end{array}$ & $\begin{array}{l}0.000 * \\
0.000 \dagger\end{array}$ & $\begin{array}{l}3 \\
(3-4)\end{array}$ & $\begin{array}{l}2 \\
(2-3)\end{array}$ & $\begin{array}{l}2 \\
(1-6.2)\end{array}$ & $\begin{array}{l}0.643 * \\
0.063 \dagger\end{array}$ & $\begin{array}{l}0.177^{*} \\
\mathbf{0 . 0 1 6} \dagger\end{array}$ \\
\hline ICU transfer $\mathbf{N}(\%)$ & 0 & $0(0)$ & $0(0)$ & $\begin{array}{l}\mathrm{NA} * \\
\mathrm{NA} \dagger\end{array}$ & 0 & $3(25)$ & $4(33)$ & $\begin{array}{l}0.217 * \\
0.093 \dagger\end{array}$ & $\begin{array}{l}0.217^{*} \\
0.093 \dagger\end{array}$ \\
\hline Discharged N (\%) & 0 & $3(25)$ & $7(58) \grave{i}$ & $\begin{array}{l}0.217^{*} \\
\mathbf{0 . 0 0 5} \dagger\end{array}$ & 0 & $0(0)$ & $1(8)$ & $\begin{array}{l}\mathrm{NA} * \\
1.000 \dagger\end{array}$ & $\begin{array}{l}0.217^{*} \\
\mathbf{0 . 0 2 7} \dagger\end{array}$ \\
\hline
\end{tabular}

Abbreviations and symbols: $\mathrm{N}$ : number;\%: percentage; ${ }^{\circ} \mathrm{C}$ : grade Celsius; min: minute; SpO2: peripheral capillary oxygen saturation; PaO2/FiO2: ratio of arterial oxygen partial pressure to fractional inspired oxygen; SBP: systolic blood pressure; DBP: diastolic blood pressure; WBC: white blood cells; AST: serum glutamic oxaloacetic transaminase; ALT: serum alanine aminotransferase; IU: international unit; MEWS: Modified Early Warning Score; IQR: Interquartile range. Statistical analysis was performed using the Wilcoxon test (for paired comparisons) or the Mann-Whitney test. P value was considered significant if $<0.05 .{ }^{*}$ Differences
between the values at baseline and after 1 week. $\dagger$ Differences between the values at baseline and after 2 weeks. Standard therapy group: COVID-19 patients under standard respiratory therapy and antiretrovirals and between the values at baseline and after 1 week. $\dagger$ Differences between the values at baseline and after 2 weeks. Standad
hydroxychloroquine treatment that were admitted in the hospital the week before starting the therapy with baricitinib. 


\section{Funding}

This work was partly supported by the Italian Ministry of Health "Ricerca Corrente" Linea 1.

\section{Acknowledgments}

The authors are grateful to all the patients, nurses and physicians who helped to perform this study.

\section{References}

1. Li R., Qiao S., Zhang G. Analysis of angiotensin-converting enzyme 2 (ACE2) from different species sheds some light on cross-species receptor usage of a novel coronavirus 2019-nCoV. I Infect Apr 2020;80(4):469-96.

2. Conner S.D., Schmid S.L. Identification of an adaptor-associated kinase, AAK1, as a regulator of clathrin-mediated endocytosis. J Cell Biol 2002;156:921-9.

3. Huang C., Wang Y., Li X., et al. Clinical characteristics of patients infected with 2019 novel coronavirus in Wuhan, China. Lancet 2020;395:497-506.

4. Cao B., Wang Y., Wen D., et al. A Trial of Lopinavir-Ritonavir in Adults Hospitalized with Severe Covid-19. N Engl J Med 2020 Mar 18 [Epub ahead of print]. doi:10.1056/NEJMoa2001282.

5. Ferner R.E., Aronson J.K. Chloroquine and hydroxychloroquine in covid-19. BMJ 2020;369:m1432. doi:10.1136/bmj.m1432.

6. Xu X., Han M., Li T., et al. Effective treatment of severe COVID-19 patients with tocilizumab, 2020. ChinaXiv: 202003.00026v1.

7. Bechman K., Subesinghe S., Norton S., et al. A systematic review and meta-analysis of infection risk with small molecule JAK inhibitors in rheumatoid arthritis. Rheumatology 2019:58:1755-66.

8. Richardson P., Griffin I., Tucker C., et al. Baricitinib as potential treatment for 2019-nCoV acute respiratory disease. Lancet 2020;395:e30-1.

9. Goletti D., Lee M.R., Wang J.Y., Walter N., Ottenhoff T.H.M. Update on tuberculosis biomarkers: from correlates of risk, to correlates of active disease and of cure from disease. Respirology May 2018;23(5):455-66.

10. Subbe C.P., Kruger M., Rutherford P., Gemmel L. Validation of a modified Early Warning Score in medical admissions. OJM 2001;94:521-6.

Fabrizio Cantini, Laura Niccoli Rheumatology Department, Azienda USL Toscana Centro, Hospital of Prato, Piazza Ospedale 1

Daniela Matarrese Azienda USL Toscana Centro, Hospital of Prato, Italy

Emanuele Nicastri

National Institute for Infectious Diseases, Lazzaro Spallanzani, IRCCS, Via Portuense, 292, Rome 00149, Italy

Paolo Stobbione AOS Antonio e Biagio e C. Arrigo, Rheumatology Unit - Alessandria, Italy

Delia Goletti National Institute for Infectious Diseases, Lazzaro Spallanzani, IRCCS, Via Portuense, 292, Rome 00149, Italy Department of Epidemiology and Preclinical Research, "L. Spallanzani" National Institute for Infectious Diseases (INMI), IRCCS, Via Portuense 292, 00149 Rome, Italy

*Corresponding author.

E-mail addresses: fbrzcantini@gmail.com (F. Cantini), daniela.matarrese@uslcentro.toscana.it (D. Matarrese), emanuele.nicastri@inmi.it (E. Nicastri),pstobbione@ospedale.al.it (P. Stobbione), delia.goletti@inmi.it (D. Goletti)

Accepted 16 April 2020 Available online 23 April 2020

https://doi.org/10.1016/j.jinf.2020.04.017

(c) 2020 The British Infection Association. Published by Elsevier Ltd. All rights reserved.
Bayesian phylodynamic inference on the temporal evolution and global transmission of SARS-CoV-2

Dear Editor,

Severe acute respiratory syndrome coronavirus 2 (SARS-CoV2) has developed a global pandemic. ${ }^{1}$ The initial transmission of SARS-CoV-2 has been limited in the national wide of China during the first two month ${ }^{2}$, while a global spread is establishing with about 2 million laboratory confirmed infections and more than 126, 000 deaths from 185 countries by April 15, 2020. ${ }^{3}$

The genome of SARS-CoV-2 exhibited a relative high similarity among the early obtained strains., ${ }^{4,5}$ However, two key mutations were recently identified, potentially contributing to the sub-lineage classification of SARS-CoV-2. ${ }^{6}$ Although the genome structure of SARS-CoV-2 has been well documented, the temporal evolution and global transmission of the virus remains poorly investigated.

Here, we retrieved 313 SRAS-CoV-2 genomes from the GISAID (www.gisaid.org) database, from which 99 genomes with exact collection dates (before Feb 29, 2019) were selected to infer the origin time and global transmission of SARS-CoV-2 by Bayesian phylodynamic approaches.

To gain insight into the temporal evolutionary dynamics of SARS-CoV-2, we performed Markov Chain Monte Carlo (MCMC) algorithms implemented in BEAST 1.10 .4 package with the 99 enrolled SARS-CoV-2 genomes. Generalized Time Reversible (GTR) with invariant sites as site heterogeneity model $(\mathrm{GTR}+I)$ was selected as the best-fit nucleotide substitution model by the Akaike Information Criterion (AIC) implemented in jModelTest. The estimated mean evolutionary rate of SARS-CoV-2 was estimated to be $6.14 \times 10^{-6}$ subs/site/day (95\% HPD: $3.61 \times 10^{-6}-8.68 \times 10^{-6}$ subs/site/day), corresponding to $2.24 \times 10^{-3}$ subs/site/year (95\% HPD: $1.32 \times 10^{-3}-3.17 \times 10^{-3}$ subs/site/year).

We recorded the information of $\mathrm{MCMC}$ reconstruction into a Maximum Clade Credibility (MCC) tree by using the program TreeAnnotator. From the MCC tree (Fig. 1), the tMRCA (Time to the Most Common Recent Ancestor) of SARS-CoV-2 was dated back to Dec 11, 2019 (95\%HPD, Nov 21, 2019 - Dec 24, 2019). Two major clades were observed from the MCC tree, with a divergence time at Dec 23, 2019 (95\%HPD, Dec 18, 2019 - Dec 29, 2019), both of which consist strains of SARS-CoV-2 from Wuhan and other regions of China.

The circulating strains of SARS-CoV-2 could be separated into four sub-clades (Fig. 1a). The two sub-clades from Clade 1 was diverged at Jan 1, 2020 (95\%HPD, Dec 27, 2019 - Jan 5, 2020), while the two sub-clades from Clade 2 was diverged at Jan 8, 2020 (95\%HPD, Jan 3 - Jan 13). With respect to the country-specific strains of SARS-CoV-2, we observed that the circulating strains in USA were from both of the two clades, the UK and Australia circulating strains were from Clade 1 , the circulating strains in Singapore, Japan, Germany, France and Italy seemed to be from Clade 2 (Fig. 1a, Table S1).

To infer the population growth dynamics of SARS-CoV-2, the viral relative genetic diversity was reconstructed by Bayesian Skyline Plot (BSP) analysis. ${ }^{7}$ BSP analysis suggested that SARS-CoV-2 possessed a relative stable effective population size $\left(N_{e}\right)$ during the first month (Dec 23, 2019 to Jan 22, 2020) of the virus outbreak (Fig. 1b). A slow but accelerating reduction in the $N_{e}$ was observed from Jan 22, 2020, with a sharp reduction of the lower 95\% HPD of the $N_{e}$ from Feb 5, 2020. A sharp reduction in the Ne suggests the initiation of a bottle-neck-effect in the virus population size. A bottle-neck-effect indicates that the current circulating virus strain was trapped, and more mutations in the virus genome will potentially occur to help the virus escape, resulting in a leap in the virus population. Despite the BSP was generated from a limited sample 
a

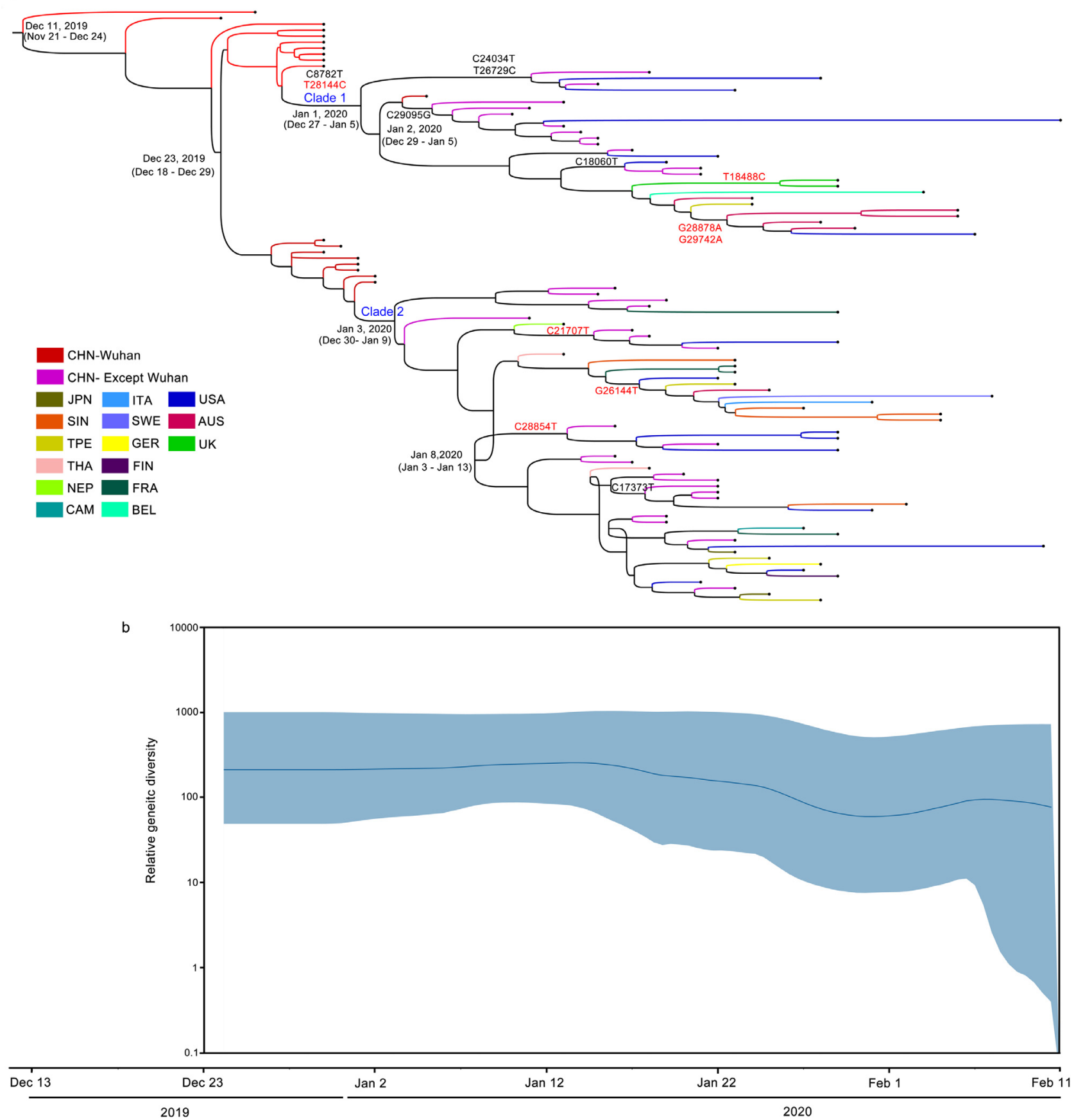

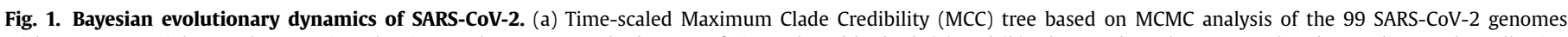

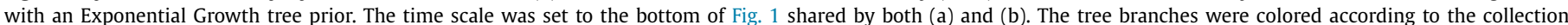

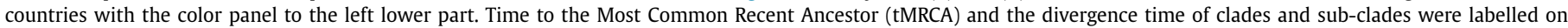

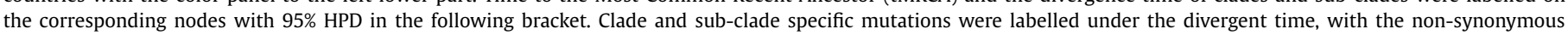

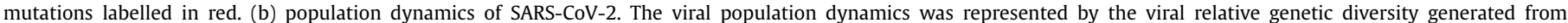

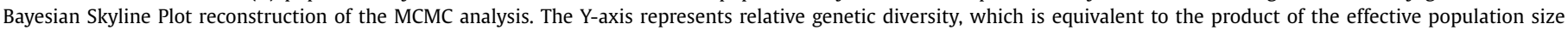
$\left(\mathrm{N}_{\mathrm{e}}\right)$ and the generation length in days $(\tau)$. The color regions show 95\% HPD limits, and the black line represent the median estimate of relative genetic diversity.

size, the results suggested a possible initiation of a bottle-neckeffect in the population size of SARS-CoV-2, indicating more infected cases will occur in the near future due to the increased mutations in the viral genome.

Despite SARS-CoV-2 remains relative stable, thirteen clade/subclade-specific mutations were observed in the present study (Fig. 1a). The mutations at nt 8782 and nt 28,144 were clade specific, i.e., C8782T and T28144C were only occurred in Clade 1, rather than in Clade 2. Only a viral strain (EPI_ISL_406,592 from Guangdong, China) in Clade 1 did not possess C8782T, while all strains in Clade 1 possess T28144C. Eleven out of the thirteen sub-clade specific mutations were also observed (Fig. 1a). Seven mutations were located in Clade 1, among which C29095G and C24034T/T26729C were observed in a sub-clade consisting of viral strains from China (outside Wuhan) and USA, respectively. G28878Aand G29742A were observed in a subclade of viral strains 
Table 1

Clade-/Sub-clade specific mutations of SARS-CoV-2 observed in Maximum Clade Credibility tree.

\begin{tabular}{lllll}
\hline Mutation & Gene & Type & Amino acid mutation & Collection country/region of the viral strain \\
\hline C8782T & ORF1a & synonymous & - & Clade 1 in Fig. 1a (detailed in Table S1) \\
C17373T & ORF1b & synonymous & - & China (outside Wuhan), USA and Singapore \\
C18060T & ORF1b & synonymous & - & China (outside Wuhan) and USA \\
C24034T & S & synonymous & - & \\
T26729C & M & synonymous & - & \\
C29095G & $\mathrm{N}$ & synonymous & - & \\
T18488C & ORF1b & non-synonymous & Ile-Thr & United Kingdom \\
C21707T & S & non-synonymous & His-Tyr & China (outside Wuhan) and USA \\
G26144T & ORF3 & non-synonymous & Gly-Val & USA, Taiwan, Australia, Sweden, Italy, and Singapore \\
T28144C & ORF8 & non-synonymous & Leu-Ser & Clade 1 in Fig. 1a (detailed in Table S1) \\
C28854T & $\mathrm{N}$ & non-synonymous & Ser-Phe & China (outside Wuhan) and USA \\
G28878A & $\mathrm{N}$ & non-synonymous & Ser-Asn & Australia and USA \\
G29742A & 3-UTR & non-synonymous & Arg-His (untranslated) & \\
\hline
\end{tabular}

Ile, Isoleucine; Thr, Threonine; His, Histidine; Tyr, Tyrosine; Gly, Glycine; Val, Valine; Leu, Leucine, Ser, Serine; Phe, Phenylalanine; Asn, Asparagine; Arg, Argnine. USA, United States of America.

from Australia and USA. Four mutations were located in Clade 2, among which C21707T and C28854T were observed in a sub-clade consisting of viral strains from China (outside Wuhan) and USA. C17373T was observed in a sub-clade of viral strains from China (outside Wuhan), USA and Singapore. G26144T was observed in a sub-clade of viral strains from USA, Taiwan, Australia, Sweden, Italy, and Singapore.

Seven of the observed mutations resulted in non-synonymous mutations in the translated viral protein, including two mutations in nucleocapsid phosphoprotein (C28854T: Ser-Phe; G28878A: SerAsn), one mutation in ORF1ab polyprotein (T18488C: Ile-Thr), Surface glycoprotein (C21707T: His-Tyr), ORF3a protein (G26144T: Gly-Val), ORF8 protein (T28144C: Leu-Ser), and ORF10 protein (G29742A: Arg-His). Notably, all of the four sub-clades possessed at least one non-synonymous mutation (Fig. 1a, Table 1).

In conclusion, continuous evolution occurred in almost all regions of the SARS-CoV-2 genome and potentially in a countryspecific manner. Further efforts on monitoring the genomic mutations of SARS-CoV-2 from different countries are recommended.

\section{Declaration of Competing Interest}

The authors declare that they have no conflicts of interest.

\section{Acknowledgements}

The authors thank the researchers who share the genome data of SARS-CoV-2 to GISAID (http://www.gisaid.org/). This work was supported by a grant from Key R \& D plan of Shanxi Province (No. 202003D31003/GZ to J. L.) and a grant from Major National Science and Technology Projects of the Ministry of Science and Technology of China (No. 2018ZX10305409-001-007 to J. L.).

\section{Reference}

1. Biondi-Zoccai G., Landoni G., Carnevale R., Cavarretta E., Sciarretta S., Frati G. SARS-CoV-2 and COVID-19: facing the pandemic together as citizens and cardiovascular practitioners. Minerva Cardioangiol 2020 Mar 9. PubMed PMID: 32150358. Epub 2020/03/10.

2. Zhang S., Diao M.Y., Duan L., Lin Z., Chen D. The novel coronavirus (SARS-CoV-2) infections in China: prevention, control and challenges. Intensive Care Med 2020 Mar 2. PubMed PMID: 32123989. Epub 2020/03/04

3. Dong E., Du H., Gardner L. An interactive web-based dashboard to track COVID-19 in real time. Lancet Infect Dis 2020 Feb 19. PubMed PMID: 32087114 Epub 2020/02/23

4. Lu R., Zhao X., Li J., Niu P., Yang B., Wu H., et al. Genomic characterisation and epidemiology of 2019 novel coronavirus: implications for virus origin and receptor binding. Lancet 2020;395(10224):565-74 Feb 22. PubMed PMID: 32007145. Epub 2020/02/03.

5. Wu A., Peng Y., Huang B., Ding X., Wang X., Niu P., et al. Genome composition and divergence of the novel coronavirus (2019-nCoV) originating in China. Cell Host Microbe 2020;27(3):325-8 Mar 11. PubMed PMID: 32035028. Epub 2020/02/09.
6. Wilen C.B., Lee S., Hsieh L.L., Orchard R.C., Desai C., Hykes B.L. Jr., et al. Tropism for tuft cells determines immune promotion of norovirus pathogenesis. Science 2018:360(6385):204-8 Apr 13. PubMed PMID: 29650672. Pubmed Central PMCID: PMC6039974. Epub 2018/04/14.

7. Heled J., Drummond A.J.. Bayesian inference of population size history from multiple loci. BMC Evol Biol 2008:8:289 Oct 23PubMed PMID: 18947398. Pubmed Central PMCID: PMC2636790. Epub 2008/10/25

Jianguo Li, Zhen Li, Xiaogang Cui, Changxin $\mathrm{Wu}$ MOE Key Laboratory of Chemical Biology and Molecular Engineering, Institutes of Biomedical Sciences, Shanxi University, Taiyuan 030006,

PR China

*Corresponding author. E-mail addresses: lijg@sxu.edu.cn (J. Li), cxw20@sxu.edu.cn (C. Wu)

Accepted 16 April 2020 Available online 20 April 2020

https://doi.org/10.1016/j.jinf.2020.04.016

(c) 2020 The British Infection Association. Published by Elsevier Ltd. All rights reserved.

\section{Viral dynamics of SARS-CoV-2 across a spectrum of disease severity in COVID-19}

Dear Editor,

Fang et al. reported in this journal that viral shedding of SARSCoV-2 in nasal swabs was longer in intensive care unit (ICU) patients compared with non-ICU patients with Coronavirus Disease 2019 (COVID-19). ${ }^{1}$ COVID-19 encompasses a heterogeneous spectrum of illness, ranging from asymptomatic and mild infections, to severely ill cases in $4-16 \%^{2,3}$ Here, we report the findings of a prospective cohort study to determine viral dynamics of SARSCoV-2 in mild to critical severity of illness, and the temporal viral burden at different body sites.

We included the first eleven laboratory-confirmed COVID-19 patients hospitalized in two hospitals in Hong Kong in February 2020. Disease severity was categorized as previously defined. ${ }^{3}$ We collected serial upper (pooled nasopharyngeal and throat swabs, $N=75$ ) and lower respiratory tract samples (sputum and tracheal aspirate, $N=43)$, peripheral blood plasma $(N=50)$, urine $(N=43)$ 
Table 1

Epidemiological and clinical characteristics and outcomes of the participants.

\begin{tabular}{|c|c|c|c|}
\hline Variables $^{1}$ & All & Critical/Severe disease & Moderate/Mild disease \\
\hline Number & 11 & 5 & 6 \\
\hline Age, years & $58(42,70)$ & $65(62,70)$ & $51.5(38,58)$ \\
\hline Male & $7(63.6 \%)$ & $4(80.0 \%)$ & $3(50.0 \%)$ \\
\hline Comorbidities $^{2}$ & $6(54.5 \%)$ & $4(80.0 \%)$ & $2(33.3 \%)$ \\
\hline Travel to Wuhan & $0(0 \%)$ & $0(0 \%)$ & $0(0 \%)$ \\
\hline Travel to other parts of China & $2(18.2 \%)$ & $1(20.0 \%)$ & $1(16.7 \%)$ \\
\hline Household contact with confirmed case & $2(18.2 \%)$ & $0(0 \%)$ & $2(33.3 \%)$ \\
\hline \multicolumn{4}{|l|}{ Symptoms at presentation } \\
\hline Fever & $8(72.7 \%)$ & $3(60.0 \%)$ & $5(83.3 \%)$ \\
\hline Cough & $8(72.7 \%)$ & $4(80.0 \%)$ & $4(66.7 \%)$ \\
\hline Shortness of breath & $3(27.3 \%)$ & $3(60.0 \%)$ & $0(0 \%)$ \\
\hline Diarrhea $^{3}$ & $2(18.2 \%)$ & $2(40.0 \%)$ & $0(0 \%)$ \\
\hline \multicolumn{4}{|l|}{ Complications } \\
\hline Viral pneumonitis & $10(90.9 \%)$ & $5(100 \%)$ & $5(83.3 \%)$ \\
\hline Cardiac ischemia & $1(9.1 \%)$ & $1(20.0 \%)$ & $0(0 \%)$ \\
\hline Acute kidney injury & $1(9.1 \%)$ & $1(20.0 \%)$ & $0(0 \%)$ \\
\hline Liver dysfunction & $3(27.3 \%)$ & $1(20.0 \%)$ & $2(33.3 \%)$ \\
\hline Myositis & $1(9.1 \%)$ & $0(0 \%)$ & $1(16.7 \%)$ \\
\hline Bacterial sepsis & $1(9.1 \%)$ & $1(20.0 \%)$ & $0(0 \%)$ \\
\hline Supplemental oxygen & $5(45.5 \%)$ & $5(100 \%)$ & $0(0 \%)$ \\
\hline Mechanical ventilation & $2(18.2 \%)$ & $2(40.0 \%)$ & $0(0 \%)$ \\
\hline Intensive care admission & $2(18.2 \%)$ & $2(40.0 \%)$ & $0(0 \%)$ \\
\hline \multicolumn{4}{|l|}{ Antiviral therapy } \\
\hline Lopinavir/ritonavir & $11(100 \%)$ & $5(100 \%)$ & $6(100 \%)$ \\
\hline Ribavirin & $8(72.7 \%)$ & $3(60.0 \%)$ & $5(83.3 \%)$ \\
\hline Beta-interferon & $5(45.5 \%)$ & $2(40.0 \%)$ & $3(50.0 \%)$ \\
\hline Corticosteroid therapy ${ }^{4}$ & $1(9.1 \%)$ & $1(20.0 \%)$ & $0(0 \%)$ \\
\hline Death & $0(0 \%)$ & $0(0 \%)$ & $0(0 \%)$ \\
\hline
\end{tabular}

1 Values are expressed in number (percentage) and median (interquartile range).

${ }^{2}$ Critical/severe disease: Patient A had hypertension, Patient $\mathrm{C}$ had coronary artery disease, Patient E had heart

block, Patient I had diabetes; moderate/mild disease: Patient $\mathrm{H}$ had diabetes, Patient $\mathrm{K}$ had hypertension.

${ }^{3}$ Diarrhea developed in 6 other patients during hospitalization, possibly due to use of antiviral agents.

${ }^{4}$ Patient E received intravenous hydrocortisone $150 \mathrm{mg} /$ day from Day 5 to 10 of illness.

and stool $(N=43)$ samples from all participants, and monitored SARS-CoV-2 viral loads in these samples. ${ }^{4}$

One participant had mild, 5 moderate, 3 severe, and 2 critical disease. All patients were discharged; no one died. Their clinical and epidemiological features are shown in Table 1. Viral loads for each sample are shown in Supplementary Table 1.

Nine participants, including 4 participants with mild-moderate disease, had viral shedding lasting longer than 14 days in the respiratory tract. In four (36\%) participants, return to PCR positivity in the respiratory tract was observed after $\geq 1$ negative test, without worsening of symptoms. In patient A, PCR positivity occurred in upper and lower respiratory tract samples after a 7-day "apparent clearance" where 3 upper and 3 lower respiratory samples were negative (Fig. 1).

Viral loads in respiratory tract samples did not correlate with disease severity. However, the timing of peak viral burden differed between participants with different severity. In all five participants with severe/critical and three with moderate disease, viral loads in respiratory tract samples continued to rise and peaked in the second week of illness (range 5.57-9.66 log copies/mL). In the remaining three with mild/moderate disease, viral load peaked in the first week of illness (range 3.25-6.40 log copies/mL) (Fig. 1 and Supplementary Fig.1 ).

Viral burden peaked later, viral load was significantly higher, and duration of viral shedding appeared to be longer in lower than in upper respiratory tract samples (Supplementary Table 2). Three of the five participants with severe/critical disease had both upper and lower respiratory tract samples tested. At the time of respiratory failure requiring supplemental oxygen or mechanical ventilation, two of these participants (patients B and E) had positive RT-PCR in lower respiratory tract samples while upper respiratory tract samples had turned negative for $\geq 7$ days (Fig. 1 and Supplementary Fig. 1).

All eleven participants had at least one stool sample tested positive for SARS-CoV-2. The timing of diarrhea did not correlate with stool PCR positivity. Four participants had longer duration (by 14 days) of viral shedding in stool than in respiratory tract. Viral loads in stool were lower than in either upper or lower respiratory tract samples (Supplementary Table 2), but did not differ between mild-moderate and severe-critical diseases.

SARS-CoV-2 was not detected in any of the 43 urine samples. In particular, all 8 urine samples from patient $B$ were negative despite the need for renal replacement therapy for acute kidney injury. His-renal biopsy showed features of acute tubular injury; electron microscopy did not reveal viral particles in proximal tubules.

One patient with moderate and one with critical disease had transient viremia, lasting 1 and 5 days, with peak viral loads 4.00 and $3.65 \log$ copies/mL, respectively.

In this study of patients with COVID-19 across a wide spectrum of severity, we observed that viral shedding in the respiratory tract lasting longer than 14 days was common. Viral load peaked later in the second week of illness in more severe disease. Extrapulmonary detection of RT-PCR positivity other than the gut was uncommon.

We observe two patterns of viral dynamics trajectory in the respiratory tract. In more severe disease, viral load appeared to peak in the second week of illness in both upper and lower respiratory tract. A more heterogeneous pattern was seen in milder disease. Time to dyspnea and intensive care was around 8-10 days after illness onset. ${ }^{5}$ Therefore, continued viral replication in the respiratory tract, correlated with this timing of clinical deterioration, as observed in other studies. ${ }^{6,7}$ This observation implied that 


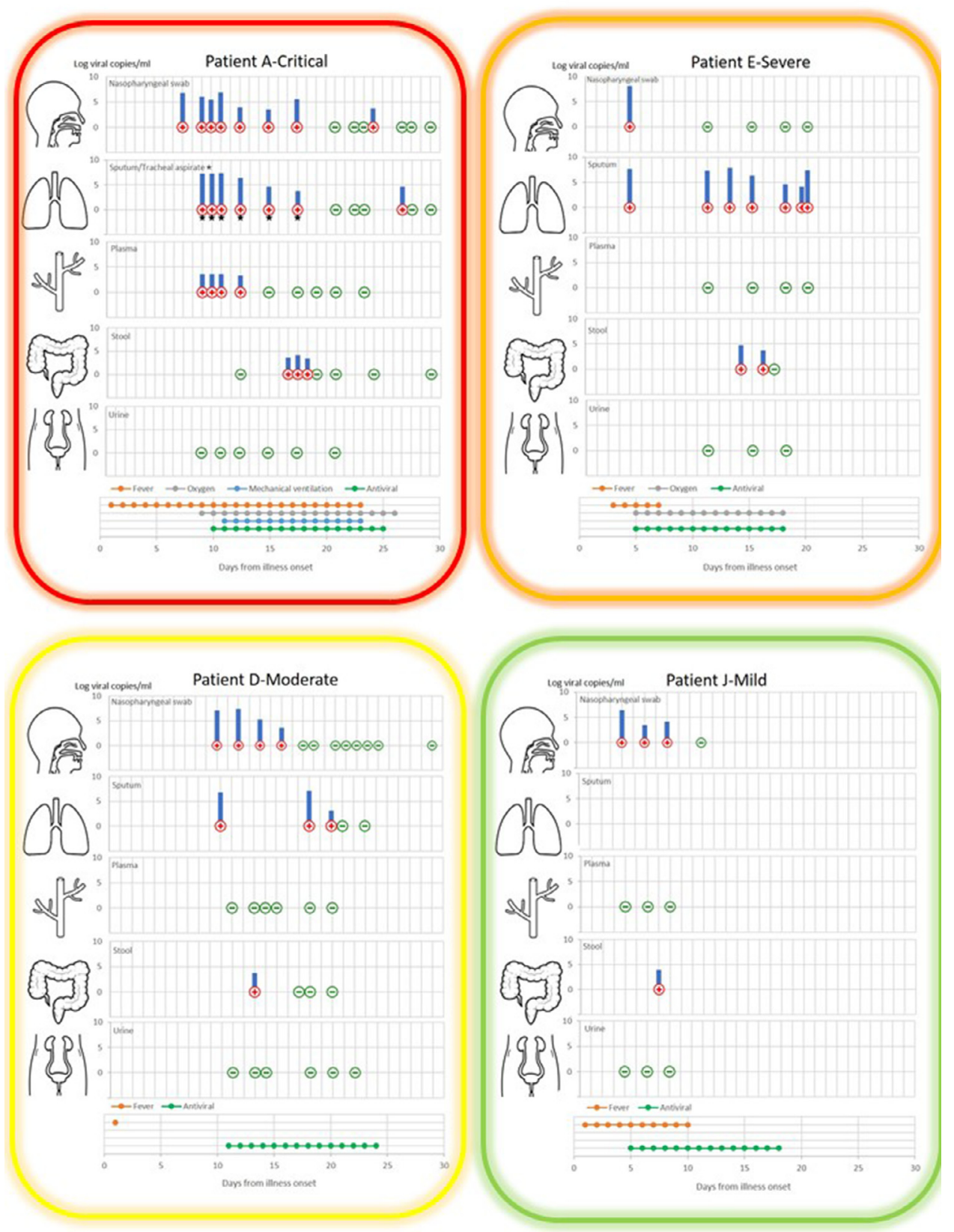

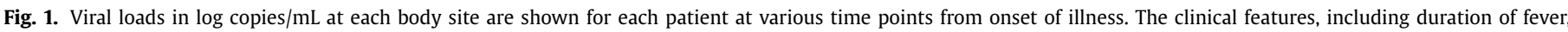
supplemental oxygen, mechanical ventilation, and antiviral therapy, are shown at the bottom.

antiviral therapy, rather than immunomodulatory agents, might be more effective as treatment for severe disease.

Viral load was significantly higher and peaked later in lower than upper respiratory tract samples. In severe/critical disease, monitoring should be performed using lower respiratory tract samples. Firstly, viral shedding was more prolonged in lower than upper respiratory tract samples, thus serves as better guidance for the duration of infection prevention measures. ${ }^{8}$ Secondly, viral loads in lower respiratory tract better reflected the temporal course of clinical progression in severe disease than upper respiratory tract samples. ${ }^{6,9}$

All patients demonstrated stool RT-PCR positivity at some stage of their disease, regardless of gastrointestinal symptoms. While other series had positivity rates of around $50 \%, 6,9,10$ repeated testing in our study allowed detection of transient positivity lasting
1-2 days. There is widespread presence of ACE2 as cellular receptors and viral particles in epithelial cells along different parts of the gastrointestinal tract. ${ }^{10}$ While the clinical role of testing SARSCoV-2 from stool as monitoring or discharge criteria remains uncertain, stool as an additional specimen to assist diagnosis, particularly in asymptomatic contacts of confirmed patients, is worth exploring.

Our study was limited by the small sample size. Asymptomatic patients were not studied, and the effect of antiviral therapy could not be determined. Viral dynamics at different sites should be further explored in larger populations of COVID-19 patients.

In conclusion, viral shedding in respiratory tract lasting longer than 14 days was common in all spectrum of COVID-19 severity. Clinical deterioration correlated temporally with viral replication in severe disease, especially in the lower respiratory tract, 
highlighting the importance of effective antiviral therapy. Extrapulmonary detection of SARS-CoV-2 PCR other than the gut was uncommon.

\section{Acknowledgments}

We would like to thank Ms Iris Wong, Ms Rity Wong and Ms Vickie Li for their clerical support in the preparation of the manuscript.

\section{Funding}

This research did not receive any specific grant from funding agencies in the public, commercial, or not-for-profit sectors.

\section{Supplementary materials}

Supplementary material associated with this article can be found, in the online version, at doi:10.1016/j.jinf.2020.04.014.

\section{References}

1. Fang Z., Zhang Y., Hang C., Zhang W., Ai J., Li S.. Comparisons of nucleic acid conversion time of SARS-CoV-2 of different samples in ICU and non-ICU patients. J Infect 2020.

2. Guan W.-.J., Ni Z.-Y., Hu Y, Liang W--.H., Ou C.-O, He J--X., Liu L., Shan $\mathrm{H}_{\text {, }}$ Lei C.-.L., Hui D.S.C., Du B., Li L.-.J., Zeng G., Yuen K.-.Y., Chen R.-.C., Tang C.-.L., Wang T., Chen P.-.Y., Xiang J., Li S.-.Y., Wang J.-.L., Liang Z.-.J., Peng Y.-.X., Wei L., Liu Y., Hu Y.-.H., Peng P., Wang J.-.M., Liu J.-.Y., Chen Z., Li G., Zheng Z.-.J., Qiu S..Q., Luo J., Ye C.-.J., Zhu S.-.Y., Zhong N.-.S.China Medical Treatment Expert Group for C Clinical characteristics of coronavirus disease 2019 in China. N Engl J Med 2020. doi:10.1056/NEJMoa2002032.

3. Wu J., Liu J., Zhao X., Liu C., Wang W., Wang D., Xu W., Zhang C., Yu J., Jiang B., Cao H., Li L.. Clinical characteristics of imported cases of COVID-19 in Jiangsu province: a multicenter descriptive study. Clinical Inf Diseas Offic Publ Infect Diseases Soc Am 2020 ciaa199.

4. 2019-Novel coronavirus (2019-nCoV) real-time rRT-PCR panel primers and probes. US Centers for Disease Control and Prevention. [Accessed 28 Jan 2020]. https://www.cdc.gov/coronavirus/2019-ncov/downloads/ rt-pcr-panel-primer-probes.pdf.

5. Huang C., Wang Y., Li X., Ren L., Zhao J., Hu Y., Zhang L., Fan G., Xu J., Gu X., Cheng Z., Yu T., Xia J., Wei Y., Wu W., Xie X., Yin W., Li H., Liu M., Xiao Y., Gao H., Guo L., Xie J., Wang G., Jiang R., Gao Z., Jin Q., Wang J., Cao B.. Clinical features of patients infected with 2019 novel coronavirus in Wuhan, China. Lancet 2020 S0140-6736(20)30183-5.

6. Pan Y., Zhang D., Yang P., Poon L.L.M., Wang Q.. Viral load of SARS-CoV-2 in clinical samples. Lancet Infect Diseas 2020 S1473-3099(20)30113-4.

7. Zhou F., Yu T., Du R., et al. Clinical course and risk factors for mortality of adult inpatients with COVID-19 in Wuhan, China: a retrospective cohort study. Lancet 2020;9.

8. Lombardi A., Bozzi G., Mangioni D., Muscatello A., Peri A.M., Taramasso L., Ungaro R., Bandera A., Gori A.. Duration of quarantine in hospitalized patients with severe acute respiratory syndrome coronavirus 2 (SARS-CoV-2) infection: a question needing an answer. J Hosp Infect 2020.

9. Young B.E., Ong S.W.X., Kalimuddin S., Low J.G., Tan S.Y., Loh J., Ng O.-.T., Marimuthu K., Ang L.W., Mak T.M., Lau S.K., Anderson D.E., Chan K.S., Tan T.Y., Ng T.Y., Cui L., Said Z., Kurupatham L., Chen M.I.C., Chan M., Vasoo S., Wang L..F., Tan B.H., Lin R.T.P., Lee V.J.M., Leo Y.-.S., Lye D.C.Singapore Novel Coronavirus Outbreak Research T Epidemiologic features and clinical course of patients infected with SARS-CoV-2 in Singapore. JAMA 2020. doi:10.1001/jama.2020.3204.

10. Xiao F., Tang M., Zheng X., Liu Y., Li X., Shan H.. Evidence for gastrointestinal infection of SARS-CoV-2. Gastroenterology 2020 S0016-5085(20)30282-1.

Grace Lui

Department of Medicine and Therapeutics, Prince of Wales Hospital, Stanley Ho Centre for Emerging Infectious Diseases, The Chinese University of Hong Kong, Hong Kong

Lowell Ling Department of Anaesthesia and Intensive Care, The Chinese University of Hong Kong, Hong Kong

Christopher KC Lai Department of Microbiology, The Chinese University of Hong Kong, Prince of Wales Hospital, Shatin, Hong Kong SAR, China
Eugene YK Tso

Department of Medicine and Geriatrics, United Christian Hospital, Hong Kong

Kitty SC Fung Department of Pathology, United Christian Hospital, Hong Kong

Veronica Chan Department of Medicine and Geriatrics, United Christian Hospital, Hong Kong

Tracy HY Ho, Fion Luk Department of Medicine and Therapeutics, Prince of Wales Hospital, Hong Kong

Zigui Chen

Department of Microbiology, The Chinese University of Hong Kong, Prince of Wales Hospital, Shatin, Hong Kong SAR, China

Joyce KC Ng, Kai-ming Chow Department of Medicine and Therapeutics, Prince of Wales Hospital,

Hong Kong

Peter KC Cheng, Rickjason CW Chan, Dominic NC Tsang Pubic Health Laboratory Services Branch, Department of Health, Centre for Health Protection, The Government of Hong Kong SAR, Hong Kong

Charles D Gomersall

Department of Anaesthesia and Intensive Care, The Chinese University of Hong Kong, Hong Kong

David SC Hui

Department of Medicine and Therapeutics, Prince of Wales Hospital, Stanley Ho Centre for Emerging Infectious Diseases, The Chinese University of Hong Kong, Hong Kong

Paul KS Chan*

Department of Microbiology, The Chinese University of Hong Kong, Prince of Wales Hospital, Shatin, Hong Kong SAR, China

*Corresponding author. E-mail address: paulkschan@cuhk.edu.hk (P.K. Chan)

Accepted 13 April 2020 Available online 18 April 2020

https://doi.org/10.1016/j.jinf.2020.04.014

(C) 2020 The British Infection Association. Published by Elsevier Ltd. All rights reserved.

\section{Clinical characteristics and prognosis in cancer patients} with COVID-19: A single center's retrospective study

\section{Dear Editor,}

We read with the interest the recent paper by Chen et al. who described the clinical progression with COVID-19 in Shanghai, China, ${ }^{1}$ which described ninety patients $(36.1 \%)$ had one or more coexisting chronic medical conditions and one patient had malignant tumor $(0.4 \%)$. A small amount of literatures have reported that the infection rate of COVID-19 was higher in cancer patients compared with non-cancer patients. In addition, cancer patients are more likely to turn to severe COVID-19 cases than non-cancer patients. ${ }^{2-4}$ In this letter, we describe the demographics, clinical characteristics, and prognosis of cancer patients with COVID-19 infection. 
Table 1

Baseline of clinical characteristics of cancer patients with COVID-19.

\begin{tabular}{|c|c|c|c|c|}
\hline & \multicolumn{4}{|l|}{ No.(\%) } \\
\hline & $\begin{array}{l}\text { Total } \\
(N=37)\end{array}$ & $\begin{array}{l}\text { Mild } \\
(N=17)\end{array}$ & $\begin{array}{l}\text { Severe/critical } \\
(N=20)\end{array}$ & $P$ value \\
\hline Age, median (IQR), y & $62(59-70)$ & $61(58-64)$ & $65.5(61-73)$ & NS \\
\hline \multicolumn{5}{|l|}{ Sex } \\
\hline Female & $17(45.9)$ & $7(41.1)$ & $10(50.0)$ & NS \\
\hline Male & $20(54.1)$ & $10(58.9)$ & $10(50.0)$ & NS \\
\hline \multicolumn{5}{|l|}{ Symptoms } \\
\hline Fever & $28(75.7)$ & $11(64.7)$ & $17(85.0)$ & NS \\
\hline Cough & $21(56.8)$ & $9(52.9)$ & $12(60.0)$ & NS \\
\hline Dyspnea & $12(32.4)$ & $2(11.8)$ & $10(50.0)$ & 0.017 \\
\hline Headache & $3(8.1)$ & $2(11.8)$ & $1(5.0)$ & NS \\
\hline Myalgia & $4(10.8)$ & $3(17.6)$ & $1(5.0)$ & NS \\
\hline Fatigue & $4(10.8)$ & $2(11.8)$ & $2(5.0)$ & NS \\
\hline Diarrhea & $4(10.8)$ & $1(5.9)$ & $3(15.0)$ & NS \\
\hline Sore throat & $2(5.4)$ & $1(5.9)$ & $1(5.0)$ & NS \\
\hline Hematochezia & $3(8.1)$ & $1(5.9)$ & $2(10.0)$ & NS \\
\hline $\begin{array}{l}\text { Antitumor therapy } \\
\text { (within one month) }\end{array}$ & $13(35.1)$ & $6(35.3)$ & $7(35.0)$ & NS \\
\hline \multicolumn{5}{|l|}{ Cancer type } \\
\hline Colorectal cancer & $11(29.7)$ & $4(23.5)$ & $7(35.0)$ & NS \\
\hline Lung cancer & $8(21.6)$ & $4(23.5)$ & $4(20.0)$ & NS \\
\hline Breast cancer & 7 (18.9) & $2(11.8)$ & $5(25.0)$ & NS \\
\hline Gynecological cancer & $5(13.5)$ & $4(23.5)$ & $1(5.0)$ & NS \\
\hline Other cancers & $6(16.2)$ & $3(17.7)$ & $3(15.0)$ & NS \\
\hline Other combidities & $12(32.4)$ & $4(23.5)$ & $8(40.0)$ & NS \\
\hline Death & $5(13.5)$ & 0 & $5(25.0)$ & \\
\hline
\end{tabular}

Abbreviations: y, year; IQR, interquartile range; NS, not significant.

A total of 1380 COVID-19 patients admitted to Renmin Hospital of Wuhan University from January 1, 2020 to March 30, 2020 were screened, and 37 cancer patients with COVID-19 were enrolled. All the enrolled patients were confirmed COVID-19 infected as positive in laboratory tests, including nucleic acid testing or antibody test for SARS-CoV-2. Severe and critical patients are diagnosed according to the New Coronavirus Pneumonia Prevention and Control Program (7th edition). ${ }^{5}$ The study was approved by the Institutional Review Board of Renmin Hospital of Wuhan University.

Demographic information and laboratory tests including complete blood count test, liver and kidney function tests, coagulation and immune function tests results were collected upon admission. Continuous variables were shown as median (interquartile range) and percentages were presented for categorical variables. MannWhitney U test was used to compare continuous variables. Fisher's exact test was used to compare categorical variables. $P<0.05$ was considered to be statistically significant.
In our study, the infection rate of COVID-19 among cancer patients in the single center was estimated to be $2.7 \%$ (37 of 1380 patients), which was 6 times higher than that in Wuhan until Mar 30, 2020 (0.45\%, 50,006 of 11,081,000). The proportion of severe/critical COVID-19 patients with cancer was $54.1 \%$, which was also significantly higher than that of the general population. ${ }^{6}$ As shown in Table 1 , there were 20 male patients (54.1\%), and the median age of the patients was 62 years old. According to the previous studies, cancer patients with COVID-19 were much older., 6,7 The most common symptoms of onset were fever (75.7\%) and cough $(56.8 \%)$, complicated with dyspnea $(32.4 \%)$ or fatigue, diarrhea and myalgia.

In addition, cancer patients with COVID-19 were divided into two groups, as mild group, and severe/critical group, according to the severity of COVID-19. Compared with the mild group, patients in the severe/critical group were more likely to have dyspnea (50\%). Among the 37 patients, thirteen patients had a history of anti-cancer therapy including surgery, radiotherapy, chemotherapy, targeted therapy, or immunotherapy within one month before hospitalization; six patients in the mild group and seven patients in the severe/critical group respectively. However, with/without the cancer therapy history did not differ significantly between the two groups, suggesting that anti-cancer therapy did not effect on the severity of COVID-19 among these cancer patients.

It is noteworthy that the most common cancer was colorectal cancer (29.7\%), followed by lung cancer (21.6\%) and breast (18.9\%). Among the severe/critical patients, there were seven colorectal cancer patients. Previous studies indicated that lung cancer patients were the most common to be infected, which needs more multicenter retrospective studies with a larger sample size to identify. $^{3-5}$

Studies have shown that the prognosis of COVID-19 patients with underlying diseases was poor, while the prognosis of patients with two or more basic diseases would be even worse. ${ }^{6}$ In our study, a total of twelve COVID-19-infected cancer patients were complicated with underlying diseases, such as hypertension, diabetes, chronic obstructive pulmonary disease etc., accounting for $32.4 \%$. In the severe/critical group, 8 cases complicated with underlying diseases, which was two times higher than that in the mild group, although there was no statistical difference between the two groups. Moreover, five cancer patients died, with a mortality rate of $13.5 \%$, all of which occurred in the severe/critical group.

In terms of the results of laboratory tests, we interestingly found that the numbers of neutrophil, NLR, IL-6, LDH and PCT (Table 2) in the severe/critical group were significantly higher than

Table 2

Laboratory results of cancer patients with COVID-19 on admission to hospital.

\begin{tabular}{|c|c|c|c|c|c|}
\hline & \multirow[t]{2}{*}{ Standard Range } & \multicolumn{3}{|l|}{ Median (IQR) } & \multirow[t]{2}{*}{$P$ value } \\
\hline & & Total $(N=37)$ & Mild $(N=17)$ & Severe/critical $(N=20)$ & \\
\hline WBC count, $\times 10^{9} / \mathrm{L}$ & $3.5-9.5$ & $4.8(3.5-7.0)$ & $4.0(3.0-6.6)$ & $5.4(4.0-8.0)$ & NS \\
\hline $\mathrm{N}$ count, $\times 10^{9} / \mathrm{L}$ & $1.8-6.3$ & $3.5(2.1-5.0)$ & $2.3(1.6-3.9)$ & $3.9(2.8-5.8)$ & 0.022 \\
\hline L count, $\times 10^{9} / \mathrm{L}$ & $1.1-3.2$ & $0.9(0.7-1.3)$ & $1.0(0.8-1.4)$ & $0.8(0.6-1.3)$ & NS \\
\hline NLR & & $3.6(1.9-6.0)$ & $2.6(1.8-3.5)$ & $5.5(3.6-6.5)$ & 0.002 \\
\hline Hemoglobin, g/L & $115-175$ & $110(103-126)$ & $110(105-127)$ & $111(99-124)$ & NS \\
\hline Platelet count, $\times 10^{9} / \mathrm{L}$ & $125-350$ & $202(145-260)$ & $190(162-260)$ & $219(140-260)$ & NS \\
\hline D-dimer, mg/L & $\leq 0.55$ & $1.2(0.6-2.4)$ & $1.3(0.5-1.8)$ & $1.1(0.6-3.4)$ & NS \\
\hline Creatinine, $\mu \mathrm{mol} / \mathrm{L}$ & $57-111$ & $53(48-61)$ & $50(44-58)$ & $57(48-72)$ & NS \\
\hline ALT, U/L & $9-50$ & $27(17-47)$ & $26(19-30)$ & $34(15-60)$ & NS \\
\hline AST, U/L & $15-40$ & $24(20-41)$ & $23(21-27)$ & $32(18-53)$ & NS \\
\hline $\mathrm{LDH}, \mathrm{U} / \mathrm{L}$ & $120-250$ & $250(200-306)$ & $215(176-253)$ & $282(236-320)$ & 0.045 \\
\hline IL-6, pg/ml & $\leq 20$ & $7.7(4.9-23.8)$ & $4.5(3.0-7.5)$ & $14.3(7.5-53.2)$ & $<0.001$ \\
\hline CD4 count, $/ \mu \mathrm{L}$ & $404-1612$ & 303 (203-469) & $373(279-588)$ & $252(168-388)$ & NS \\
\hline CD8 count, $/ \mu \mathrm{L}$ & $220-1129$ & $222(158-302)$ & $261(200-300)$ & $210(117-471)$ & NS \\
\hline PCT, ng/mL & $<0.1$ & $0.06(0.03-0.1)$ & $0.04(0.02-0.04)$ & $0.1(0.1-0.5)$ & $<0.001$ \\
\hline
\end{tabular}

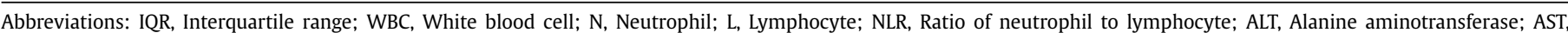
Aspartate aminotransferase; LDH, Lactate Dehydrogenase; IL-6, Interleukin-6; CD4, Cluster of differentiation 4; CD8, Cluster of differentiation 8; PCT, Procalcitonin. 
those in the mild group. Studies have shown that increased neutrophils and decreased lymphocytes will increase the risk of severe illness in COVID-19 patients. $^{6}$ At the same time, the increase of NLR was also an independent prognostic factor in T1-2 rectal cancer patients. ${ }^{7}$ In addition, LDH and PCT were significantly higher in the severe/critical group than that in the mild group. These two indexes were also increased in the general population of patients required ICU admission. ${ }^{6}$ Moreover, IL-6 was known to participate in the storm of inflammatory factors caused by COVID-19. The storm could be the main cause of death in infected patients. ${ }^{8}$ Therefore, we should pay more attention to the above laboratory indicators in order to identify early and reduce the severe ratio and mortality of cancer patients with COVID-19.

In conclusion, our report originally described and analyzed clinical characteristics and prognosis in cancer patients with COVID-19. Cancer patients had a high infection rate of SARS-CoV-2 and were easy to become severe or critical cases, which should be monitored closely during the COVID-19 epidemic. More multicenter retrospective studies are needed to investigate the comprehensive demographics and risk factors for cancer patients with COVID-19.

\section{Declaration of Competing Interest}

All the authors have no conflicts of interest to declare.

\section{Funding}

This study was supported by the National Natural Science Foundation of China (No. 81903137).

\section{References}

1. Chen Jun, Oi Tangkai, Liu Li, et al. Clinical progression of patients with COVID-19 in Shanghai, China. J Infect 2020.

2. Liang Wenhua, Guan Weijie, Chen Ruchong, et al. Cancer patients in SARS-CoV-2 infection: a nationwide analysis in China. Lancet Oncol 2020.

3. Yu Jing, Ouyang Wen, Melvin L. K. chua, et al. SARS-CoV-2 transmission in patients with cancer at a tertiary care hospital in Wuhan, China. JAMA Oncol 2020.

4. Zhang L., Zhu F., Xie L., et al. Clinical characteristics of COVID-19-infected cancer patients: a retrospective case study in three hospitals within Wuhan, China. Ann Oncol 2020

5. National Health Commission of China. New coronavirus pneumonia prevention and control program. (7th ed); 2020. Mar 3 http://www.gov.cn/zhengce/ zhengceku/2020-03/04/5486705/files/ae61004f930d47598711a0d4cbf874a9.pdf (in Chinese)

6. Wang Dawei, Hu Bo, Hu Chang, et al. Clinical characteristics of 138 hospitalized patients with 2019 novel coronavirus-infected pneumonia in Wuhan, China. JAMA 2020

7. Xia Lijian, Li Wen, Zhai Jian Cheng, et al. Significance of neutrophil-to-lymphocyte ratio, platelet-to-lymphocyte ratio, lymphocyte-to-monocyte ratio and prognostic nutritional index for predicting clinical outcomes in T1-2 rectal cancer. BMC Cancer 2020;20:208.

8. Mehta P., McAuley D.F., Brown M., et al. COVID-19: consider cytokine storm syndromes and immunosuppression. Lancet 2020

Jia $\mathrm{Ma}^{1}$

Department of Radiation Oncology, Hubei Cancer Hospital, Tongji Medical College, Huazhong University of Science and Technology, Wuhan 430071, PR China

Jing Yin ${ }^{1}$

Department of Respiratory Disease and Intensive Care, Renmin Hospital of Wuhan University, Wuhan 430060, PR China

Yu Qian*

Department of Thoracic Cancer, Hubei Cancer Hospital, Tongji Medical College, Huazhong University of Science and Technology, Wuhan 430079, PR China

Yuan $\mathrm{Wu}^{*}$ Department of Radiation Oncology, Hubei Cancer Hospital, Tongji Medical College, Huazhong University of Science and Technology, Wuhan 430071, PR China
*Corresponding authors.

E-mail addresses: 173653835@qq.com (Y. Qian), gwgfe@163.com

${ }^{1}$ These authors contributed equally to this work. Accepted 8 April 2020

Available online 14 April 2020

https://doi.org/10.1016/j.jinf.2020.04.006

(c) 2020 The British Infection Association. Published by Elsevier Ltd. All rights reserved.

\section{Prolonged virus shedding even after seroconversion in a patient with COVID-19}

\section{Dear Editors,}

Previous reports revealed that the emergence of the novel coronavirus (SARS-CoV-2) infection (COVID-19) had raised global concern. ${ }^{1}$ Several studies discussing the clinical pictures of COVID19 and specific antibody responding to SARS-CoV-2 have been published. $^{2-4}$ However, the time sequences of clinical manifestations, virus shedding kinetics, contagiousness, and specific antibody reaction, which are essential for understanding pathophysiology and infection control strategy, have less been discussed. Here we present a COVID-19 patient with prolonged viral shedding and detailed time sequence of these parameters mentioned above.

A 50-year-old woman, who suffered from acute-onset fever up to $38.6^{\circ} \mathrm{C}$ four hours ago, visited the emergency department of a medical center in Taipei City, Taiwan. She denied of cough or other subjective discomforts, and disclosed that she lived in Wuhan, China and just traveled to Taiwan two days prior to hospital visit. Given the patient's travel history, she was transferred to a negative-pressure isolation room for suspecting COVID-19.

Chest radiography was normal. Hemogram revealed only mild thrombocytopenia $(143 \mathrm{~K} / \mu \mathrm{L})$, while other blood tests were within normal limits. Sputum and throat swab specimens yielded positive results for SARS-CoV-2 by real-time reverse transcriptionpolymerase chain reaction (RT-PCR). Fever subsided rapidly after admission. However, elevated temperature up to $38.2^{\circ} \mathrm{C}$ was noted four days later. She did not have obvious respiratory symptoms and remained good spirit. All blood tests, except mildly elevated C-reactive protein (CRP) $(1.47 \mathrm{mg} / \mathrm{dL})$ and mild thrombocytopenia, were normal. A once-daily low-grade fever persisted until ninth day after symptom onset. The CRP level reached to the peak on the tenth day after symptom onset and then normalized gradually.

Clinical specimens for SARS-CoV-2 testing were obtained in accordance with guidelines from the Centers for Disease Control and Prevention. ${ }^{5}$ During hospitalization, sputum and throat swab specimens were collected for SARS-CoV-2 RT-PCR and virus culture every other day. Throat wash by gargling using $10 \mathrm{~mL}$ normal saline were collected when sputum specimens were not available. ${ }^{6}$ Stool was collected for RT-PCR on the third, 14th and 20th day after symptom onset, and plasma was also sent within the first four days of hospitalization. Serum was sent for SARS-CoV-2 antibody detection every or every other day within the first 21 days of hospitalization.

Plasmid DNA containing the SARS-CoV-2 target sequences, including the envelope (E), nucleocapsid $(\mathrm{N})$, and RNA-dependent RNA polymerase (RdRp) genes, was used to construct the standard curve to estimate the SARS-CoV-2 viral load by real-time RT-PCR. 


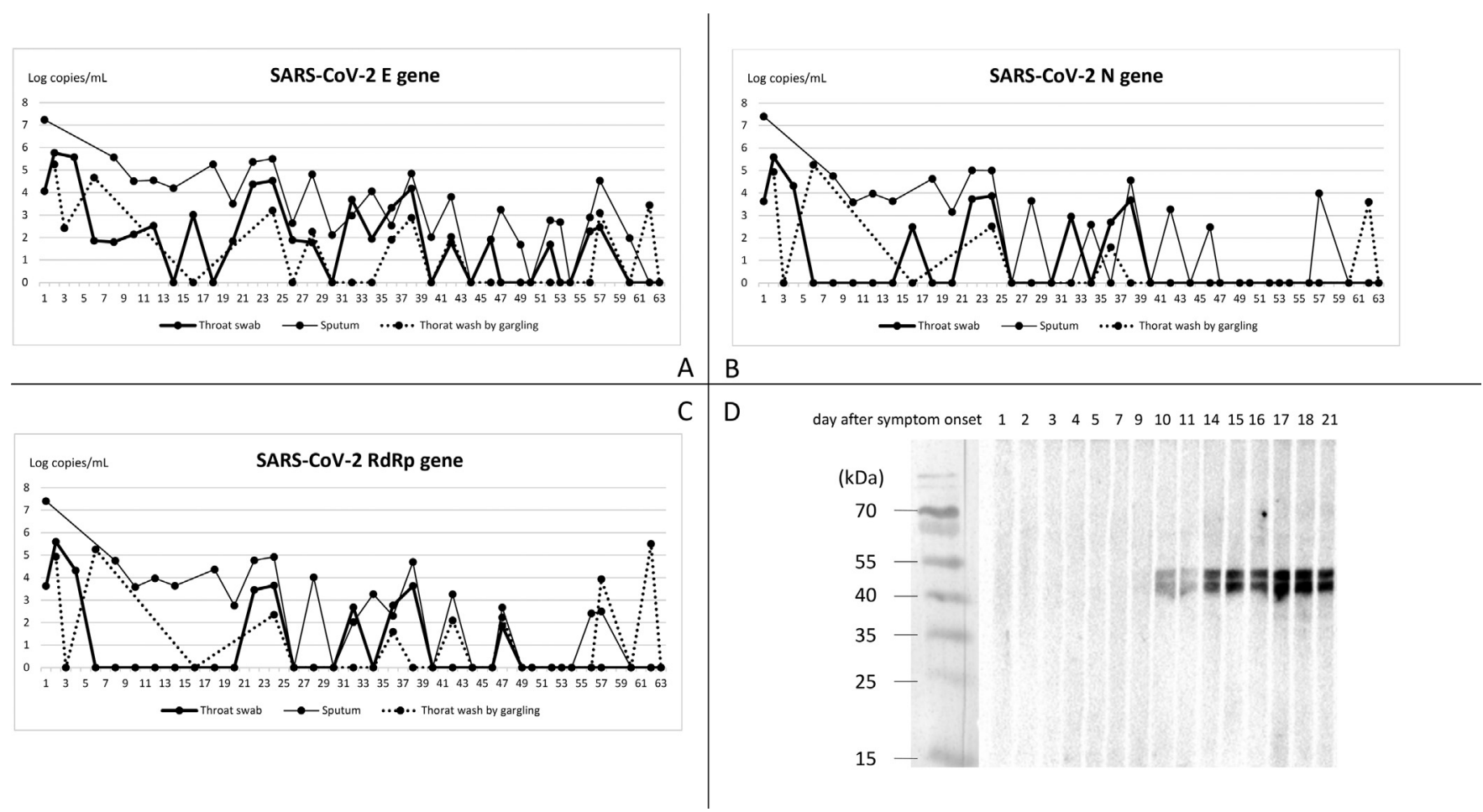

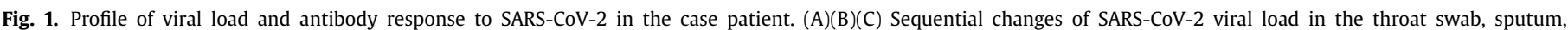

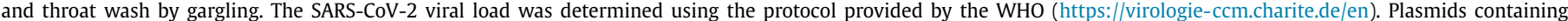

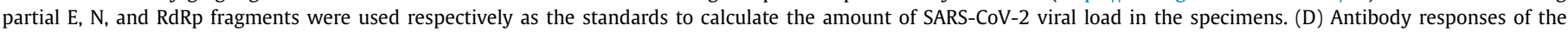
present case. Antibody responses of the present case to viral proteins extracted from SARS-CoV-2 infected Vero-E6 cells were determined by the western blot.

In addition, SARS-CoV-2 isolation was performed via Vero E6 and LLC-MK2 cell cultures. The full-length viral sequence was determined using SARS-CoV-2 amplified from the sputum specimen collected on the ninth day after symptom onset, and was submitted to the GISAID (accession number is EPI_ISL_408,489). Antibody response to SARS-CoV-2 viral $\mathrm{N}$ proteins was determined by western blotting using infected cell lysates.

The sequential changes of SARS-CoV-2 viral load in throat swab, sputum, and gargling water are presented in Figure. A drop of three logs of viral loads was observed among all specimens within one week after admission. However, SARS-CoV-2 persisted to be detectable till 63th day after symptom onset. Among respiratory specimens from different sites, specimen from sputum showed superior sensitivity to samples from throat swab and gargling wash. Initially, specimen from gargling wash showed considerable results compared with specimens from sputum or throat swab. Nevertheless, RT-PCR examinations from sputum still outweighed samples from gargling and throat swab after fever subsided. Among three target genes of the RT-PCR examinations, E gene of SARSCoV-2 showed superior sensitivity to $\mathrm{N}$ and $\mathrm{RdRp}$ gene after clinical symptoms resolved. The stool specimen collected on the third day after symptom onset yielded positive results, but turned negative in the following specimens. The presence of SARS-CoV-2 could not be detected in the plasma samples while the SARS-CoV-2 titers in the respiratory specimen remained high.

SARS-CoV-2 could be isolated from cell cultures in throat swab collected upon admission, and all sputum specimens collected within 18 days after symptoms onset. RT-PCR continued to detect virus till the 63th day after symptom onset regardless virus could only be isolated from respiratory specimens collected within the first 18 days. Antibody to SARS-CoV-2 was firstly identified on the tenth day after symptom onset. In the meanwhile, no more fever above $37.5^{\circ} \mathrm{C}$ was noted, and CRP began to decline. Recovery of platelet count took place two days earlier than the emergence of SARS-CoV-2 antibody.

This case demonstrated that the virus shedding might continue even after clinical resolution and seroconversion. In addition, although SARS-CoV-2 virus could not be isolated after the 18th day of symptom onset, the positive RT-PCR results continued for more than 60 days. Because of the long interval between these two time points, it might be reasonable to infer that a small amount of viable virus, yet could not be detected by virus culture, remained present after the 18th day of disease course and last for more days. This implies the contagious period of COVID-19 might last more than one week after "clinical recovery". Many of COVID-19 patients in Taiwan also had similar findings (unpublished data). Such prolonged virus shedding was also observed among asymptomatic pediatric patients in fecal specimen. ${ }^{7}$ However, this needs more studies to clarify since it would be a major issue in realizing and controlling the COVID-19 epidemics.

Serial RT-PCR results in our case highlighted the importance of the clinical specimens sampled from lower respiratory tract for detecting SARS-CoV-2 virus, ${ }^{8}$ which is different from the report from Zou L, et al. ${ }^{9}$ Additionally, our case demonstrated that throat wash by gargling could be an alternative method for COVID-19 diagnosis, since specimen from lower respiratory tract was barely available at the early stage of infection. Nevertheless, when the patient became afebrile, sputum still outweighed specimens from throat swab or gargling wash.

Our case highlighted the prolonged virus shedding course of COVID-19 even after the clinical symptoms resolved and seroconversion developed. It implies the possibility of a prolonged contagious period and should be investigated further to better control the epidemics. Our study also demonstrated viral detection from throat gargling sample could be an alternative diagnostic method for patients without sputum. Fig. 1 


\section{Declaration of Competing Interest}

None to declare.

\section{Acknowledgments}

None to declare.

\section{References}

1. Tang J.W., Tambyah P.A., Hui D.S.C.. Emergence of a novel coronavirus causing respiratory illness from Wuhan, China. I Infect 2020;80(3):350-71.

2. Xiao D.A.T., Gao D.C., Zhang D.S.. Profile of specific antibodies to SARS-CoV-2: the first report. J Infect 2020 pii: S0163-4453(20)30138-9[Epub ahead of print] doi:10.1016/j.jinf.2020.03.012.

3. Guan W.J., Ni Z.Y., Hu Y., Liang W.H., Ou C.Q., He J.X., et al. Clinical characteristics of coronavirus disease 2019 in China. N Engl J Med 2020 [Epub ahead of print]. doi:10.1056/NEJMoa2002032.

4. Yang W., Cao O., Oin L., Wang X., Cheng Z., Pan A., et al. Clinical characteristics and imaging manifestations of the 2019 novel coronavirus disease (COVID-19):a multi-center study in Wenzhou city, Zhejiang, China. J Infect 2020 pii: S01634453(20)30099-2[Epub ahead of print]<. doi:10.1016/j.jinf.2020.02.016.

5. Centers for Disease Control and Prevention. Interim guidelines for collecting handling, and testing clinical specimens from persons under investigation (PUIs) for coronavirus disease 2019 (COVID-19). Available at:https://www.cdc.gov coronavirus/2019-nCoV/lab/guidelines-clinical-specimens.html Accessed 7 Mar 2020

6. Wang W.K., Chen S.Y., Liu I.J., Chen Y.C., Chen H.L., Yang C.F., et al. Detection of SARS-associated coronavirus in throat wash and saliva in early diagnosis. Emerg Infect Dis 2004;10:1213-19.

7. Xu Y., Li X., Zhu B., Liang H., Fang C., Gong Y., et al. Characteristics of pediatric SARS-CoV-2 infection and potential evidence for persistent fecal viral shedding. Nat Med 2020 [Epub ahead of print]<. doi:10.1038/s41591-020-0817-4

8. Wang W., Xu Y., Gao R., Lu R., Han K., Wu G., et al. Detection of SARS-CoV2 in different types of clinical specimens. JAMA 2020 [Epub ahead of print]. doi:10.1001/jama.2020.3786.

9. Zou L., Ruan F., Huang M., Liang L., Huang H., Hong Z., et al. SARS-CoV-2 viral load in upper respiratory specimens of infected patients. N Engl J Med 2020 [Epub ahead of print]. doi:10.1056/NEJMc2001737.

Wang-Da Liu Sui-Yuan Chang ${ }^{1}$ Jann-Tay Wang Ming-Jui Tsai

Chien-Ching Hung Chia-Lin Hsu

Shan-Chwen Chang*

National Taiwan University Hospital, Taipei city, Taiwan

*Corresponding author.

E-mail address: changsc@ntu.edu.tw (S.-C. Chang)

1 These authors contributed equally to this paper.

Accepted 31 March 2020

Available online 10 April 2020

https://doi.org/10.1016/j.jinf.2020.03.063

(C) 2020 The British Infection Association. Published by Elsevier Ltd. All rights reserved.

Lymphocyte subset (CD4+, CD8+) counts reflect the severity of infection and predict the clinical outcomes in patients with COVID-19

Dear Editor,

We read with interest the recent article by Chen et al., which found lower CD4 $+T$ cells count was associated with ICU admission in patients with the coronavirus disease 2019 (COVID-19). ${ }^{1}$ Among the clinical and laboratory features of COVID-19, a number of abnormalities have been observed and described, the most prominent of which is total lymphopenia. Through routine blood analysis, a significant reduction in lymphocytes is frequently observed; however, there still lacks thoroughly research about the lymphocyte subset counts. Here, we aimed to investigate the changes of lymphocyte subset counts in COVID-19 patients and determine if these changes are associated with disease severity and prognosis.

This retrospective, single-center study was approved by the institutional ethics board of Zhongnan Hospital of Wuhan University, Wuhan, China (No. 2,020,015). A total of 39 RT-PCR-confirmed COVID-19 patients (admission date from January 18 to February 10, 2020) were enrolled, whose lymphocyte subset counts were tested on admission. The follow-up period lasted till Feb 19, 2020.

We obtained demographic and clinical characteristics and laboratory test results from the electronic medical record system. All data were typed in a pre-designed data collection form and checked to verify data accuracy. Continuous and categorical variables were directly expressed as the median (interquartile range (IQR)) and number (\%), respectively. The Mann-Whitney U test was used to compare the lymphocyte subset absolute counts of different conditions and outcomes. All statistical analyses were performed using SPSS, version 22.0 (IBM Corp., Armonk, NY).

The demographic and clinical characteristics of the patients enrolled are listed in Table 1 . The median age of the patients was 53 years (IQR, 41-61), and they included 20 women and 19 men. The median of the time from onset to admission was 5 days (IQR, 3-7). On admission, leucocyte counts below the normal range appeared in 13 (34.2\%) patients, and most patients had leucocyte counts within the normal range. Lymphocyte counts were below the normal range in $29(76.3 \%)$ patients, and no patients showed an increase. The median of lymphocyte count was $0.73 \times 10^{9} / \mathrm{L}$ (IQR, 0.56-1.07). Lymphocyte subset counts of all subsets decreased in more than half of the patients on admission. T cells decreased in 24 (61.5\%) patients, CD4+ T cells decreased in 22 (56.4\%) patients, CD8 $+T$ cells decreased in $28(71.8 \%)$ patients, B cells decreased in $27(69.2 \%)$ patients, and NK cells decreased in $30(76.9 \%)$ patients. No patient had subsets increased. Among patients enrolled, the median time of onset to RT-PCR turning negative was 14 (IQR, 10-20) days.

Among the 39 patients, 15 (38.5\%) had comorbidities, and 17 (43.6\%) spent time from onset to admission over 5 days. According to the Guidelines for the Diagnosis and Treatment of COVID19 (Trial Version 6), ${ }^{2} 21$ (53.8\%) patients were classified as having mild and moderate infection, 18 (46.2\%) had severe and critical infection. Half of the patients $(20[51.3 \%])$ had a negative RTPCR result within 14 days after onset. Until the end of follow-up, $16(43.2 \%)$ patients were given an outcome of continual cure or death. $T$ cells, CD4 $+T$ cells, and CD8 $+T$ cells were all statistically higher in patients who had a mild infection, timely hospitalization, and fast recovery (all $p<0.05$ ). Patients whose RT-PCR turning negative result within 14 days after onset showed higher levels of both T and B cells $(p<0.05)$. The existence of comorbidities statistically affected the amount of CD8+ T cells $(p<0.05)$. There was no difference in lymphocyte subset levels between patients with different changes upon imaging after admission (all $p>0.05$ ). All analyses indicated that changes in NK cell counts and the ratio of CD4 $+T$ cells to CD8 $+T$ cells $(C D 4+/ C D 8+)$ were not different between different conditions and outcomes. These finding are shown in Table 2.

Counts of lymphocyte and lymphocyte subset are of great value to ensure immune system functionality. Viral infections, immunodeficiency diseases, and other infectious diseases usually lead to abnormal changes in the levels of lymphocyte subsets. ${ }^{3-5}$ In this study, we focused on the abnormal counts of lymphocyte and 
Table 1

Demographic and clinical characteristics of 39 patients with COVID-19.

\begin{tabular}{llll}
\hline Characteristics (normal range) & Median (IQR) / N (\%) & Increased, N (\%) & Decreased, N (\%) \\
\hline Age, year & $53(41-61)$ & - & - \\
Sex & $20(51.3)$ & - & - \\
$\quad$ Female & $19(48.7)$ & - & - \\
$\quad$ Male & $5(3-7)$ & - & - \\
Onset to admission, d & $4.11(3.33-5.16)$ & $13(34.2)$ & $3(7.9)$ \\
Leucocytes $\left(3.5-9.5 \times 10^{9} / \mathrm{L}\right)$ & $0.73(0.56-1.07)$ & 0 & $29(76.3)$ \\
Lymphocytes $\left(1.1-3.2 \times 10^{9} / \mathrm{L}\right)$ & $561.0(300.0-1056.0)$ & 0 & $24(61.5)$ \\
T cells $\left(805-4459 \times 10^{6} / \mathrm{L}\right)$ & $308.0(176.0-665.0)$ & 0 & $22(56.4)$ \\
CD4+ T cells $\left(345-2350 \times 10^{6} / \mathrm{L}\right)$ & $168.0(117.0-368.0)$ & 0 & $28(71.8)$ \\
CD8+ T cells $\left(345-2350 \times 10^{6} / \mathrm{L}\right)$ & $1.640(1.140-2.380)$ & $14(35.9)$ & $7(17.9)$ \\
CD4+/CD8+ $(0.96-2.05)$ & $146.0(56.0-272.0)$ & 0 & $27(69.2)$ \\
B cells $\left(240-1317 \times 10^{6} / \mathrm{L}\right)$ & $136.0(57.0-207.0)$ & 0 & $30(76.9)$ \\
NK cells $\left(210-1514 \times 10^{6} / \mathrm{L}\right)$ & $14(10-20)$ & - & - \\
Onset to RT-PCR turning negative, d & & & \\
\hline
\end{tabular}

Table 2

Lymphocyte subset counts of 39 patients with COVID-19 in different conditions and outcomes.

\begin{tabular}{|c|c|c|c|c|c|c|}
\hline & T cells, $\times 10^{6} / \mathrm{L}$ & CD4 $+T$ cells, $\times 10^{6} / \mathrm{L}$ & CD8 $+T$ cells, $\times 10^{6} / \mathrm{L}$ & $\mathrm{CD} 4+$ / CD8+ & B cells, $\times 10^{6} / \mathrm{L}$ & NK cells, $\times 10^{6} / \mathrm{L}$ \\
\hline \multicolumn{7}{|l|}{ Comorbidities } \\
\hline Yes $(n=15,38.5 \%)$ & $375.0(203.0-914.0)$ & $252.0(126.0-424.0)$ & $142.0(76.0-337.0)$ & $1.870(1.430-2.380)$ & $91.0(44.0-185.0)$ & $136.0(33.0-164.0)$ \\
\hline$\leq 5(n=22,56.4 \%)$ & $896.0(484.5-1216.5)$ & $530.0(278.0-712.8)$ & $312.5(158.5-619.0)$ & $1.645(1.065-2.275)$ & $167.0(53.5-285.3)$ & $156.5(45.0-254.5)$ \\
\hline$>5(n=17,43.6 \%)$ & $362.0(258.5-605.0)$ & $221.0(128.0-305.5)$ & $137.0(88.5-205.5)$ & $1.480(1.160-2.490)$ & $119.0(69.5-232.5)$ & $136.0(63.0-152.0)$ \\
\hline \multicolumn{7}{|l|}{ Imaging changes } \\
\hline $\begin{array}{l}\text { Progression }(n=23 \text {, } \\
74.2 \%)\end{array}$ & $501.0(266.0-878.0)$ & $290.0(148.0-630.0)$ & $164.0(81.0-288.0)$ & $1.780(1.260-2.530)$ & $110.0(55.0-246.0)$ & $107.0(31.0-192.0)$ \\
\hline \multicolumn{7}{|l|}{ Severity degree } \\
\hline $\begin{array}{l}\text { Mild or moderate } \\
(n=21,53.8 \%)\end{array}$ & $914.0(468.0-1214.0)$ & $591.0(266.0-718.5)$ & $288.0(165.0-414.5)$ & $1.780(1.305-2.330)$ & $174.0(69.5-306.5)$ & $149.0(58.5-240.5)$ \\
\hline $\begin{array}{l}\text { Severe and critical } \\
(n=18,46.2 \%)\end{array}$ & $343.5(237.0-730.3)$ & $217.5(112.8-324.5)$ & $122.5(76.0-256.8)$ & $1.345(0.930-2.413)$ & $105.0(55.8-235.5)$ & $123.5(44.5-177.8)$ \\
\hline$P$ value & $0.004^{*}$ & $0.013^{*}$ & $0.006^{*}$ & 0.955 & 0.145 & 0.571 \\
\hline \multicolumn{7}{|l|}{$\begin{array}{l}\text { Onset to RT-P CR } \\
\text { turning negative (d) }\end{array}$} \\
\hline$\leq 14(n=20,51.3 \%)$ & $896.0(361.3-1156.0)$ & $530.0(248.3-715.0)$ & $337.5(151.0-414.8)$ & $1.800(1.285-2.583)$ & $230.5(94.3-363.0)$ & $130.5(39.0-210.8)$ \\
\hline$>14(n=19,48.7 \%)$ & $426.0(195.0-719.0)$ & $242.0(103.0-320.0)$ & $142.0(96.0-273.0)$ & $1.440(1.080-2.060)$ & $90.0(49.0-174.0)$ & $136.0(59.0-192.0)$ \\
\hline \multicolumn{7}{|l|}{ Clinical outcome } \\
\hline $\begin{array}{l}\text { Hospital discharge } \\
(n=21,56.8 \%)\end{array}$ & $878.0(362.0-1256.0)$ & $518.0(208.0-700.0)$ & $338.0(154.0-511.5)$ & $1.460(0.980-2.335)$ & $185.0(72.0-282.0)$ & $139.0(45.5-243.5)$ \\
\hline $\begin{array}{l}\text { Continual cure or death } \\
(n=16,43.2 \%)\end{array}$ & $375.5(215.0-664.5)$ & $260.0(129.5-317.0)$ & $130.0(70.0-182.0)$ & $1.825(1.200-2.425)$ & $90.5(50.5-204.3)$ & $101.0(51.0-160.3)$ \\
\hline$P$ value & $0.014^{*}$ & $0.046^{*}$ & $0.005^{*}$ & 0.399 & 0.098 & 0.350 \\
\hline
\end{tabular}

Note:.

* represent the $P$ value $<0.05$.

lymphocyte subset. This result is quite different from that associated with pneumonia caused by common respiratory viruses, such as respiratory syncytial virus, which is typically associated with a normal or elevated lymphocyte count. ${ }^{6}$

Here, we found that the CD4 $+T$ cell and CD8 $+T$ cell counts were closely related to disease severity and clinical outcome when we compared the counts of lymphocyte subsets in different patient groups. The more serious the disease and the worse the prognosis, the lower were the $T$ cell, CD4 $+T$ cell, and CD8 $+T$ cell counts on admission. Based on these findings, we believe that the CD4+ and CD8+ $T$ cell counts in patients with COVID-9 could reflect dis- ease severity and predict disease prognosis and are therefore good biomarkers of COVID-19 activity.

In conclusion, lymphocyte subset (CD4+ and CD8+ $T$ cell) counts reflected the disease severity and associated with clinical outcomes, which can be considered as good biomarkers of COVID19. Early hospitalization influenced the level of CD4+ and CD8+ $T$ cells so patients required a quick hospitalization. If patients have relatively low counts of CD4+ and CD8 $+T$ cell on admission, they may be in a relatively severe infection with the SARS-CoV-2 virus and come to a worse prognosis. These patients should gain more attention to the change of their illness severity. 


\section{Author contributions}

LG and ZL contributed conception and design of the study; YH, SW, SC and MT contributed to data acquisition and check; WL performed the statistical analysis and wrote the first draft of the manuscript; WZ, LZ, MW and DC revised the tables; MW, QH, HX and WZ contributed to manuscript revision. All authors contributed to data interpretation and approved the final version.

\section{Funding sources}

This research did not receive any specific grant from funding agencies in the public, commercial, or not-for-profit sectors.

\section{Declaration of Competing Interest}

None.

\section{Acknowledgment}

None.

\section{References}

1. Chen J., Qi T., Liu L., Ling Y., Qian Z., Li T., et al. Clinical progression of patients with COVID-19 in Shanghai, China. J Infect

2. National Health Commission of the People's Republic of China. Guidelines for the Diagnosis and Treatment of COVID-19 (Trial Version 6) 2020. Available from: http://www.gov.cn/zhengce/zhengceku/2020-02/19/content_5480948.htm.

3. van Dam J.G., Damoiseaux J., Christiaans M.H.L., Bruggeman C.A.. Acute primary infection with cytomegalovirus (CMV) in kidney transplant recipients results in the appearance of a phenotypically aberrant $\operatorname{CD} 8(+) \mathrm{T}$ cell population. Microbiol Immunol 2000;44(12):1011-17.

4. Wong R.S.M., Wu A., To K.F. Lee N., Lam C.W.K., Wong C.K. et al. Haematological manifestations in patients with severe acute respiratory syndrome: retrospective analysis. Br Med J 2003;326(7403):1358-62.

5. Veazey R., Ling B.H., Pandrea I., McClure H., Lackner A., Marx P.. Decreased CCR5 expression on $\mathrm{CD} 4(+) \mathrm{t}$ cells of SIV-infected sooty mangabeys. AIDS Res Hum Retrov 2003;19(3):227-33.

6. Welliver R.C.. Respiratory syncytial virus and other respiratory viruses. Pediat Infect Disease J 2003;22(2):S6-S12.

Zeming Liu ${ }^{1}$, Wei Long ${ }^{1}$

Department of Plastic Surgery, Zhongnan Hospital of Wuhan University, Wuhan, 430071, China

Mengqi $\mathrm{Tu}^{1}$

Department of Radiology, Zhongnan Hospital of Wuhan University, Wuhan, 430071, China

Sichao Chen ${ }^{1}$, Yihui Huang ${ }^{1}$, Shipei Wang, Wei Zhou, Danyang Chen, Ling Zhou, Min Wang Department of Plastic Surgery, Zhongnan Hospital of Wuhan University, Wuhan, 430071, China

Meng Wu Department of Ultrasound, Zhongnan Hospital of Wuhan University, Wuhan, 430071, China

Qi Huang

Department of Respiratory and Critical Care Medicine, NHC Key Laboratory of Pulmonary Diseases, Union Hospital, Tongji Medical College, Huazhong University of Science and Technology, Wuhan, 430022, China

Haibo $\mathrm{Xu}^{*}$ Department of Radiology, Zhongnan Hospital of Wuhan University, Wuhan, 430071, China

Wen Zeng*

Department of Ophthalmology, Zhongnan Hospital of Wuhan University, Wuhan, 430071, China
Liang Guo*

Department of Plastic Surgery, Zhongnan Hospital of Wuhan University, Wuhan, 430071, China

*Corresponding authors. E-mail addresses: 714380246@qq.com (H. Xu), 524578732@qq.com (W. Zeng), guoliangwhzn@163.com (L. Guo)

1 These authors contributed equally to this work. Accepted 27 March 2020 Available online 11 April 2020

https://doi.org/10.1016/j.jinf.2020.03.054

(c) 2020 The British Infection Association. Published by Elsevier Ltd. All rights reserved.

\section{Dynamics of faecal SARS-CoV-2 in infected children during the convalescent phase}

Dear Editor,

We read with interest the recent paper in this Journal by He et al. who reviewed the current evidence on COVID-19 and concluded that faecal shedding of SARS-CoV-2 should not be ignored as one of the possible transmission routes of the virus. ${ }^{1}$ We would like to share findings from our paediatric patients who were positive for nucleic acid testing for SARS-CoV-2 in stools up to 8-20 days after clearance of viral RNA in respiratory specimens.

With the World Health Organization declaring a pandemic, the outbreak of coronavirus disease 2019 (COVID-19) poses a global threat with the highest risk impact. ${ }^{2}$ The aetiological agent is a newly identified pathogen which was later renamed as severe acute respiratory syndrome coronavirus 2 (SARS-CoV-2). There has been accumulating evidence suggests that the virus plagues people ubiquitously, although paediatric patients seem to present with distinct characteristics from infected adults. ${ }^{3-6}$

Between January 17, 2020 and February 23, 2020, a total of 3 children with laboratory confirmed COVID-19 was reported in Qingdao, Shandong Province, China. Baseline characteristics and clinical, laboratory, and radiological data were collected. Dynamic profiles of real-time reverse transcription polymerase chain reaction (RT-PCR) results in throat swabs and faecal specimens were closely monitored till March 10, 2020, the final date of follow-up.

All the three paediatric patients were diagnosed with mild pneumonia and fever was the most consistent and predominant symptom at any time during the illness. Only one child had gastrointestinal symptoms. All children were in stable condition during the course of hospitalisation and none of them required respiratory support or intensive care. Their laboratory and radiological features were not typical for COVID-19. The three infected children showed good response to supportive and anti-viral treatment with a relatively short time to resolution.

Surprisingly, we found SARS-CoV-2 remained detectable in faeces of paediatric patients for approximately 4 weeks, whereas negative conversion of viral RNA in respiratory specimens occurred within 2 weeks after disease onset. Two children showed negative results for faecal detection of SARS-CoV-2 20 days after clearance of viral RNA in the respiratory tract, while another child persistently tested positive on faecal samples even 8 days after respiratory samples turning negative. Chronological changes in RTPCR results of respiratory and faecal specimens are shown in Fig. 1. 


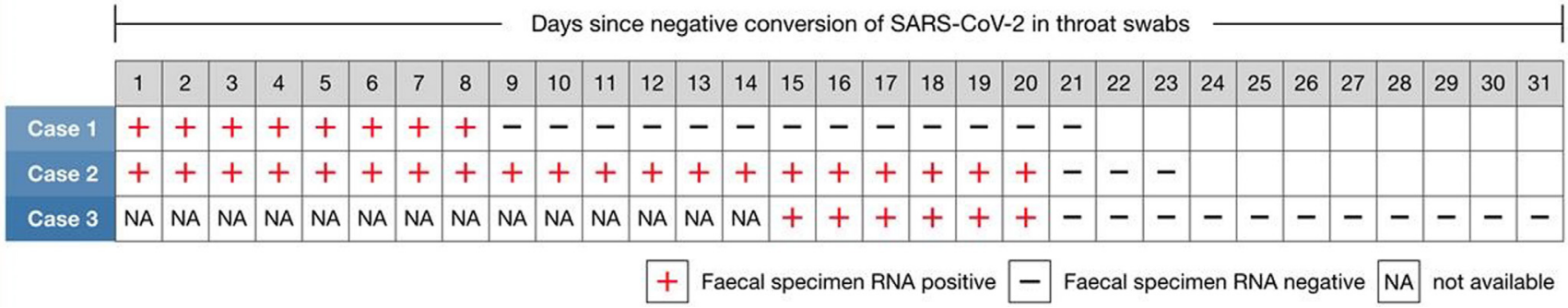

Fig. 1. Timeline for Detection of SARS-CoV-2 RNA in Respiratory and Faecal Specimens.

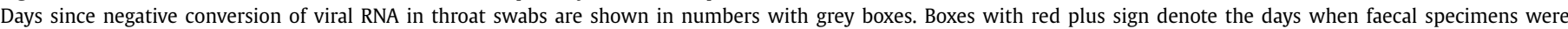

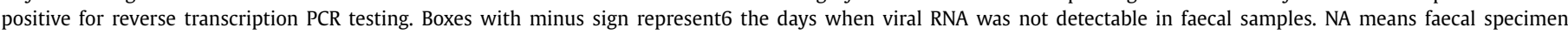
was not collected from the patients on that day and laboratory result was not available.

In general, children appear to be less severely affected by SARS-CoV-2 in contrast with adult patients. ${ }^{3-6}$ The mechanism underlying this youthful resilience to COVID-19 is yet to be systematically determined. Notably, asymptomatic infection is not uncommon amongst children. A recent study on the prevalence of COVID-19 in children demonstrated that 39 of 171 (27.7\%) laboratory confirmed cases did not have any symptoms of infection. ${ }^{3}$ An asymptomatic child had SARS-CoV-2 RNA detectable in faeces at least 9 days after viral clearance in the respiratory tract. ${ }^{7}$ It might be possible that asymptomatic children infected with SARS-CoV2 go undetected and represent as important contributors to virus transmission in the community, causing the pandemic to propagate. Aggressive efforts should be made to prevent spreading of the infection in schoolyard environments.

Faecal shedding of viral RNA has been constantly reported in patients infected with SARS-CoV-2.7-10 One study reported over half of the 17 patients had faecal samples positive for SARS-CoV2 detection, although virus copies in stools were less than those in respiratory specimens. ${ }^{8}$ However, the researchers did not mention age distribution of these patients, neither did they investigate the duration of faecal samples positive for nucleic acid testing. Another study on paediatric cases indicated that viral loads in the gastrointestinal tract might be greater than that in the respiratory system. Eight out of ten paediatric patients were positive for nucleic acid testing in rectal swabs after respiratory specimens showing negative. ${ }^{9}$ Hence, SARS-CoV-2 may exist in the digestive system for a longer duration and convalescent patients with prolonged faecal shedding of SARS-CoV-2 may be an infectious source if fitness for discharge is based on respiratory testing.

In the face of a novel disease, scientists and clinicians still have much to learn about the potential routes of virus transmission. Evidence so far raises the possibility of faecal-oral transmission, reinforcing the need for nucleic acid testing of stool samples from COVID-19 patients during the convalescent phase. Close surveillance of convalescent patients would be crucial to curb the COVID19 pandemic, and maybe outbreaks yet to come.

\section{References}

1. He Y., Wang Z., Li F., Shi Y.. Public health might be endangered by possible prolonged discharge of SARS-CoV-2 in stool. J Infect 2020. doi:10.1016/j.jinf.2020. 02.031.

2. WHO main website. https://www.who.int (accessed February 28th, 2020).

3. Lu X., Zhang L., Du H., Zhang J., Li Y.Y., Qu J., et al. SARS-CoV-2 infection in children. N Engl J Med 2020. doi:10.1056/NEJMc2005073.

4. Cai J., Xu J., Lin D., Yang Z., et al. A case series of children with 2019 novel coronavirus infection: clinical and epidemiological features. Clin Infect Dis 2020. doi:10.1093/cid/ciaa198.

5. Dong Y., Mo X., Hu Y., Qi X., Jiang F., Jiang Z., Tong S.. Epidemiological characteristics of 2143 pediatric patients with 2019 coronavirus disease in china. Pediatrics 2020. doi:10.1542/peds.2020-0702.

6. Wei M., Yuan J., Liu Y., Fu T., Yu X., Zhang Z.-.J.. Novel coronavirus infection in hospitalized infants under 1 year of age in China. JAMA 2020. doi:10.1001/jama. 2020.2131
7. An T., Zhen-dong T., Hong-ling W., et al. Detection of novel coronavirus by RTPCR in stool specimen from asymptomatic child, China. Emerg Infect Disease J 2020;26(6). doi:10.3201/eid2606.

8. Pan Y., Zhang D., Yang P., Poon L.L.M., Wang Q.. Viral load of SARS-CoV-2 in clinical samples. Lancet Infect Dis 2020. doi:10.1016/S1473-3099(20)30113-4.

9. Xu Y., Li X., Zhu B., et al. Characteristics of pediatric SARS-CoV-2 infection and potential evidence for persistent fecal viral shedding. Nat Med 2020. doi:10. 1038/s41591-020-0817-4.

10. Xiao F., Tang M., Zheng X., Liu Y., Li X., Shan H.. Evidence for gastrointestinal infection of SARS-CoV-2. Gastroenterology 2020. doi:10.1053/j.gastro.2020.02.055.

Yuhan Xing ${ }^{1}$

Department of Paediatrics, Prince of Wales Hospital, Faculty of Medicine, The Chinese University of Hong Kong, Hong Kong, China

Wei $\mathrm{Ni}^{1}$, Qin Wu, Wenjie Li, Guoju Li, Wendi Wang, Jianning Tong, Xiufeng Song

Qingdao Women and Children's Hospital, Qingdao University,No.6 Tongfu Road, Qingdao, Shandong Province 266000, China

Gary Wing Kin Wong*

Department of Paediatrics, Prince of Wales Hospital, Faculty of Medicine, The Chinese University of Hong Kong, Hong Kong, China

Quansheng Xing*

Qingdao Women and Children's Hospital, Qingdao University,No.6 Tongfu Road, Qingdao, Shandong Province 266000, China

*Corresponding authors.

E-mail addresses: wingkinwong@cuhk.edu.hk (G.W.K. Wong), xingqs0532@163.com (Q. Xing)

1 These author contributed equally Accepted 26 March 2020 Available online 10 April 2020

https://doi.org/10.1016/j.jinf.2020.03.049

(c) 2020 The British Infection Association. Published by Elsevier Ltd. All rights reserved.

High-resolution computed tomographic imaging disclosing COVID-19 pneumonia: A powerful tool in diagnosis

\section{Dear Editor,}

We read with great interest the recent studies by $\mathrm{Xu}$ et al. and Yang et al. in this journal, ${ }^{1,2}$ both depicting the computed tomographic (CT) imaging features of Corona Virus Disease 2019 
(COVID-19). In consideration of this pandemic, declared by WHO in 9 March 2020, threatening the public health worldwide, these results provided detailed imaging information of COVID-19 and favored the effective diagnosis.

$\mathrm{Xu}$ et al. reported 50 patients with confirmed COVID-19 and found that the CT imaging on admission mainly presented patchy ground glass opacities in the peripheral areas under the pleura and infiltration of bilateral lower lobes. ${ }^{1}$ Besides, severe and critically ill patients were significantly older than either mild or common patients, and had significantly more infected lobes. It was consistent with the previous study that severe and critically ill cases were older, ${ }^{3,4}$ and also suggested that older patients could have more abnormality in CT imaging. Yang et al. reported the CT imaging of 149 confirmed patients with mild infection from the perspective of pulmonary segments. ${ }^{2}$ The main pattern of CT abnormality was multifocal peripheral ground glass or mixed opacity with predominance in the lower lung, among which lung segments 6 and 10 were mostly involved.

A series of studies on COVID-19 CT imaging, with difference in sampling scale, study design and description perspective, were also reported. Earlier, two articles from Wang et al. and Guo et al. reporting all-round clinical characteristics of COVID-19 patients distributed short context on the CT presentation. ${ }^{3,4}$ Among them, Wang et al. enrolled 138 patients infected during hospitalization including 36 critically ill cases and 102 non-critically ill cases. Bilateral distribution of patchy shadows and ground glass opacity, as the hallmark of CT scan, were seen in all patients. ${ }^{4}$ The study of Guo et al. involved a nationwide sampling of 1099 COVID-19 patients. 167 severe cases and 808 non-severe cases received CT scan and the main abnormality was also ground-glass opacity and bilateral patchy shadowing. ${ }^{3}$ No further in-depth description was depicted. However, Chung et al., specialized in imaging, reported 21 cases and pointed that $57 \%$ patients were manifested with ground glass opacities and 33\% presented peripheral distribution. But no difference was seen regarding the lesion distribution on lobes, perhaps due to the limited number of patients. Lung cavitation, discrete pulmonary nodules, pleural effusions and lymphadenopathy were absent. ${ }^{5}$ Song et al. enrolled 51 patients and pinpointed on different forms of lung lesion that pure ground grass opacity (pGGO) in $77 \%$ patients, GGO with reticular and/or interlobular septal thickening in $75 \%$ patients, GGO with consolidation in $59 \%$ patients and pure consolidation in $55 \%$ patients. Furthermore, there were $90 \%$ patients with lesions distributed in the lower lobes, $86 \%$ patients with lesions distributed in the lung periphery and $80 \%$ patients with lesions distributed in the posterior part of the lung. ${ }^{6}$ Shi et al. focused on temporal changes throughout the disease course and stratified 81 patients on the interval from symptom onset to first CT scan. They indicated the rapid evolution within 1-3 weeks from focal unilateral to diffuse bilateral ground-glass opacities that progressed to or co-existed with consolidations. ${ }^{7}$

These findings concurred with our retrospective study. We enrolled 165 patients with COVID-19 pneumonia (confirmed by RT-PCR) from January 2 to February 5, 2020 in 5 different hospitals. All these 5 hospitals were designated hospitals for treating COVID-19, including one outside Wuhan city and one outside Hubei province. All patients received chest CT scan on admission. For all lung lesion, we found that $95.4 \%$ was located in the middle and lower parts of lung while only $4.6 \%$ in the upper part (Fig. 1). We then introduced a CT imaging score system to quantify the pathological changes of COVID-19 patients (Table 1). To reveal the relationship between age and CT imaging abnormality, we classified these patients into 3 groups and compared the young group (with age $\leq 40$ years) with the old (with age $\geq 60$ years). Of note, the patients in the old group had significantly more severe CT imaging (Fig. 2A). The representative CT imaging of the young
The proportion of lesion distribution on different sites

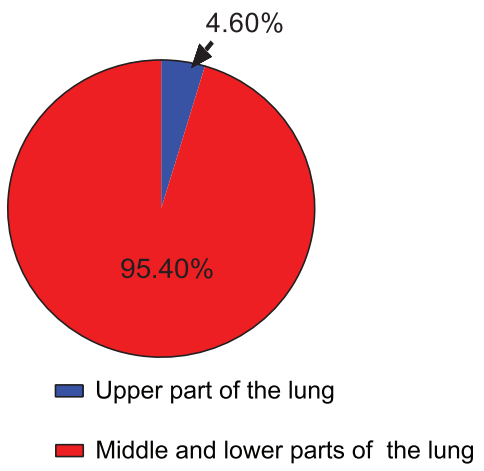

Fig. 1. The lesion distribution on different sites was calculated based on all lung lesions. The result showed the proportion in the upper part of the lung and the middle and lower parts of the lung.

Table 1

CT imaging score system to quantify the severity of COVID-19 patients.

\begin{tabular}{lll}
\hline No. & Performance & Score \\
\hline$(1)$ & Unbilateral patchy shadow or ground glass opacity & 5 \\
$(2)$ & Bilateral patchy shadow or ground glass opacity & 7 \\
$(3)$ & Diffuse changes for (1) or (2) & 2 \\
$(4)$ & Unbilateral solid shadow, striped shadow & 2 \\
$(5)$ & Bilateral solid shadow, striped shadow & 4 \\
$(6)$ & Unbilateral pleural effusion & 2 \\
$(7)$ & Bilateral pleural effusion & 4 \\
$(8)$ & Increased or enlarged mediastinal lymph nodes & 1 \\
\hline
\end{tabular}

and the old on admission were listed in Fig. 2B. Radiographic improvement was obviously seen after effective therapy.

The number of COVID-19 patients is still surging in multiple areas around the world. By 22 March 2020, a total of 222,707 cases were diagnosed outside China. Given the relative scarcity and false negative result of nucleic acid testing, the data may be far from the true reality. Currently the detection of SARS-CoV-2 nucleic acid serves as the basis for diagnosis. It was reported that the sensitivity of RT-PCR was lower than that of CT because it can be influenced by the accuracy of test kit, the viral load, and the quality of specimen sampling. ${ }^{8}$ COVID-19 features attacking on the respiratory system, where CT imaging enjoys its accuracy and convenience in real-timely reflecting the lung condition. Shi et al. also confirmed the CT manifestations in asymptomatic patients preceded the symptom onset. Thus, CT could greatly compensate RTPCR in diagnosis, especially for patients with false-negative RT-PCR results.

In conclusion, a cluster of studies suggest the primary pattern on CT imaging of COVID-19 pnuemonia is GGO of different subtypes, with the distribution prominence in lower, posterior and peripheral lung, which can quickly change during hospitalization. Old patients have severe presentation of CT imaging. Therefore, CT scan as an important tool deserves attention in disease diagnosis, which will facilitate the patients sorting on severity and the early intervention of quarantine or treatment, dependent on the clinical manifestation. Given the improved efficiency of CT imaging evaluation with artificial intelligence and big data, it is imperative to collect $\mathrm{CT}$ imaging as comprehensive as possible enabling the in-depth learning. Evaluation of CT imaging through telemedicine could probably relief the imbalance of medical resources to some extent. Despite the available information, more extended detailed studies on CT imaging is still needed. 
A

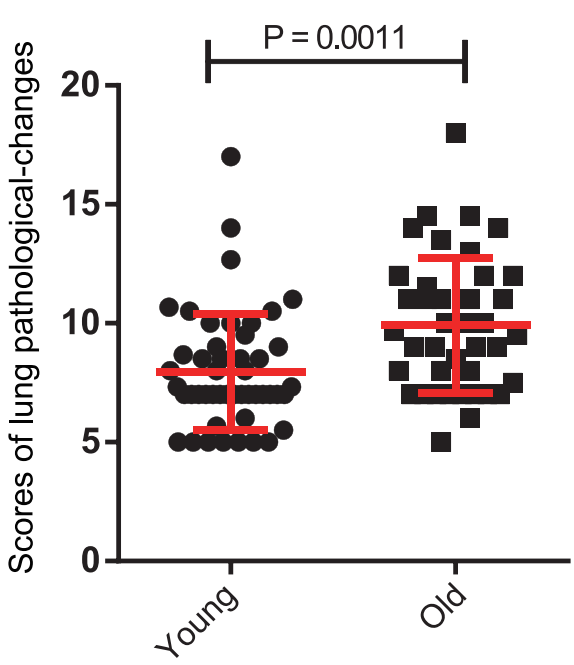

B

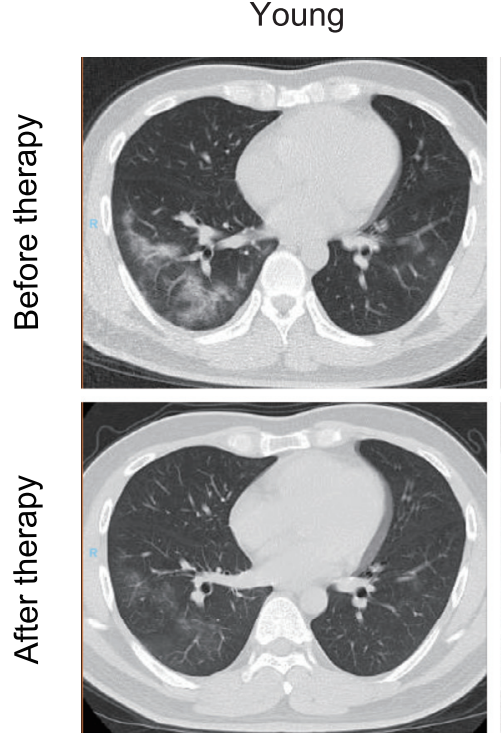

Old

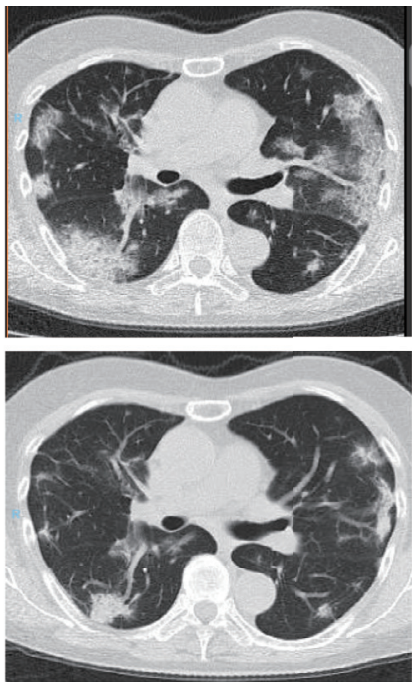

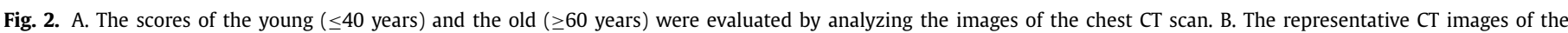
young and the old patients. These CT images were taken before or after therapy, respectively.

\section{Declaration of Competing Interest}

None.

\section{Authors' contributions}

All the authors participated in generating the idea. Zili Zhang and Yin Shen wrote the initial version of the letter. Desheng $\mathrm{Hu}$, Haijun Wang and Lei Zhao critically reviewed and edited it with their comments.

\section{Funding}

This study was funded by the National Natural Science Foundation of China (No. 31770983 and 81974249 to DH)

\section{References}

1. Xu Y.H., Dong J.H., An W.M., Lv X.Y., Yin X.P., Zhang J.Z., et al. Clinical and computed tomographic imaging features of novel coronavirus pneumonia caused by SARS-CoV-2. J Infect 2020 Feb 25 PubMed PMID:32109443.

2. Yang W., Cao Q., Oin L., Wang X., Cheng Z., Pan A., et al. Clinical characteristics and imaging manifestations of the 2019 novel coronavirus disease (COVID-19):a multi-center study in Wenzhou city, Zhejiang, china. J Infect 2020 PubMed PMID:32112884.

3. Guan W.J., Ni Z.Y., Hu Y., Liang W.H., Ou C.Q., He J.X., et al. Clinical characteristics of coronavirus disease 2019 in China. N Engl J Med 2020 PubMed PMID:32109013.

4. Wang D., Hu B., Hu C., Zhu F., Liu X., Zhang J., et al. Clinical characteristics of 138 hospitalized patients with 2019 novel coronavirus-infected pneumonia in Wuhan, China. JAMA 2020 PubMed PMID:32031570Pubmed Central PMCID: PMC7042881.

5. Chung M., Bernheim A., Mei X., Zhang N., Huang M., Zeng X., et al. CT imaging features of 2019 novel coronavirus (2019-nCoV). Radiology 2020;295(1):202-7 PubMed PMID:32017661

6. Song F., Shi N., Shan F. Zhang Z., Shen J., Lu H., et al. Emerging 2019 nove coronavirus (2019-nCoV) pneumonia. Radiology 2020;295(1):210-17 PubMed PMID:32027573 .
7. Shi H., Han X., Jiang N., Cao Y., Alwalid O., Gu J., et al. Radiological findings from 81 patients with COVID-19 pneumonia in Wuhan, China: a descriptive study Lancet Infectious Diseases 2020.

8. Fang Y., Zhang H., Xie J., Lin M., Ying L., Pang P., et al. Sensitivity of chest CT for COVID-19: comparison to RT-PCR. Radiology 2020:200432 PubMed PMID:32073353.

Zili Zhang ${ }^{1}$

Department of Integrated Traditional Chinese and Western Medicine, Union Hospital, Tongji Medical College, Huazhong University of Science and Technology, Wuhan 430022, China

Yin Shen ${ }^{1}$, Haijun Wang

Department of Neurosurgery, Union Hospital, Tongji Medical College, Huazhong University of Science and Technology, Wuhan 430022,

China

Lei Zhao

Department of Infectious Disease, Union Hospital, Tongji Medical College, Huazhong University of Science and Technology, Wuhan 430022, China

Desheng $\mathrm{Hu}^{*}$

Department of Integrated Traditional Chinese and Western Medicine, Union Hospital, Tongji Medical College, Huazhong University of Science and Technology, Wuhan 430022, China

*Corresponding author E-mail address: desheng.hu@hust.edu.cn (D. Hu)

${ }^{1}$ These authors contributed equally to this work Accepted 26 March 2020 Available online 10 April 2020

https://doi.org/10.1016/j.jinf.2020.03.047

(c) 2020 The British Infection Association. Published by Elsevier Ltd. All rights reserved. 


\section{A potential inhibitory role for integrin in the receptor targeting of SARS-CoV-2}

Dear Editor,

Corona Virus Disease 2019 (COVID-19) has caused a global pandemic in over 100 countries. Severe Acute Respiratory Syndrome Corona Virus 2 (SARS-CoV-2) was identified as the pathogen of COVID-19. Both SARS-CoV-2 and SARS-CoV belong to the subgenus sarbecvirus of Coronaviridae. One major structural protein Spike (S) has attracted great attention because of its function in recognizing receptor, angiotensin-converting enzyme 2 (ACE2). ACE2 binds to the receptor-binding motif (RBM) in the receptor-binding domain (RBD) of SARS-CoV-2 and SARS-CoV. Although ACE2 is distributed in many organs, lung is the major target of both SARS-CoV-2 and SARS-CoV. SARS-CoV-2 tends to infect fewer organs than SARSCoV. For instance, COVID-19 patients showed less diarrhea than SARS patients. ${ }^{1}$ The underlying mechanism remains inconclusive.

Integrins are heterodimeric proteins comprising $\alpha$ and $\beta$ subunits in cell surface. Many integrins recognize Arg-Gly-Asp (RGD) and Lys-Gly-Asp (KGD) motifs which are displayed on the exposed loops of proteins. RGD could associate broader types of integrins such as $\alpha \mathrm{V} \beta 1, \alpha \mathrm{V} \beta 3, \alpha \mathrm{V} \beta 5, \alpha \mathrm{V} \beta 6, \alpha \mathrm{V} \beta 8, \alpha \operatorname{IIb} \beta 3, \alpha \mathrm{M} \beta 2$, $\alpha \mathrm{L} \beta 2$ and $\alpha 3 \beta 1$, while KGD-recognizing integrins are restricted to $\alpha \operatorname{IIb} \beta 3, \alpha \mathrm{V} \beta 5, \alpha \mathrm{V} \beta 6$ and $\alpha \mathrm{V} \beta 8$. $^{2}$ A recent study proposed a proviral role for integrins in SARS-CoV-2 entry. ${ }^{3}$ In current study, we found RGD/KGD motif presents not only in $S$ protein but also in its receptor ACE2. We suggested inhibitory roles for integrins in the entry of both SARS-CoV-2 and SARS-CoV.

RGD and KGD are two classical integrin-binding motifs. First, we performed sequence analysis of $S$ proteins from SARS-CoV-2 (YP_009724390.1) and SARS-CoV (NP_828851.1). An RGD motif (403-405) was identified in SARS-CoV-2 S protein (Fig. 1A). In SARS-CoV S protein, there is a KGD motif (390-392) (Fig. 1A). By searching NCBI databases and literatures, we identified similar RGD/KGD motifs in several coronaviruses including Pangolin/MP789/2019, ${ }^{4}$ Pangolin/GX/P5L/2017, ${ }^{4}$ Bat_CoV_Rc-CoV-
3 (BBJ35999.1), Bat_SARSr-CoV_WIV1 (AGZ48828.1), Bat_SARSrCoV_WIV16 (ALK02457.1), Bat_SARSr-CoV_RsSHC014 (AGZ48806.1), Bat_SARSr-CoV_Rs3367 (AGZ48818.1). These results suggested that $\mathrm{RGD} / \mathrm{KGD}$ integrin-binding motif is conserved in several coronaviruses including SARS-CoV-2 and SARS-CoV.

In order to associate with integrin, RGD/KGD motif should be exposed to the surface of the protein. To investigate whether $\mathrm{RGD} / \mathrm{KGD}$ motif in $\mathrm{S}$ proteins from SARS-CoV-2 and SARS-CoV is on the surface, we analyzed the structures of SARS-CoV-2 $\mathrm{S}$ trimer (PDB: $6 \mathrm{VSB})^{5}$ and SARS-CoV S trimer (PDB: 5XLR) ${ }^{6}$ by Chimera software Ver 1.14. RGD located at the top of protrusions in SARS$\mathrm{CoV}-2 \mathrm{~S}$, and KGD is displayed on exposed loop in SARS-CoV $\mathrm{S}$ (Fig. $1 \mathrm{~B}$ and $1 \mathrm{C}$ ). These results suggested that $\mathrm{S}$ proteins are accessible to integrins.

$\mathrm{RGD} / \mathrm{KGD}$ motif in $\mathrm{S}$ protein is close to RBM of $\mathrm{S}$ protein. Next, we checked the structure of ACE2 with SARS-CoV-2 S RBD (PDB: 6LZG) and ACE2 with SARS-CoV S RBD (PDB: 2AJF) ${ }^{7}$ by Chimera software Ver 1.14. RGD/KGD in S protein is near the groove of complex of RBD and ACE2 (Fig. 1D and 1E). If S protein associates with integrin, there would be no space for ACE2 to contact with S.

ACE2 is known to associate with integrin. An RGD sequence (203-205) in ACE2 is partially buried inside the protein and thus not responsible for integrin association. ${ }^{8}$ We identified a KGD motif in 353-355 of ACE2 (BAB40370.1), which is a key region for binding $S$ protein (Fig. 1F). This KGD motif is on the exposed small loop in the structure of open ACE2 dimer (PDB: 6M1D) and closed ACE2 dimer (PDB: 6M18), ${ }^{9}$ which indicated that integrin could interact with ACE2 through this motif (Fig. 1G).

We proposed the following model for the role of integrin in receptor recognition of S protein (Fig. 2). Upon SARS-CoV-2 or SARS$\mathrm{CoV}$ infection, integrin could interact with ACE2 and $S$ protein individually. Integrin associates with ACE2 through its KGD motif including K353, which is one of key AAs for S protein recognition. Integrin associates with $\mathrm{S}$ protein by its $\mathrm{RGD} / \mathrm{KGD}$ motif, which would shield the space of RBM for contacting with ACE2. In those scenarios, both ACE2 K353 (inside KGD) and S protein RBM (near RGD/KGD) are shielded by integrin. Thus, ACE2 could not recog-
A

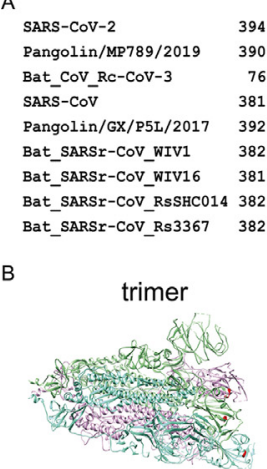

C

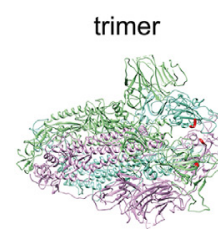

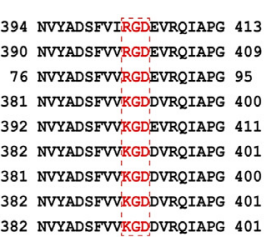

D
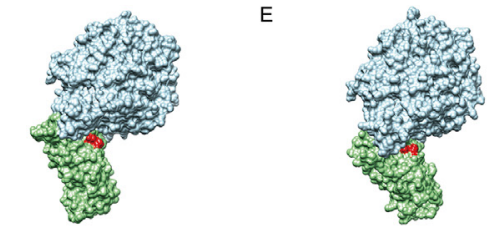

ACE2 344 CHPTAWDLGKKGḠ'FRILMCTK 363

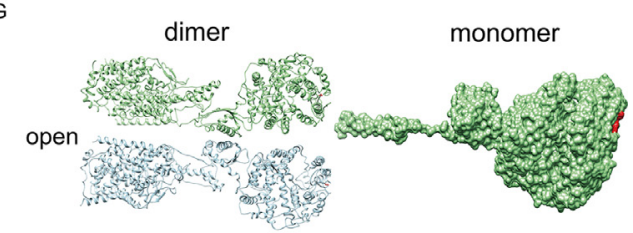

monomer
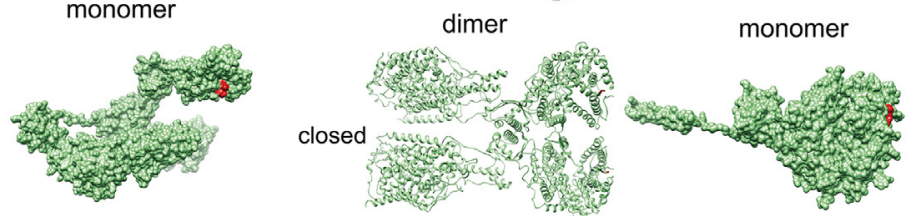

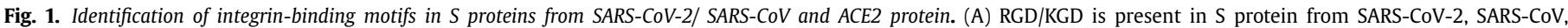

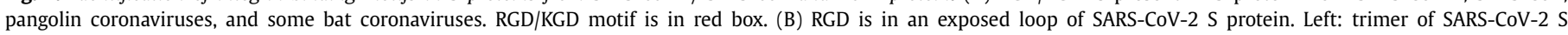

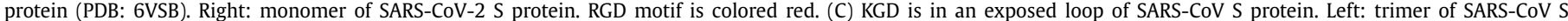

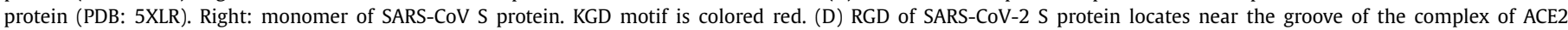

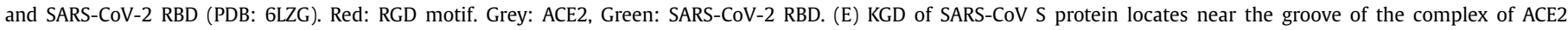

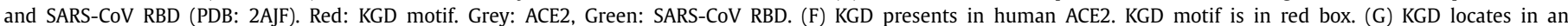

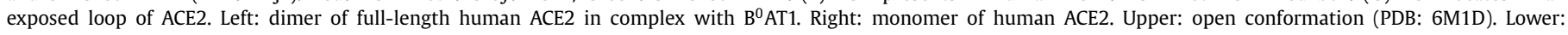
closed conformation (PDB: 6M18). KGD motif is colored red. 


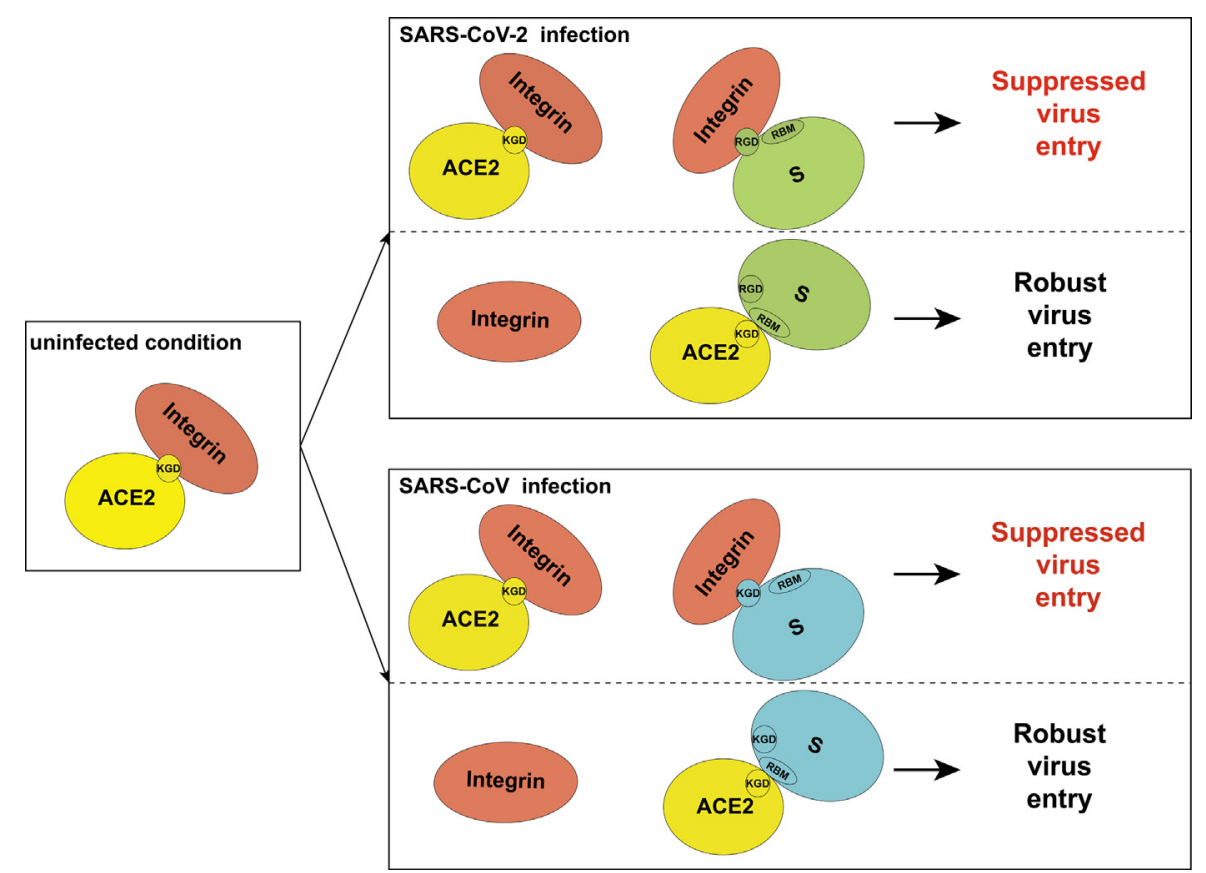

Fig. 2. Proposed model for the inhibitory role of integrin in SARS-COV-2 and SARS-CoV.

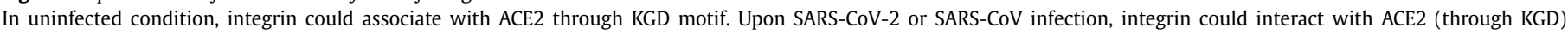

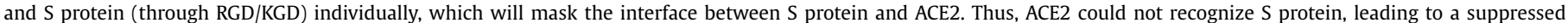
viral entry. When ACE2 associates with S protein, a robust virus entry will occur.

nize $S$ protein, leading to a suppressed viral entry. In the condition of ACE2 targeting of S protein, integrin no longer blocks ACE2-S interaction, resulting in a robust virus entry.

Several host proteins were predicted to associate with SARSCoV-2 S protein. ${ }^{3,10}$ Recently, people reported that the SARS-CoV$2 \mathrm{~S}$ protein acquired an RGD integrin-binding motif and claimed that this motif was absent from other coronaviruses. ${ }^{3}$ They further speculated that RGD acquired by SARS-CoV-2 would promote virus entry by association of integrins, thus enhance the transmission ability. We disagree with that because both RGD and KGD could recognize integrins. The difference is that RGD recognizes more types of integrins than KGD. When integrins bind to $S$ protein, the stereo-hindrance effect will prevent ACE2 targeting by $S$ protein. Moreover, ACE2 contains a KGD integrin-binding motif inside the $\mathrm{S}$-binding region. When integrins bind to $\mathrm{S}$ protein, ACE2 targeting by $S$ protein will also be inhibited. Taken together, our model favors an inhibitory role for integrins in virus entry by associating with both $S$ protein and ACE2.

Potential association of $\mathrm{S}$ protein and integrins provide mechanistic insights for the pathogenesis of SARS-CoV-2 and SARS-CoV. Because RGD recognized a broader spectrum of integrins than KGD, more integrins could block receptor binding of SARS-CoV-2 S than that of SARS-CoV S. Consequently, SARS-CoV-2 would infect fewer organs than SARS-CoV, which might partially explain why SARSCoV-2 caused less mortality than SARS-CoV.

In conclusion, we identified an RGD/KGD integrin-binding motif in $\mathrm{S}$ proteins from SARS-CoV-2 and SARS-CoV. We also discovered a KGD integrin-binding motif in ACE2. Integrins were predicted to inhibit receptor targeting of S proteins from SARS-CoV-2 and SARSCoV by shielding both S protein and ACE2. We proposed a previous unappreciated inhibitory role for integrin in virus entry, which will improve our understanding on the virus entry for both SARS-CoV-2 and SARS-CoV.

\section{Acknowledgments}

This work was supported by grants from National Key Plan for Research and Development of China [2016YFD0500300], National Natural Science Foundation of China [81871663 and 81672035], the Innovation Project of Shandong Academy of Medical Sciences and Academic promotion programme of Shandong First Medical University [2019LJ001]. We thank Dr. Jianxun Qi for sharing the structure of 6LZG.

\section{References}

1. He Y., Wang Z., Li F., Shi Y.. Public health might be endangered by possible prolonged discharge of SARS-CoV-2 in stool. J Infect 2020. doi:10.1016/j.jinf.2020. 02.031.

2. Kuo Y.J., Chung C.H., Huang T.F. From discovery of snake venom disintegrins to a safer therapeutic antithrombotic agent. Toxins (Basel) 2019;11.

3. Sigrist C.J., Bridge A., Le Mercier P.. A potential role for integrins in host cell entry by SARS-CoV-2. Antiviral Res 2020;177:104759.

4. Lam T.T.-Y., Shum M.H.-H., Zhu H.-C., Tong Y.-G., Ni X.-B., Liao Y.-S., Wei W. Cheung W.Y.-M., Li W.-J., Li L.-F., Leung G.M., Holmes E.C., Hu Y.-L., Guan Y. 2020. Identification of 2019-nCoV related coronaviruses in Malayan pangolins in southern China. doi:10.1101/2020.02.13.945485 bioRxiv:2020.02.13.945485.

5. Wrapp D., Wang N., Corbett K.S., Goldsmith J.A., Hsieh C.L., Abiona O., Graham B.S., McLellan J.S.. Cryo-EM structure of the 2019-nCoV spike in the prefusion conformation. Science 2020. doi:10.1126/science.abb2507.

6. Gui M., Song W., Zhou H., Xu J., Chen S., Xiang Y., Wang X.. Cryo-electron microscopy structures of the SARS-CoV spike glycoprotein reveal a prerequisite conformational state for receptor binding. Cell Res 2017;27:119-29.

7. Li F. Li W., Farzan M., Harrison S.C.. Structure of SARS coronavirus spike receptor-binding domain complexed with receptor. Science 2005;309:1864-8.

8. Clarke N.E., Fisher M.J., Porter K.E., Lambert D.W., Turner A.J.. Angiotensin converting enzyme (ACE) and ACE2 bind integrins and ACE2 regulates integrin signalling. PLoS One 2012;7:e34747.

9. Yan R., Zhang Y., Li Y., Xia L., Guo Y., Zhou Q.. Structural basis for the recognition of the SARS-CoV-2 by full-length human ACE2. Science 2020. doi:10.1126 science.abb2762.

10. Ibrahim I.M., Abdelmalek D.H., Elshahat M.E., Elfiky A.A.. COVID-19 spike-host cell receptor GRP78 binding site prediction. J Infect 2020. doi:10.1016/j.jinf.2020. 02.026

Junwen Luan ${ }^{1}$

Institute of Basic Medicine, Shandong Provincial Hospital Affiliated to Shandong First Medical University, Jinan 250062, Shandong, China

The authors declare that there are no conflicts of interest. 
Yue $\mathrm{Lu}^{1}$

Institute of Basic Medicine, Shandong Provincial Hospital Affiliated to Shandong First Medical University, Jinan 250062, Shandong, China School of Medicine and Life Sciences, University of Jinan-Shandong Academy of Medical Sciences, Jinan 250200, Shandong, China

Shan Gao, Leiliang Zhang* Institute of Basic Medicine, Shandong Provincial Hospital Affiliated to Shandong First Medical University, Jinan 250062, Shandong, China

*Corresponding author. E-mail address: armzhang@hotmail.com (L. Zhang)

1 These authors contributed equally to this work. Accepted 26 March 2020 Available online 10 April 2020

https://doi.org/10.1016/j.jinf.2020.03.046

(C) 2020 The British Infection Association. Published by Elsevier Ltd. All rights reserved.

\section{Regional air pollution persistence links to COVID-19 infection zoning}

Dear Editor,

In this Journal, Tian and colleagues have described the clinical features of COVID-19 in the highly urbanised environment of Beijing ${ }^{1}$.

The authors declare no conflict of interest and no financial support for this study.
There is a strong established link between severe viral respiratory disease, which causes infection in $10 \sim 20 \%$ of the population, and air pollution. ${ }^{2}$ Fine particulate matter with an aerodynamic diameter of $2.5 \mathrm{~m}$ or less (PM2.5), $10 \mathrm{~m}$ or less (PM10), sulfur dioxide $\left(\mathrm{SO}_{2}\right)$, nitrogen dioxide $\left(\mathrm{NO}_{2}\right)$, carbon monoxide $(\mathrm{CO})$, and ozone $\left(\mathrm{O}_{3}\right)$ affect airways through inhalation and exacerbate the susceptibility to and severity of respiratory virus infections ${ }^{3}$.

Notable research conducted in this field has demonstrated that PM2.5 levels in the air of Beijing directly influences the transmission of influenza virus. ${ }^{4} \mathrm{O}_{3}$ has been found to be significantly negatively associated with influenza transmissibility while CO levels had a positive association. ${ }^{5}$ In particular, fine particles, such as PM2.5, tend to stay longer in the air than heavier particles and their minute size increases the chances to let them penetrate deep into the lungs, bypassing the nose and throat. This leads to progressive and chronic inflammation of the respiratory airways with excessive mucus production and decreased ciliary activity with subjects chronically exposed to air pollutants more prone to develop severe respiratory diseases after viral infections.

At the time of this letter, the countries with the highest number of COVID-19 infections were China and Italy. There is a common link between these countries which is the very high level of air pollutants. For instance, in the areas of these countries most affected by COVID-19 outbreaks, mean PM2.5 concentrations vastly exceed the hourly standard of $75 \mu \mathrm{g} / \mathrm{m} 3$. In Italy, the outbreaks were focused in the North, exactly in the Po valley, cities of Lodi, Cremona and Bergamo, which are in the five Italian cities with highest pollution levels. The region, which is often referred as the "Industrial Triangle" after the economic boom of the sixties of the twentieth century, is characterized by a high density of factories, traffic and intensive agriculture. Such dense anthropic activity produces a significant pollutant emission in the region, which along with its specific topography its and climatic features, produces a hood where fine particulates are trapped. Indeed, Po Valley is a plain surrounded by Alps, characterised by weak winds and
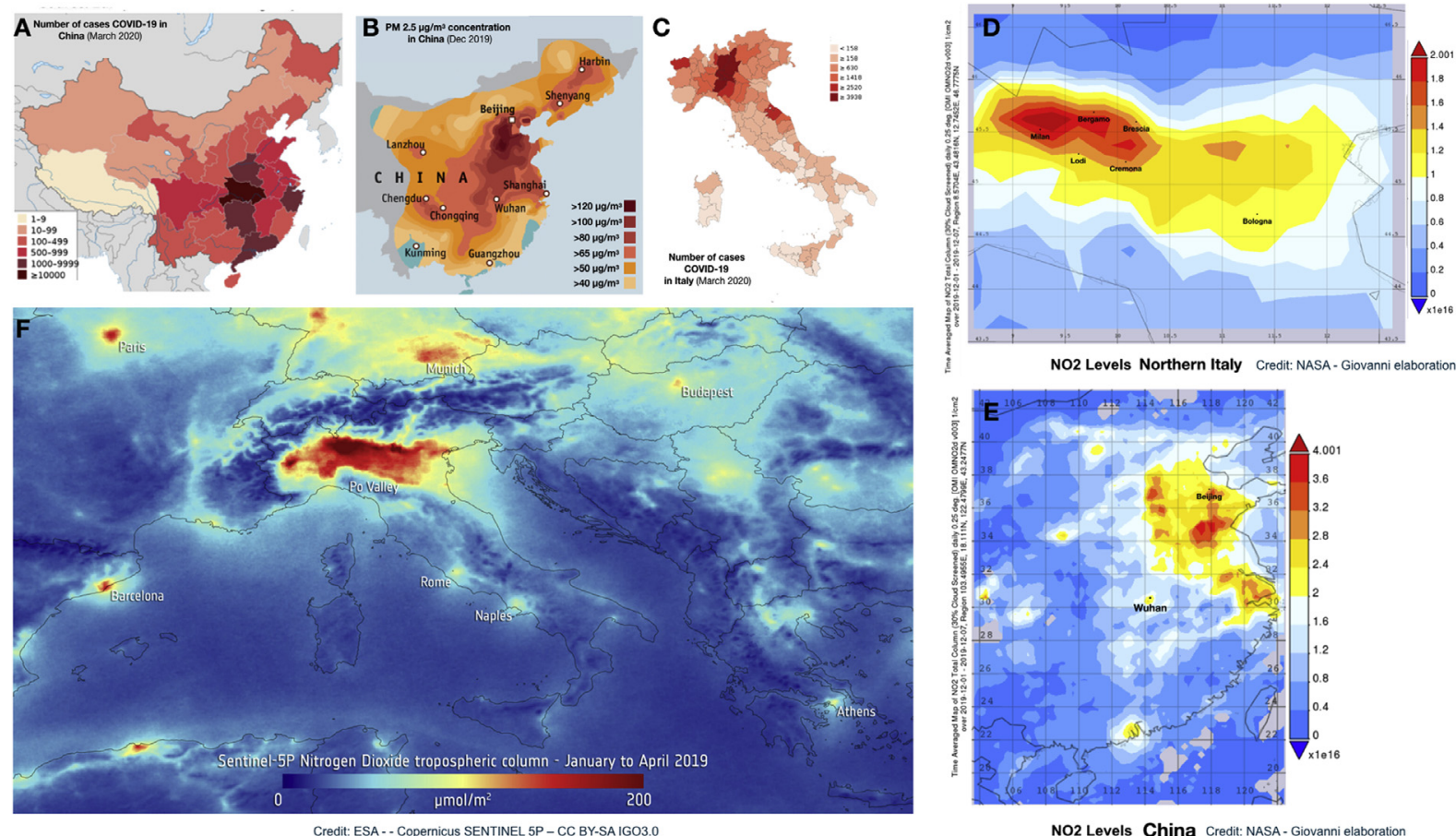

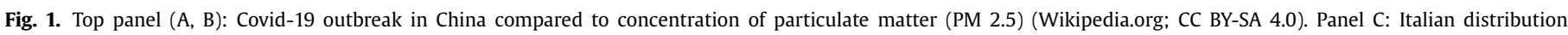

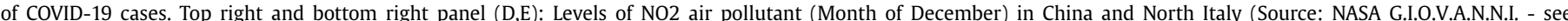

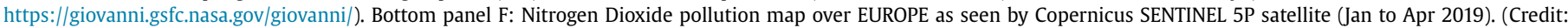
ESA - Copernicus SENTINEL 5P CC BY-SA IGO3.0, https://www.esa.int/ESA_Multimedia/Images/2019/05/Nitrogen_dioxide_over_northern_Italy). 
frequent episodes of climatic inversion, inhibiting the air recycling and thus the pollutants dissolution. In the last month of December and January, the concentrations of PM 2.5 over this region reached unprecedented values that are similar to those characterizing the Hubei Region, China, ${ }^{6}$ where the first peak of COVID-19 infection was registered Fig. 1.

This discloses a potential correlation between the distribution of severe COVID-19 outbreaks and the pollutants stagnation resulting from a combination of specific climatic conditions, local human emissions and regional topography. Such a potential relation has been not taken into account so far, although many scientific reports from China stated that viral particles may be suspended in the air for several minutes in contrast to the current knowledge about virus diffusion ${ }^{7}$. Even though these reports have been object of criticism for their methodology, here we reconsider such a possibility, at least for those region like Hubei Region or Po valley, where it might actually justify the on-going outbreaks and the associated high rate of contagion.

Our hypothesis is that the atmosphere, rich of air pollutants, together with certain climatic conditions may promote a longer permanence of the of viral particles in the air, thus favoring an "indirect" diffusion in addition to the direct one (individual to individual). We therefore encourage further investigations focusing on the role of these aspects in the development of the COVID19 outbreaks over highly industrialized areas. If confirmed, our hypothesis may imply a higher level of control on the risk of infection spread. Indeed, its potential evolution may be partly anticipated by weather forecasting and seasonal prediction systems, thus allowing for timely measures of mitigation over critical regions. Also, it may further strengthen the need to reduce the level of air pollutants as part of public health measures to curb the spread of COVID-19 and other infections.

\section{References}

1. Characteristics of COVID-19 infection in Beijing. Tian S, Hu N, Lou J, Chen K, Kang X, Xiang Z, Chen H, Wang D, Liu N, Liu D, Chen G, Zhang Y, Li D, Li J, Lian H, Niu S, Zhang L, Zhang J. J Infect. 2020 Feb 27. pii: S0163-4453(20)30101-8. doi:10.1016/j.jinf.2020.02.018.

2. Iuliano A.D., Roguski K.M., Chang H.H., Muscatello D.J., Palekar R., Tempia S., et al. Global seasonal influenza-associated mortality collaborator network. Lancet 2018;391(10127):1285-300.

3. Ciencewicki J.. Air pollution and respiratory viral infection. Inhal Toxicol 2007; 19:1135-46.

4. Liang Y., Fang L., Pan H., Zhang K., Kan H., Brook J.R., Sun Q.. PM2.5 in Beijing temporal pattern and its association with influenza. Environ Health 2014;13:102

5. Ali S.T., Wu P., Cauchemez S., He D., Fang V.J., Cowling B.J., Tian L.. Ambient ozone and influenza transmissibility in Hong Kong. Eur Respir J 2018;51(5).

6. Arpa Lombardia: air pollutants monitoring; www.arpalombardia.it.

7. Aerosol and Surface Stability of SARS-CoV-2 as Compared with SARS-CoV-. N Engl J Med. 2020 Mar 17. doi:10.1056/NEJMc2004973.

Antonio Frontera IRCCS San Raffaele Scientific Institute, Via Olgettina 60, Milan, Italy

Claire Martin Royal Papworth Hospital NHS Foundation Trust, Papworth Rd, Trumpington, Cambridge CB2 OAY, UK

Kostantinos Vlachos

Hôpital Haut Leveque, 1 avenue Magellan, Bordeaux, France LIRYC institute, Pessac 33600, France

Giovanni Sgubin Department of Climatology, Environnements et Paléoenvironnements Océaniques et Continentaux, University of Bordeaux, Bordeaux, France
Accepted 26 March 2020 Available online 10 April 2020

https://doi.org/10.1016/j.jinf.2020.03.045

(C) 2020 The British Infection Association. Published by Elsevier Ltd. All rights reserved.

\section{Effect of regular intravenous immunoglobulin therapy on prognosis of severe pneumonia in patients with COVID-19}

Dear Editor,

We read with interest the recent review by Han et al. ${ }^{1}$ that addressed the nature of the virus and its clinical characteristics to response to the COVID-19 outbreak. At present, there is no vaccine or specific drugs for the human coronavirus. The most effective measures to COVID-19 are still early detection and quarantine of new sources of infection, and early diagnosis and supportive treatments for comfirmed patients. As of March 18, 2020, China had a total of 81,151 confirmed cases of COVID-19, including those in health care workers. Italy, Japan, South Korea, the United States and other countries also reported new coronavirus cases, and the total global case load outside of China was 115,682 confirmed cases. The mortality rate of critically ill patients with the COVID-19 pneumonia is as high as $61.5 \%{ }^{2}$

Intravenous immunoglobulin(IVIG) has been clinically used as an adjunctive drug in the treatment of severe pneumonia caused by influenza, ${ }^{3}$ but there is controversy about its therapeutic effect on COVID-19 pneumonia, despite inclusion in the Trial Version 7 of National Health Commission \& State Administration of Traditional Chinese Medicine stating that it can be considered for use in severe and critically ill patients. For this reason, this study retrospectively observed the relationship between the prognosis of patients with severe and critical COVID-19 pneumonia and the adjuvant therapy of IVIG and explored whether IVIG could improve the clinical symptoms, laboratory examination and prognosis of these patients.

In this retrospective study, we reviewed 58 cases of severe or critical illness due to COVID-19 diagnosed in the intensive care unit of Wuhan Third Hospital from January to February 2020. The study was approved by the hospital's ethics committee and exempted from written informed consent.

Inclusion criteria: All patients were diagnosed with COVID-19 and confirmed by real-time RT-PCR.

Exclusion criteria: Patients with incomplete data. Severe criteria: Meet one of the following 1 . Shortness of breath. $R R \geq$ 30 times/min 2. At rest, oxygen saturation $\leq 93 \%$; 3 . Arterial blood oxygen partial pressure/oxygen absorption concentration $\leq 300 \mathrm{mmHg}$. High altitude $(>1000 \mathrm{~m})$ areas should be calibrated according to the following formula: $\mathrm{PaO}_{2} / \mathrm{FiO}_{2} \times$ [barometric pressure $(\mathrm{mmHg}) / 760]$ 4. Pulmonary imaging showed obvious lesion progression $\geq 50 \%$ within $24-48$ hours. Critical criteria: Meet one of the following: 1 . Respiratory failure, requiring mechanical ventilation; 2. Shock; 3. Complications of other organ failure require ICU care.

Primary outcome: 28-day mortality.

Secondary outcomes: 14-day mortality, hospital length of stay, length of stay in the ICU, and use of mechanical ventilation. 

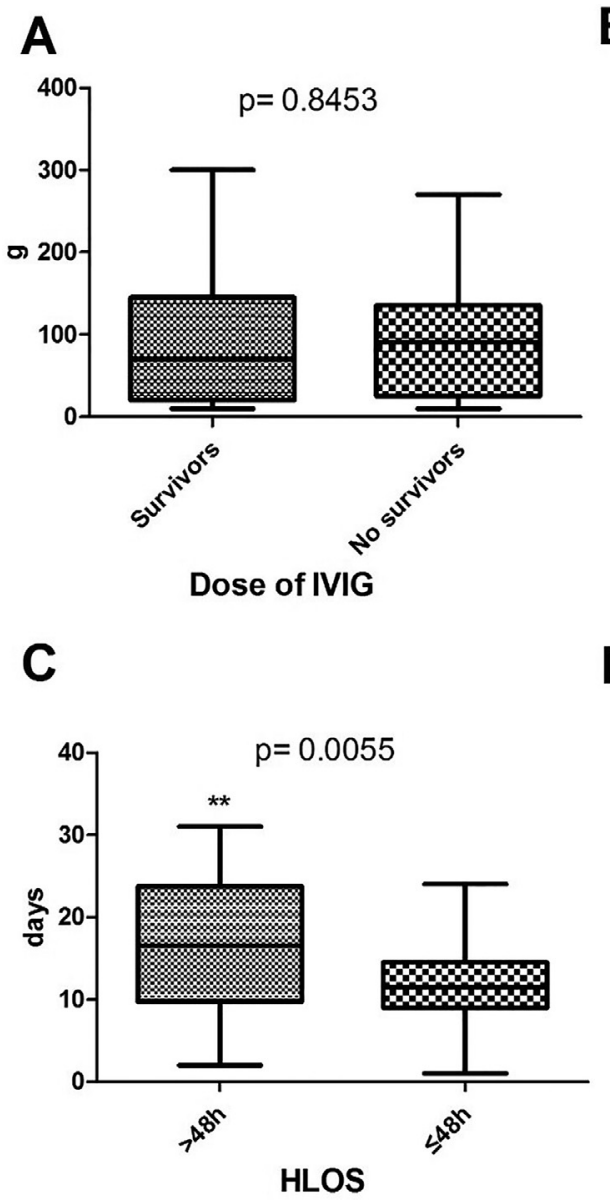

B

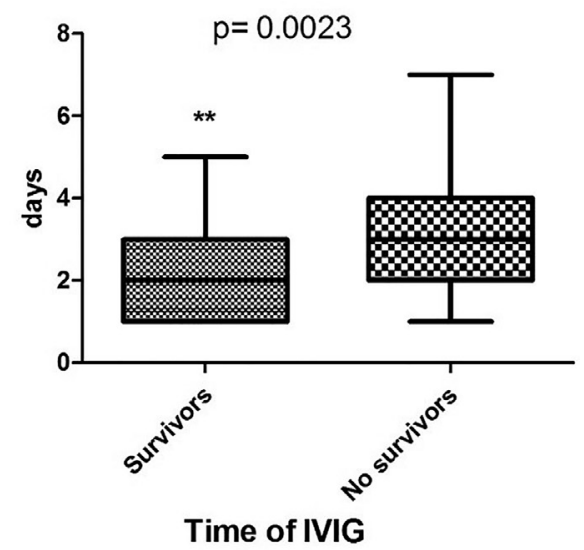

D

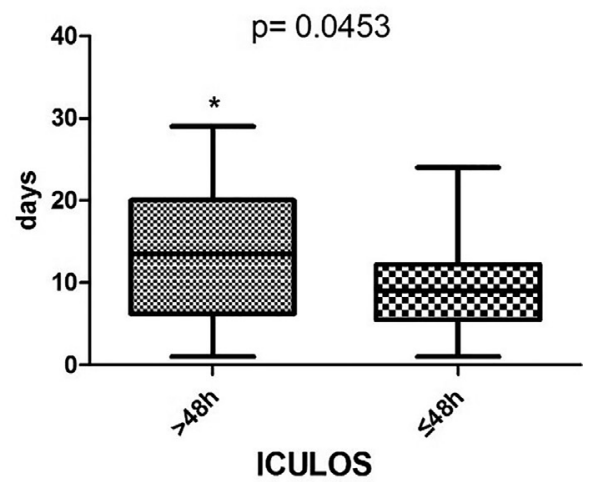

Fig. 1. A. Dose of IVIG B. Time of IVIG C. Hospital length of stay D. ICU length of stay.

Grouping: $>48$ h group and $\leq 48$ h group were divided according to the use of intravenous immunoglobulin within $48 \mathrm{~h}$ after admission.

Our treatment plan was as follows: all patients received oxygen therapy and Abidor antiviral treatment and were initially administered the antibiotic moxifloxacin, according to the patient's clinical symptoms and signs and laboratory results, which were used to determine whether to adjust the antibiotics. In addition, according to the patient's condition, they were subjected to low molecular heparin anticoagulation, and when the absolute lymphocyte count fell to $<0.5 \times 10^{9} / \mathrm{L}$, they received intravenous immunoglobulin at $20 \mathrm{~g} /$ day and correction for hypoalbuminemia. If the absolute number of lymphocytes was still low five days later, we used Thymosin to boost immune function. Patients in critical condition received intravenous administration of small doses of glucocorticoids (1-2 mg/kg) for 5-7 days depending on their condition. All other treatments were administered according to the WHO guidelines.

We obtained epidemiological, demographic, clinical, laboratory, management, and outcomes data from patient records. Final clinical results were followed up through February 29, 2020.

The study included 58 patients diagnosed with COVID-19 pneumonia. Among them, 36 (62.1\%) were males, with an average age of 62 years old. The youngest age was 29 years old, the oldest age was 86 years old, and the median age was 63 (54-72) years old.

The cumulative dose of intravenous immunoglobulin over 28 days was significantly increased in the $>48 \mathrm{~h}$ group $(\mathrm{n}=28)$
$(88.57 \pm 71.14$ vs $64.35 \pm 54.74 \mathrm{~g}, p=0.006)$ compared to that in the $\leq 48 \mathrm{~h}$ group $(\mathrm{n}=30)$. After admission, patients in the $>48 \mathrm{~h}$ group had an average delay of 1 day in using IVIG for the first time than patients in the $\leq 48 \mathrm{~h}$ group $(2.707 \pm 1.427$ vs $1.567 \pm 0.504$ days, $p=0.000$ ). The time of using IVIG in survivors group was earlier than no survivors group $(2.257 \pm 0.1981$ vs $3.391 \pm 0.3190$ days, $p=0.0023$ ) (Fig. 1B). Of all enrolled patients, 11 (18.96\%) required mechanical ventilation, 5 (8.62\%) noninvasive mechanical ventilation, 6 (10.3\%) invasive mechanical ventilation, and 2 (3.45\%) highflow oxygen aspiration.

A total of 23 of the 58 patients died within 28 days of admission, 7 in the $\leq 48 \mathrm{~h}$ group and 16 in the $>48 \mathrm{~h}$ group. There was a statistically significant difference in 28 day mortality between the two groups $(23.3 \%$ vs $57.1 \%, p=0.009)$. The length of stay in the hospital of the $\leq 48 \mathrm{~h}$ group was significantly shorter than in the $>48$ h group $(11.50 \pm 1.030$ vs $16.96 \pm 1.620$ days, $p=0.0055)$ (Fig. 1C), and the length of stay in the ICU of the $\leq 48 \mathrm{~h}$ group was also significantly shorter than that of the $>48 \mathrm{~h}$ group $(9.533 \pm 1.089$ vs $13.50 \pm 1.632$ days, $p=0.0453)$ (Fig. $1 \mathrm{D})$. The proportion of patients requiring mechanical ventilation in the $\leq 48 \mathrm{~h}$ group was also significantly lower than in the $>48$ h group $(6.67 \%$ vs $32.14 \%, p=0.016$ ). The 28 -day survival time of $\leq 48 \mathrm{~h}$ group was significantly longer than the $>48$ h group (Fig. 2).

Our study included 58 patients diagnosed with severe COVID19. Twenty-three (39.6\%) critically ill patients died within 28 days. All patients were treated with IVIG. This is the first clinical study to evaluate the efficacy of IVIG in the treatment of severely ill COVID-19 patients. 
A

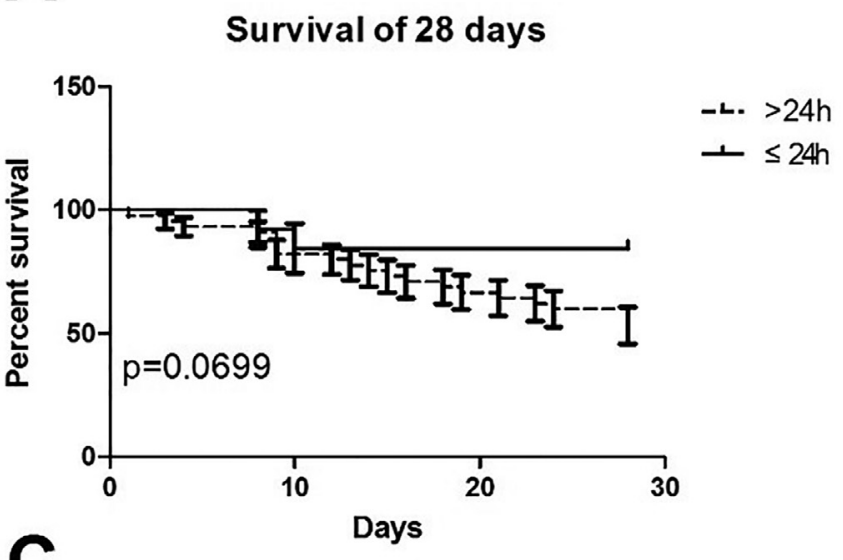

Survival of 28 days

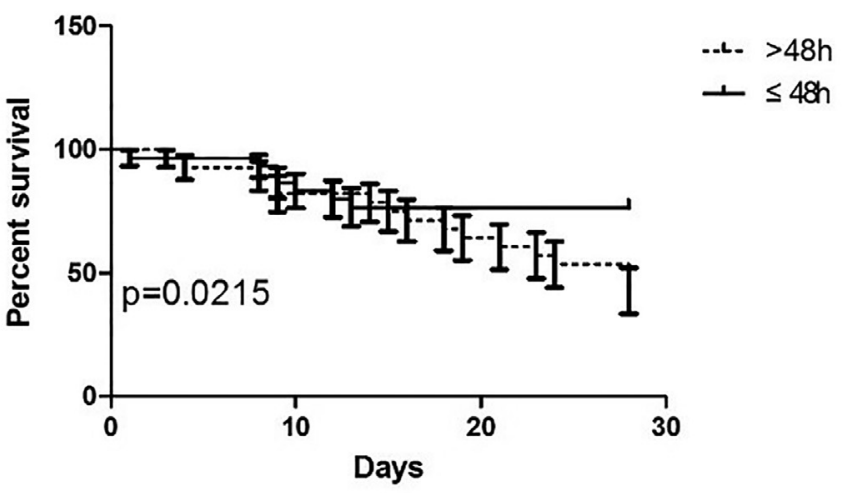

Survival of 14 days

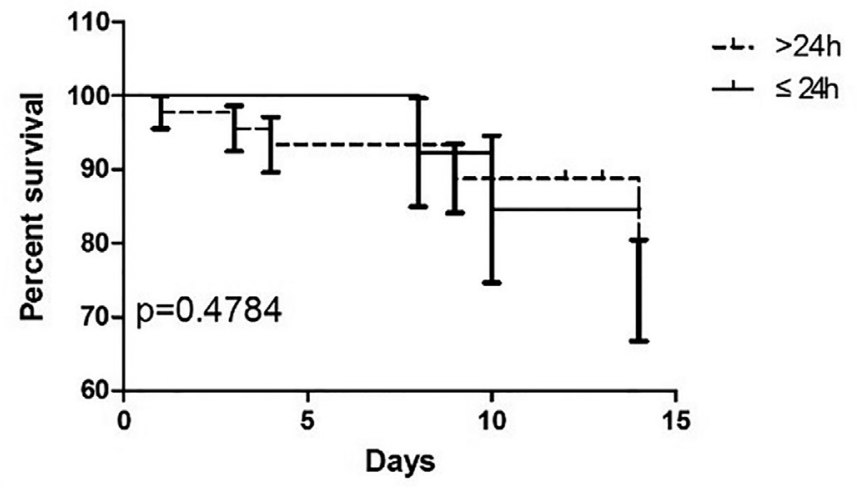

Survival of 14 days

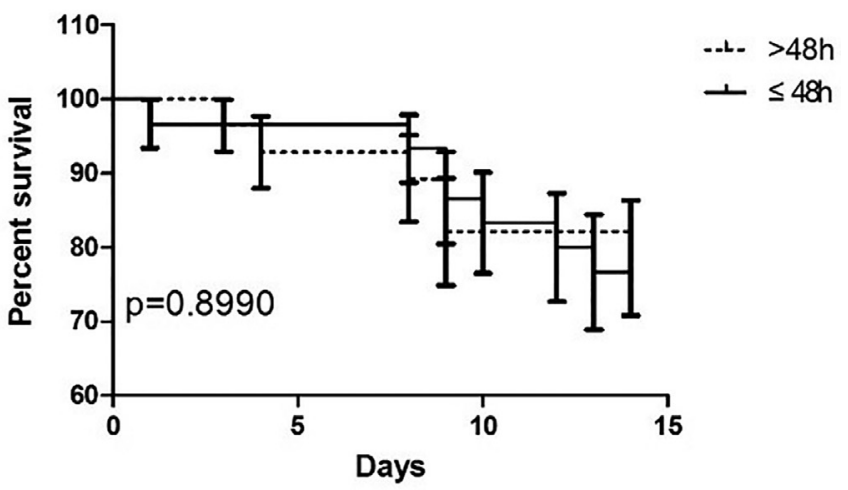

Fig. 2. Survival of 28 days and 14 days.

IVIG is applied in the adjuvant treatment of critical patients. As a blood product purified from the mixed plasma of healthy people, protein is the main component, and it is rich in bacterial antibodies and viral IgG, etc. Continuous infusion can improve the IgG level in the serum, effectively neutralizing the pathogens in the respiratory tract of patients, and thereby promoting the recovery from diseases and shortening the course of disease. ${ }^{4}$ IVIG can improve the body's defense, block the receptors associated with the target cell, and prevent the pathogen from further damaging the target cell. ${ }^{4}$ In addition, the use of IVIG can also influence the process of lymphocyte differentiation and maturation, hinder the normal immune response of white blood cells, inhibit the production of inflammatory factors, and thus decrease the inflammatory injury experienced by patients. ${ }^{3,5,6}$ A previous meta-analysis using IVIG in SARS infection concluded that whether intravenous infusion of IVIG could improve the prognosis is still unclear. ${ }^{7}$ There are also literature reports on the use of IVIG in MERS infection, ${ }^{8}$ but there is no evidence that IVIG has anti-MERS activity, as specific efficacy has not been reported. Studies on influenza virus infection, such as H1N1, have shown that IVIG can prevent severe pandemic influenza infection. ${ }^{9}$ A multicenter, double-blind, randomized, controlled trial using hyperimmune globulin in the treatment of patients with severe $2009 \mathrm{H} 1 \mathrm{~N} 1$ infection found that the use of h-IVIG in the treatment of severe H1N1 infection within 5 days of symptom onset was associated with reduced viral load and reduced mortality. ${ }^{3}$ It is therefore worth examining when to use IVIG to assist the treatment of COVID-19. In our first analysis, we found that the use of IVIG within $24 \mathrm{~h}$ after admission had no significant statistical difference in either the 28-day mortality or the 14-day mortality rates, but the use of IVIG within 48 h could significantly reduce the 28-day mortality rate, indicating that the initiation time of IVIG was related to the reduction of the COVID-19 mortality rate.

In our study, treatment with IVIG within $48 \mathrm{~h}$ of admission not only reduced ventilator use, but also reduced hospital and ICU length of stay, ultimately improving 28-day mortality. Our study demonstrated that IVIG treatment in COVID-19 patients with severe pneumonia can improve the patients' indicators within a short time and improve the treatment efficiency of the patients with high effectiveness.

To the best of our knowledge, this is the first study to evaluate the efficacy of IVIG therapy in critically ill patients infected with COVID-19. In four previously published studies of critically ill patients, the use of IVIG was not mentioned in detail, and it was impossible to summarize the effect of IVIG use on prognosis of these patients with COVID-19 pneumonia. ${ }^{2,10}$ Our research also has several limitations. Our study only included 58 patients with severe illness. The 28-day mortality rate of this population cannot represent all patients with severe COVID-19, and the mortality rate is also different at based on different times of illness onset within the same center. We included all critical patients in the intensive care unit of Wuhan Third hospital who met the inclusion criteria. Because of the exploratory nature of the study, the calculation of sample size is exempted. Meanwhile, the next step is to confirm this conclusion with a larger sample size. This is a retrospective study. The data in this study allowed for a preliminary evaluation of the efficacy of IVIG therapy in critically ill patients with 
COVID-19 pneumonia. However, additional prospective randomized controlled studies are needed for further verification.

In summary, initiation of IVIG as adjuvant treatment for COVID19 pneumonia within $48 \mathrm{~h}$ of admission to the ICU can reduce the use of mechanical ventilation, shorten the hospital length of stay, promote the early recovery of patients, and improve the effective treatment of patients to achieve significant clinical efficacy.

\section{Abbreviation}

IVIG, intravenous immunoglobulin

COVID-19, Coronavirus disesse-19

ICU, Intensive care unit

CT, Computed tomography

MERS, Middle East respiratory syndrome

SARS, Severe acute respiratory syndrome

RT-PCR, Reverse transcription-polymerase chain reaction

HLOS, hospital length of stay

ICULOS, Intensive care unit length of stay

\section{Declaration of Competing Interest}

We declare no competing interests.

\section{Acknowledgments}

We thank Li Yi for his help in the English improving in this article. We thank the hospital staff for their efforts in recruiting patients.

\section{Ethical approval and consent to participate}

Ethics approval from Wuhan Third Hospital Institutional Review Board: reference number (KY2020-007).Written informed consent was waived due to the rapid emergence of this infectious disease.

\section{Consent for publication}

All the authors have approved the manuscript and agree with publication.

\section{Availability of supporting data}

After publication, the data will be made available to others on reasonable requests to the corresponding author.

\section{References}

1. Han $\mathrm{Q}$ Lin $\mathrm{Q}$ Jin $\mathrm{S}$, et al. Coronavirus 2019-nCoV: A brief perspective from the front line. J Infect 2020 pii: S0163-4453(20)30087-6.[Epub ahead of print]. doi:10.1016/j.jinf.2020.02.010

2. Yang Xiaobo, Yu Yuan, Xu Jiqian, et al. Clinical course and outcomes of critically ill patients with SARS-CoV-2 pneumonia in Wuhan, China: a singlecentered,retrospective, observational study. Lancet Respir Med 2020 Published OnlineFebruary 21, 2020. doi:10.1016/S2213-2600(20)30079-5.

3. Ivan F.N, Hung, et al. Hyperimmune IV Immunoglobulin treatment: a multicenter double-blind randomized controlled trial for patients with severe 2009 influenza A(H1N1) infection. Chest 2013:144(2):464-73.

4. Takashi T, Hiroki M, Kiyohide F, et al. Intravenous immunoglobulin and mortality in pneumonia patients with septic shock: an observational nationwide study. Clin Infect Diseases 2015;61(3):385-92.

5. Diebel LN, Liberati DM, Diglio CA, et al. Immunoglobulin a modulates inflammatory responses in an in vitro model of pneumonia. J Trauma Injury Infect Crit Care 2005:1099-106.

6. Busse PJ, Razvi S, Cunningham-Rundles C. Efficacy of intravenous immunoglobulin in the prevention of pneumonia in patients with common variable immunodeficiency. J Allergy Clin Immunol 2002;109(6):1001-4.

7. Stockman LJ, Bellamy R, Garner P. SARS: Systematic Review of Treatment Effects. PLoS Med 2006;3(9):e343.

8. Mustafa S, Balkhy H, Gabere MN. Current treatment options and the role of peptides as potential therapeutic components for Middle East Respiratory Syndrome (MERS): A review. J Infect Publ Health 2017;11(1):9-17.
9. Steven, Rockman, Sue, et al. Intravenous Immunoglobulin Protects Against Severe Pandemic Influenza Infection. EBioMedicine 2017;19:119-27.

10. Wang D, Hu B, Hu C. Clinical characteristics of 138 hospitalized patients with 2019 novel coronavirus-infected pneumonia in Wuhan, China. JAMA 2020 published online Feb 7. doi:10.1001/jama.2020.1585.

Yun $\mathrm{Xie}^{1}$

Department of Critical Care Medicine, Shanghai General Hospital, Shanghai Jiaotong University School of Medicine, 650 New Songjiang Road, Songjiang, 201600, Shanghai, China

Song $\mathrm{Cao}^{1}$, Hui Dong ${ }^{1}$

Department of Critical Care Medicine, Wuhan Third Hospital,Wuhan University, 216 Guanshan avenue, Hongshan district, Wuhan, 430070, Hubei, China

Qingyun Li

Department of Respiratory, Shanghai Ruijin Hospital, Shanghai Jiao Tong University School of Medicine, 197 Ruijin two Road, Luwan district, 200020, Shanghai, China

Erzhen Chen Shanghai Ruijin Hospital, Shanghai Jiao Tong University School of Medicine, 197 Ruijin two Road, Luwan district, 200020, Shanghai,

China

Wenkai Zhang, Luyu Yang*, Shouzhi Fu* Department of Critical Care Medicine, Wuhan Third Hospital,Wuhan University, 216 Guanshan avenue, Hongshan district, Wuhan, 430070, Hubei, China

Ruilan Wang*

Department of Critical Care Medicine, Shanghai General Hospital, Shanghai Jiaotong University School of Medicine, 650 New Songjiang Road, Songjiang, 201600, Shanghai, China

*Corresponding authors. E-mail address: wangyusun@hotmail.com (R. Wang)

1 These author contributed equally. Accepted 26 March 2020 Available online 10 April 2020

https://doi.org/10.1016/j.jinf.2020.03.044

(C) 2020 The British Infection Association. Published by Elsevier Ltd. All rights reserved.

\section{Evaluation of control measures for COVID-19 in Wuhan, China}

Dear Editor,

Recent article in this Journal has reported trend of the coronavirus disease (COVID-19) in China. ${ }^{1}$ The outbreak of COVID-19 was first reported from Wuhan, China, had spread to more than 100 countries. ${ }^{2}$ Recent studies had forecasted COVID-19 incidence in China and worldwide based on mathematical models, ${ }^{3,4}$ but they did not take into account the control measures adopted by the Chinese government; the forecast results were appreciably higher than actual numbers. For instance, the article forecasted that the number of infections in Wuhan would reach 75,815 on January 25, 2020 , but the actual number was simply $618 .^{3}$ Therefore, it is indispensable to establish a new dynamic model of the epidemic to evaluate the effectiveness of control measures in Wuhan (Fig. 1). 


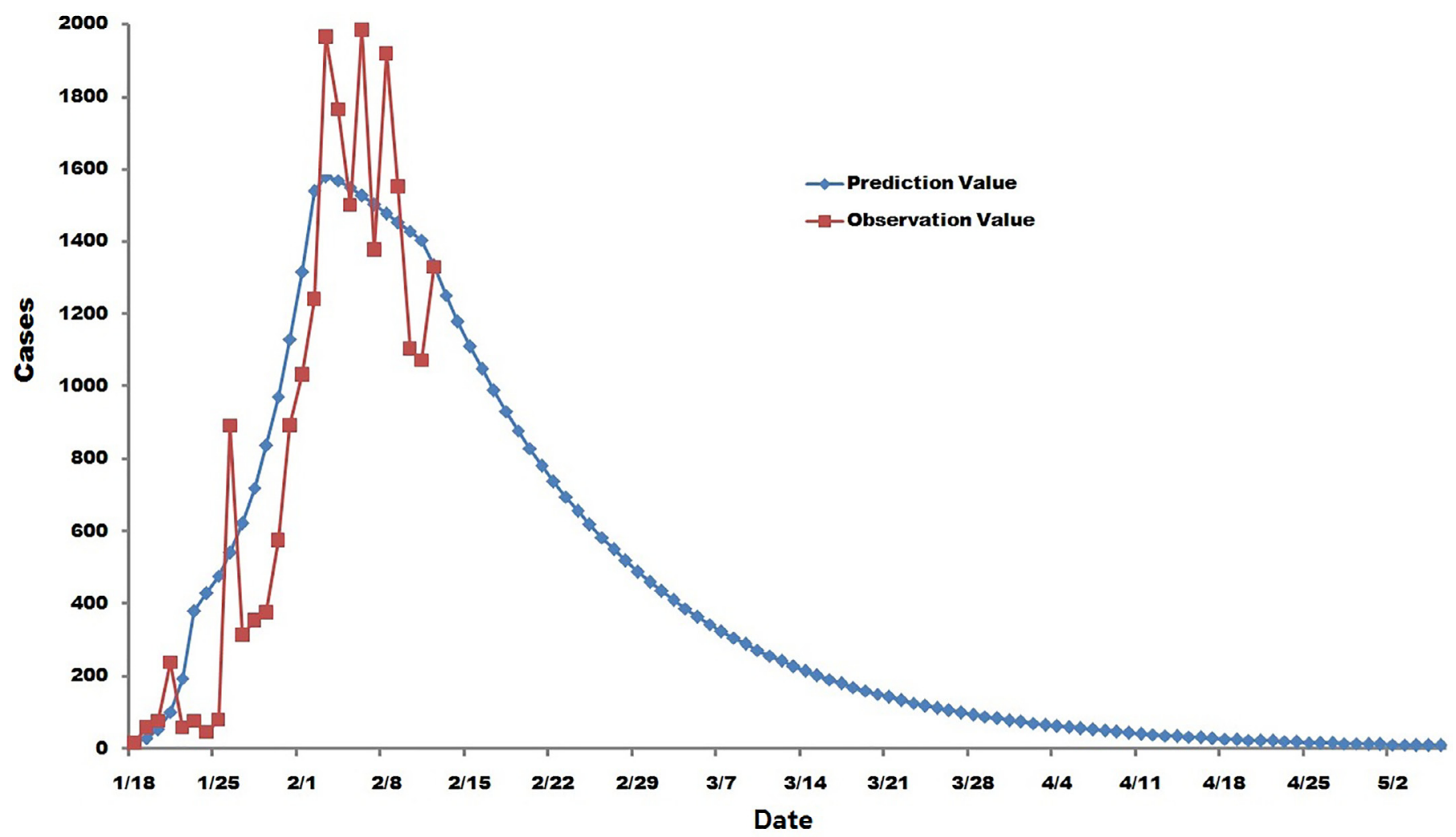

Fig. 1. Fit of prediction value and actual value.

In our study, we used data released by the National Health Commission. ${ }^{5}$ Since the data were not updated from January 1 to January 17 , we used data from January 18 to February 13 to establish our model. Epidemic prevention and control in Wuhan can be divided into three stages: the first stage was the natural occurrence and spread of the epidemic from January 18 to January 23; the second stage was the blockade of Wuhan and the advocacy of residents going out less from January 23 to February 5; and the third stage was cabin hospitals put into use from February 6 to February 13 to ensure that all cases are admitted to hospitals and close contacts are under intensive medical observation. We used the susceptible-exposed-infected-removed (SEIR) dynamic model ${ }^{6}$ to simulate the spread of the epidemic and Simulated Annealing (SA) algorithm to identify optimal parameters. ${ }^{7}$ The formula of SEIR model is as follows:

$\frac{\mathrm{d}(\mathrm{S}(\mathrm{t}))}{\mathrm{d}(\mathrm{t})}=-\mathrm{C} \times \alpha 1 \times \mathrm{I}(\mathrm{t}) \times \frac{\mathrm{S}(\mathrm{t})}{\mathrm{N}}-\mathrm{C} \times \alpha 2 \times \mathrm{E}(\mathrm{t}) \times \frac{\mathrm{S}(\mathrm{t})}{\mathrm{N}}$

$\frac{\mathrm{d}(\mathrm{E}(\mathrm{t}))}{\mathrm{d}(\mathrm{t})}=\mathrm{C} \times \alpha 1 \times \mathrm{I}(\mathrm{t}) \times \frac{\mathrm{S}(\mathrm{t})}{\mathrm{N}}+\mathrm{C} \times \alpha 2 \times \mathrm{E}(\mathrm{t}) \times \frac{\mathrm{S}(\mathrm{t})}{\mathrm{N}}-\beta \times \mathrm{E}(\mathrm{t})$

$\frac{\mathrm{d}(\mathrm{I}(\mathrm{t}))}{\mathrm{d}(\mathrm{t})}=\beta \times \mathrm{E}(\mathrm{t})-\gamma \times \mathrm{I}(\mathrm{t})$

$\frac{\mathrm{d}(\mathrm{I}(\mathrm{t}))}{\mathrm{d}(\mathrm{t})}=\gamma \times \mathrm{I}(\mathrm{t})$

$C=1, t<=6$;

$C=C 1,6<t<=16$;

$C=C 2, t>16$

The susceptible, exposed, infected, and $r$ removed populations at time $\mathrm{t}$ were set as $\mathrm{S}(\mathrm{t}), \mathrm{E}(\mathrm{t}), \mathrm{I}(\mathrm{t})$, and $\mathrm{R}(\mathrm{t})$, respectively, and the total population in Wuhan was set as $\mathrm{N}$. The number of the susceptible infected by each infected person per unit time (d) was set as $\alpha 1$, and by each exposed person, $\alpha 2$. Moreover, according to the literature, the incubation period was $1 / \beta=4 \mathrm{~d},{ }^{8}$ and the infection period was $1 / \gamma=3.5 \mathrm{~d} .{ }^{9}$ After adopting control measures, the number of susceptible infected by each infected person per unit time (d) was set as $C^{*} \alpha 1$, and by each exposed person, $C^{*} \alpha 2$. The optimal parameters of the model found out through SA algorithm.

The goodness of fit between the forecast value and the actual incidence was $81.98 \%$, suggesting that our model can reflect the actual incidence and spread of the epidemic. Based on this model, we calculated the basic reproduction number in Wuhan, $R_{0}=3.31$, the effective reproduction number of the second stage, $R_{T}=1.12$, and the effective reproduction number of the second stage, $R_{T}=0.71$ $\left(R_{T}<1\right.$, the inflection point of the epidemic appeared and the incidence began to decline).

In this article, the effectiveness of control measures at different stages of COVID-19 in Wuhan was evaluated for the first time. The results showed that the effective reproduction number after blockade of the city was $R_{T}=1.12$, showing that blockade reduced transmission of infection by $66.16 \%$. Although the adopted prevention and control measureswere effective, the effective reproduction number remained greater than 1 , indicating that the epidemic continues to spread. This could be attributable to medical limitations: not all patients could be admitted to hospitals, and close contacts were mainly isolated at home, resulting in family outbreaks. Since February 6, cabin hospitalshave been put into use to ensure that all cases are admitted to hospitals and close contacts are under intensive medical observation. Consequently, the effective reproduction number has decreased to less than $1\left(R_{T}=0 \cdot 71\right)$, indicating the inflection point of the epidemic; thus, the incidence of the disease will gradually decrease until its disappearance. 


\section{Declaration of Competing Interest}

The authors declare that they have no competing interests.

\section{Funding}

This work was financially supported by grants from the China Mega-Project on Infectious Disease Prevention (No. 2017ZX10303401).

\section{References}

1. Li Qiang, Feng Wei, Quan Ying-Hui. Trend and forecasting of the COVID-19 outbreak in China. J Infect 2020;80(4):472-4.

2. World Health Organization. Coronavirus disease (COVID-2019) situation reports - 50. 2020. Available at: https://www.who.int/docs/default-source/coronaviruse/ situation-reports/20200310-sitrep-50-covid-19.pdf?sfvrsn=55e904fb_2.

3. Wu J.T., Leung K., Leung G.M.. Nowcasting and forecasting the potential domestic and international spread of the 2019-nCoV outbreak originating in Wuhan, China: a modelling study. Lancet 2020 [Epub ahead of print].

4. Zhao S., Musa S.S., Lin Q., Ran J., Yang G., Wang W., et al. Estimating the unreported number of novel coronavirus (2019-nCoV) Cases in China in the First Half of January 2020: A data-driven Modelling analysis of the early outbreak. $J$ Clin Med 2020;9:388

5. National Health Commission of the People's Republic of China. http://www.nhc gov.cn/. Accessed at 17 February, 2020.

6. Saito M.M., Imoto S., Yamaguchi R., Sato H., Nakada H., Kami M., et al. Extension and verification of the SEIR model on the 2009 influenza A (H1N1) pandemic in Japan. Math Biosci 2013;246:47-54.

7. Kirkpatrick S., Gelatt C.D. Jr, Vecchi M.P.. Optimization by simulated annealing Science 1983;220:671-80.

8. Xu X.W., Wu X.X., Jiang X.G., Xu K.J., Ying L.J., Ma C.L., et al. Clinical findings in a group of patients infected with the 2019 novel coronavirus (SARS-Cov-2) outside of Wuhan, China:retrospective case series, BMJ 2020:368:m606.

9. Li Q., Guan X., Wu P., Wang X., Zhou L., Tong Y., et al. Early Transmission Dynamics in Wuhan, China, of Novel Coronavirus-Infected Pneumonia. N Engl J Med 2020 [Epub ahead of print].

Ligui Wang, Hui Chen, Shaofu Qiu, Hongbin Song*

Center for Disease Control and Prevention of Chinese People's Liberation Army, 20 Dong-Da-Jie Street, Fengtai District, Beijing,

100071, China

*Corresponding author. E-mail address: hongbinsong@263.net (H. Song)

Accepted 24 March 2020 Available online 10 April 2020

https://doi.org/10.1016/j.jinf.2020.03.043

(c) 2020 The British Infection Association. Published by Elsevier Ltd. All rights reserved.

\section{Personal respirators for population level control of the COVID19 pandemic}

Dear Editor,

Since the readers of this Journal were first alerted to the emerging problem of COVID-19 ${ }^{1}$, the severe acute respiratory syndrome coronavirus 2 (SARS-CoV-2) virus is causing a global pandemic ${ }^{2-4}$, resulting in more than two million confirmed cases and almost 140 000 deaths to mid-April ${ }^{5}$. SARS-CoV-2 is transmitted by aerosol droplets or facial touching ${ }^{6}$, and fatalities are usually due to respiratory complications. The primary control measure is social distancing, but maintaining such controls will be challenging.

Traditional control measures from an infectious disease include personal hygiene, vaccination, vector control, environmental controls, prophylaxis and quarantine. For example, vaccinia virus erad-

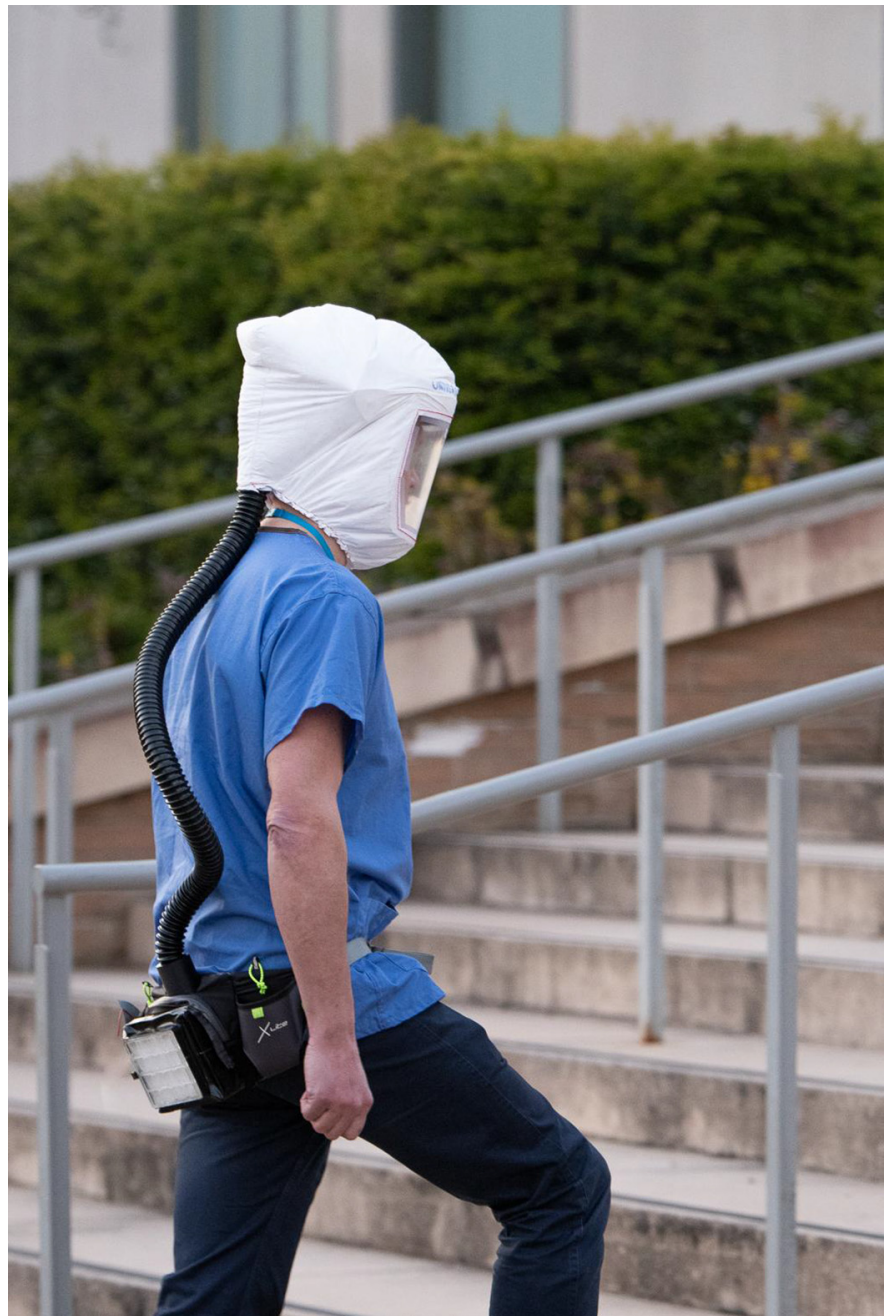

Fig. 1. PeRSo prototype. Photo credit Ric Gillams.

icated smallpox, bed nets control malaria and condoms reduce HIV transmission. As SARS-CoV-2 transmits to the face or mouth, an alternative solution would be to protect these areas, which can be achieved by a personal respirator. Widespread use of personal respirators has not been possible to date due to their complexity and limited supply. We have developed a simple personal respirator in Southampton (PeRSo), made from cheap, mass-produced components ${ }^{7,8}$. The motor unit fan pulls air through a high efficiency filter, powered by rechargeable batteries. The clear air is delivered into a hood with a clear plastic visor and passes standard sniff and bacterial tests (Fig. 1). We have initiated manufacture locally and are aiming to roll out widely in the United Kingdom, and are investigating components suitable for local production in the developing world (PeRSo-DW).

However, in addition to protecting healthcare staff as per the original design intention, PeRSos could potentially be used for wider control of SARS-CoV-2. Whilst this may seem fanciful, if one had proposed in December 2019 that one third of the world would be under lockdown three months later, this would have seemed ridiculous. Wearing PeRSos outside the house would allow society to return to productivity, with industries and business re-enabled, and individuals able to meet face-to-face.

Evidently, implementation challenges exist, but the alternative of waiting for a vaccine indefinitely seem worse in terms of economic impact. As a control strategy, PeRSo use outside the house would be compulsory in areas with active transmission. Once the cycle of transmission is broken, respirator use would be optional. 
Strengthened public health screening would be required to identify breakdown areas, leading to travel restrictions and return to compulsory PeRSo use. Humans would all look highly unusual, but SARS-CoV-2 would be controlled and this would act as a bridge to a new vaccine or drug therapy. Whilst the costs may seem high, compared to the economic costs of a prolonged lock-down, this is trivial.

We propose the PeRSos should be mass produced and deployed to healthcare workers in areas of SARS-CoV-2 transmission urgently. Later, wider use could be considered, such as in roles involving frequent interpersonal contact. Ultimately, this will permit a return to normal vaccine becomes available, just as a bed net protects in malarial regions. Public health interventions of increased surveillance and compliance with regular hand hygiene, in particular before and after removing the PeRSo, will also be needed. The return to a semblance of global "normality", and the upswing economic productivity, will reduce the impact of the pandemic on the poorest in the world.

\section{Acknowledgments}

PE was supported by MRC Global Challenges Research Fund: Bioengineering to combat the tuberculosis epidemic MR/P023754/1.

\section{References}

1. Tang JW, Tambyah PA, Hui DSC. Emergence of a novel coronavirus causing respiratory illness from Wuhan, China. The Journal of infection 2020;80(3):350-71.

2. Zhu N, Zhang D, Wang W, Li X, Yang B, Song J, et al. A Novel Coronavirus from Patients with Pneumonia in China, 2019. N Engl J Med. 2020;382(8):727-33.

3. Kucharski AJ, Russell TW, Diamond C, Liu Y, Edmunds J, Funk S, et al. Early dynamics of transmission and control of COVID-19: a mathematical modelling study. Lancet Infect Dis 2020

4. World Health Organization. Coronavirus disease 2019 (COVID-19) Situation Report - 692020 [updated March 29 Available from: https://www.who.int/docs/ default-source/coronaviruse/situation-reports/20200329-sitrep-69-covid-19. pdf?sfvrsn=8d6620fa_4.

5. World Health Organization. Coronavirus disease (COVID-19) Pandemic 2020 [updated April 17. Available from: https://www.who.int/emergencies/diseases/ novel-coronavirus-2019.

6. Huang C, Wang Y, Li X, Ren L, Zhao J, Hu Y, et al. Clinical features of patients infected with 2019 novel coronavirus in Wuhan, China. Lancet 2020;395(10223):497-506.

7. PeRSo 2020 [Available from: https://www.southampton.ac.uk/perso].

8. Elkington P, Dickinson A, Mavrogordato M, Spencer D, Gillams R, De Grazia A, et al. A Personal Respirator Specification for Health-care Workers Treating COVID-19 (PeRSo). engrxiv Preprints. 2020.

Paul Elkington* School of Clinical and Experimental Sciences, Faculty of Medicine, University of Southampton, UK Institute for Life Sciences, University of Southampton, UK NIHR Biomedical Research Centre, University Hospital NHS Foundation Trust, Southampton, UK

Hywel Morgan

Institute for Life Sciences, University of Southampton, UK Electronics and Computer Sciences, University of Southampton

*Corresponding author. Professor Paul T Elkington, Clinical and Experimental Sciences, University of Southampton, Southampton SO16 1YD, UK.

E-mail address: p.elkington@soton.ac.uk (P. Elkington)

Available online 23 April 2020

\section{https://doi.org/10.1016/j.jinf.2020.04.025}

(C) 2020 The British Infection Association. Published by Elsevier Ltd. All rights reserved.
The economics of infection prevention: why it is crucial to invest in hand hygiene and nurses during the novel coronavirus pandemic

\section{Dear Editor,}

It is a well-known fact that healthcare associated infections (HAIs) are a global problem that affect between around 7 and 10\% of patients, depending on the country. ${ }^{1}$ The novel coronavirus pandemic (COVID-19) is exacerbating this already dire situation and is currently causing a significant increase in the rate of HAIs around the world. ${ }^{2,} 3$ The severe acute respiratory syndrome coronavirus2 (SARS-CoV-2) virus is mainly transmitted through droplets, close contact with infected individuals and contaminated surfaces. ${ }^{4}$ This makes healthcare workers (HCWs) a highly susceptible population both for contracting as well as for spreading the virus. The infection prevention and control (IPC) measures to limit or prevent HAIs caused by the SARS-CoV-2 are crucial to combatting this pandemic. Hand hygiene is widely recognized as the most effective and economically viable measure in IPC. ${ }^{5}$

Even before COVID-19, HAIs were a pandemic in and of themselves. Annually, they are responsible for the death of millions of people per year- more than tuberculosis, malaria, and AIDS combined. In Europe, over 4 million patients are affected by approximately 4.5 million episodes of HAIs every year, leading to 16 million extra days of hospital stay, 37,000 attributable deaths and the contributing factor to an additional 110,000 deaths, resulting in $€$ 7 billion of additional healthcare costs. ${ }^{1}$ In the USA, it is estimated that around 1.7 million patients are affected by HAIs each year, and that they account for 99,000 deaths, costing hospitals between US\$35.7 to US\$45 billion. ${ }^{1}$ Although the direct costs due to these types of infections are already very significant, the indirect costs to health systems and economies are both extremely high and almost impossible to measure.

As seen in the last two major outbreaks of the coronavirus family (severe acute respiratory syndrome (SARS) and Middle East respiratory syndrome (MERS)), coronavirus epidemics can have a severe effect on both countries' individual economies and the global economy as a whole. The COVID-19 pandemic is currently estimated to have cost $1-2 \%$ of global gross domestic product (GDP). ${ }^{2}$ This number is of course still evolving and will vary greatly across regions and countries. Recently, it has been estimated that COVID19 could cost the global economy up to US\$1.1 trillion in lost income. ${ }^{6}$ Infectious disease outbreaks challenge healthcare systems in many different aspects, impacting everything from resource allocation and staffing, education, politics and governance, to the systems' culture and economics. The current pandemic has highlighted the need for every country to be better prepared to deal with the effects that an infectious disease outbreak could have on healthcare systems and society as a whole.

Preventing nosocomial spread of COVID-19 is a top priority for healthcare systems around the world. Though all HCWs are exposed at various levels, nurses are evidently at the front lines with the most patient contact. They are the ones responsible for daily patient care, while simultaneously being responsible for protecting patients against HAIs. If their IPC practices, especially their hand hygiene, are suboptimal, nurses become a source of transmission of infections between patients and to themselves. Contaminated hands are one of the main vectors of spreading SARS-CoV$2 .^{7}$ It is crucial that nurses adhere to proper hand hygiene in order to reduce HAIs, save money and ultimately, save lives. To achieve acceptable levels of hand hygiene compliance, nursing teams need to be adequately staffed, well trained, and have access to good quality alcohol-based handrub. ${ }^{8}$ Adequate hand hygiene would ensure prevention of nosocomial spread not only from patient to patient through contaminated HCW hands, but also from patients to HCWs. 
Globally, an increasing number of HCWs are also contracting nosocomial COVID-19 as a consequence of providing patient care. As of early March 2020, more than 3300 HCWs in China ${ }^{9}$ and $10 \%$ of all physicians and nurses in Lombardy, Italy were infected with the virus. ${ }^{3}$ This emergency is worldwide of course, but the breadth and scope of COVID-19 infection in HCWs will only become apparent as the pandemic progresses.

Following its designation of 2020 as the Year of the Nurse and the Midwife, the World Health Organization (WHO) identified that there is a shortage of 9 million nurses and midwives around the world. ${ }^{10}$ The emergence of the COVID-19 pandemic has only further highlighted the global need for HCWs. Adequate staffing is not the only challenge to the HCW population; IPC measures are crucial for keeping HCWs healthy and operational in hospitals. In addition to being a population that is not easily replaceable once taken out of the workforce, an increased strain on the staffing levels of HCWs also has a negative effect on patient outcomes.

Hand hygiene with alcohol-based handrub is globally recommended as one of the most effective and low-cost procedures against SARS-CoV-2 cross-transmission. ${ }^{5}$ It is well known that improving hand hygiene compliance among HCWs reduces HAIs in hospital settings. ${ }^{11,12}$ The economic implications of successful hand hygiene improvement have long been established. It has been demonstrated that these programs cost less than $1 \%$ of the HAI-related costs, making them relatively cheap and unequivocally worth investing in. ${ }^{13}$ In another study, the net benefit of a hospital-wide hand hygiene program was reported as $\$ 5,289,364$ USD, again proving the program's cost-effectiveness compared to the costs generated by HAIs. ${ }^{14}$ According to the aforementioned study, every US $\$ 1$ spent on the program could result in a $\$ 23.70$ USD return on investment- the highest return of any IPC measure. ${ }^{14}$

Good hand hygiene programs are also dependent on systemic components of the healthcare facility, including access to supplies, how nurses are allocated, organized and trained, and the work culture. Constant exposure to patients with COVID-19, a lack of supplies such as adequate personal protective equipment in many hospitals, fatigue and stressful work environments put nurses at a higher risk of acquiring or transmitting the virus. ${ }^{15,} 16$ Infected HCWs reduce the workforce of well-trained HCWs that are able to provide sufficient care for their patients, which in turn reduces the hospitals' ability to deal with an outbreak. ${ }^{17}$ Since emergency situations are associated with increased HCW anxiety, some individuals may be less willing to work in such contexts, which can in turn create or exacerbate any already existing staffing shortages. ${ }^{18}$

If societies want to make economically sound, lasting investments they must invest not only in the materials needed, but also in the people doing the actual work. According to the existing evidence, investing in health sectors such as education and job creation will improve health outcomes, global health security, and inclusive economic growth. ${ }^{10}$ Ensuring adequate HCW staffing, training and support lead to a decreasing rate of HAIs, and is considered a core component of effective IPC programs by the WHO. ${ }^{1}$

Clean and safe care starts with investing in our nurses, and the message to policy makers should be clear: "increase nurse staffing levels to prevent infections and improve quality of care. Create the means to empower nurses and midwives." Doing any less wouldn't make human or economic sense.

\section{Declaration of Competing Interest}

None declared.

\section{Acknowledgements}

This work is supported by the Infection Control Programme (SPCI), University of Geneva Hospitals and Faculty of Medicine,
Geneva, Switzerland; hand hygiene research activities at the SPCI are also supported by the Swiss National Science Foundation (grant no. 32003B_163262).

Didier Pittet works with WHO in the context of the WHO initiative 'Private Organizations for Patient Safety - Hand Hygiene'. The aim of this WHO initiative is to harness industry strengths to align and improve implementation of WHO recommendations for hand hygiene in health care indifferent parts of the world, including in least developed countries. In this instance, companies/industry with a focus on hand hygiene and infection control related advancement have the specific aim of improving access to affordable hand hygiene products as well as through education and research. All listed authors declare no financial support, grants, financial interests or consultancy that could lead to conflicts of interest.

The authors alone are responsible for the views expressed in this article and they do not necessarily represent the views, decisions or policies of the institutions with which they are affiliated. WHO takes no responsibility for the information provided or the views expressed in this paper.

\section{References}

1. World Health Organization. Guidelines on core components of infection prevention and control programmes at the national and acute health care facility level2016. Available from: https://apps.who.int/ iris/bitstream/handle/10665/251730/9789241549929-eng.pdf;jsessionid= 6496491DA1E50BAD15A6B959F4C1584E? sequence $=1$.

2. Arshad Ali S., Baloch M. Ahmed N. Arshad Ali A Iqbal A. The outbreak of Coronavirus Disease 2019 (COVID-19)-An emerging global health threat. Journal of infection and public health 2020;13(4):644-6.

3. Thomas-Rüddel D., Winning J., Dickmann P., Ouart D., Kortgen A., Janssens U. et al. Coronavirus disease 2019 (COVID-19): update for anesthesiologists and intensivists March 2020. Anaesthesist. 2020:1-10.

4. World Health Organization. Rational use of personal protective equipment for coronavirus disease 2019 (COVID-19)2020. Available from: https://apps.who.int/ iris/bitstream/handle/10665/331215/WHO-2019-nCov-IPCPPE_use-2020.1-eng. pdf.

5. World Health Organization Infection prevention and control during health care when novel coronavirus ( $\mathrm{nCoV}$ ) infection is suspected. Interim guidance. 2020. 25 January 2020Available from: https://apps.who.int/iris/rest/bitstreams/ 1266296/retrieve.

6. Maffioli EM.. How Is the World Responding to the 2019 Coronavirus Disease Compared with the 2014 West African Ebola Epidemic? The Importance of China as a Player in the Global Economy. The American Journal of Tropical Medicine and Hygiene 2020

7. Kampf G., Todt D., Pfaender S., Steinmann E.. Persistence of coronaviruses on inanimate surfaces and their inactivation with biocidal agents. J Hosp Infect 2020;104(3):246-51.

8. World. Health. Organization. Guidelines on hand hygiene in health care. First global patient safety challenge clean care is cafer care 2009. Available from: https://apps.who.int/iris/bitstream/handle/10665/44102/9789241597906_ eng.pdf? sequence $=1$

9. The L.. COVID-19: protecting health-care workers. The Lancet 2020;395(10228):922.

10. World Health Organization Nursing and midwifery. Fact sheets 2020. Available from: https://www.who.int/news-room/fact-sheets/detail/ nursing-and-midwifery

11. Pittet D.. Compliance with hand disinfection and its impact on hospital-acquired infections. J Hosp Infect 2001;48(Suppl A):S40-6.

12. Pittet D., Hugonnet S., Harbarth S., Mourouga P., Sauvan V., Touveneau S., et al. Effectiveness of a hospital-wide programme to improve compliance with hand hygiene. Infection Control Programme. Lancet. 2000;356(9238):1307-12.

13. Pittet D., Sax H., Hugonnet S., Harbarth S.. Cost implications of successful hand hygiene promotion. Infect Control Hosp Epidemiol 2004;25(3):264-6.

14. Chen YC., Sheng WH., Wang JT., Chang SC., Lin HC., Tien KL., et al. Effectiveness and limitations of hand hygiene promotion on decreasing healthcare-associated infections. PLoS One 2011:6(11):e27163.

15. World Health Organization. Coronavirus disease (COVID-19) outbreak: rights, roles and responsibilities of health workers, including key considerations for occupational safety and health2020. Available from: https://www.who.int/docs/ default-source/coronaviruse/who-rights-roles-respon-hw-covid-19.pdf?sfvrsn= bcabd401_0.

16. Heymann DL., Shindo N.. COVID-19: what is next for public health? The Lancet 2020:395(10224):542-5

17. Abdullah AS., Tomlinson B., Cockram CS., Thomas GN.. Lessons from the severe acute respiratory syndrome outbreak in Hong Kong. Emerg Infect Dis 2003:9(9):1042-5

18. Schwartz J., King C.-C., Yen M.-Y.. Protecting Healthcare Workers During the Coronavirus Disease 2019 (COVID-19) Outbreak: Lessons From Taiwan's Severe Acute Respiratory Syndrome Response. Clinical Infectious Diseases 2020. 
Alexandra Peters

Infection Control Programme, University of Geneva Hospitals and Faculty of Medicine, Geneva, Switzerland

Nasim Lotfinejad

Department of Research, Faculty of Medicine, Mashhad University of Medical Sciences, Mashhad, Iran

Alice Simniceanu Infection Prevention and Control Hub and Antimicrobial Resistance Division, World Health Organization, Geneva, Switzerland

Didier Pittet*

Infection Control Programme, University of Geneva Hospitals and Faculty of Medicine, Geneva, Switzerland

*Corresponding author: Professor Didier Pittet, Infection Control Programme, University of Geneva Hospitals and Faculty of Medicine, 4 Rue Gabrielle-Perret-Gentil, 1211 Geneva 14, Switzerland. Tel.: +41 22372 9828/+41 22372 9833(direct). E-mail address: didier.pittet@hcuge.ch (D. Pittet)

Accepted 18 April 2020

Available online 23 April 2020

https://doi.org/10.1016/j.jinf.2020.04.029

(C) 2020 The British Infection Association. Published by Elsevier Ltd. All rights reserved.

\section{The SARS-CoV-2 seroprevalence is the key factor for deconfinement in France}

\section{Dear Editor,}

Severe acute respiratory syndrome coronavirus 2 (SARS-CoV-2) emerged in Wuhan, China in December 2019 and spread largely by sustained human-to-human transmission. ${ }^{1}$. The WHO declared the resulting disease a pandemic. ${ }^{2}$. The virus, which causes severe respiratory illness in susceptible individuals, has spread so rapidly that it threatens to saturate health services, particularly their intensive care capacity. While this presently concerns mainly Italy, ${ }^{3}$ Spain, ${ }^{4}$ and France, other countries, such as the United States, may well succumb as it is difficult to predict how the infection will spread in the general population. A calibrated response to the epidemic must take into account the number of cases, including infected asymptomatic individuals, most of whom are not detected due to a lack of testing. The existing models for SARS-CoV-2 are based on published positive cases and do not take into account either people's age or any evolutive diffusion coefficient. ${ }^{5}$

Our statistical model for predicting the spread of SARS-CoV-2 in France is based on a diffusion and transmission coefficient that varies with an individual's age, the likelihood of contagion, and two administration parameters (confinement and quarantine). We use models to measure how the dynamics of the SARS-CoV-2 infection is affected by these different factors and how to adapt the deconfinement strategy.

Consider the variables $\left(S_{n}, P_{n}, Q_{n}, I_{n}\right)$. We define $A$ as the age class variable:

$A \in\{<18$ y.o, $18-64,65-74, \geq 75$ y.o $\}$.

On day $n$, for a given age class $A, S_{n, A}$ is the number of healthy people, $P_{n, A}^{i}$ is the number of undetected contagious carriers infected for $i$ days $\left(1 \leq i \leq N_{c}\right)$. Similarly, $Q_{n, A}^{i}$ is the number of de- tected contagious carriers infected for $i$ days $\left(1 \leq i \leq N_{c}\right)$ on day $n$. $D_{A}$ is the mortality rate per target age group. We assume that there is the same risk of virus-caused death at any stage of the infection. $I_{n, A}$ is the number of people who are immunized or have died for a given age class $A$.

We define $N_{C}$ as the number of days a person is contagious and $\alpha_{n}$ as the percentage of the population tested on day $n . R_{0}$ is the number of healthy people who a contagious person contacts and infects. We assume that the contagion coefficient varies over time and peaks when the virus load is maximal: 7 days after the start of infection. ${ }^{6} N$ is the total population at the start of the epidemic phase, $c$ is the multiplier for the pace of the epidemic throughout the confinement $(0 \leq c \leq 1)$, and $q$ is the same multiplier during the quarantine period $(0 \leq q \leq 1)$. $c$ and $q$ are equal to 1 when there is no confinement or quarantine phase.

$P_{n}=\sum_{A}\left(1-D_{A}\right) \cdot \sum_{i=1}^{N_{c}} P_{n, A}^{i}$

And

$Q_{n}=\sum_{A}\left(1-D_{A}\right) \sum_{i=1}^{N_{c}} Q_{n, A}^{i}$

$N$ is given by:

$N=\sum_{A} N_{A}=\sum_{A} S_{n, A}+P_{n, A}+Q_{n, A}+I_{n, A}$

On the transition from day $n$ to day $n+1$, we have:

$1 \forall 1 \leq i \leq N_{c}-1, P_{n+1, A}^{i+1}=P_{n, A}^{i}\left(1-\alpha_{n, A}\right)$

$2 P_{n+1, A}^{1}=\frac{S_{n, A}}{N_{A}} \cdot\left[\sum_{i} P_{n, A}^{i} \cdot R_{0}^{i} \cdot c+\sum_{i} Q_{n, A}^{i} \cdot R_{0}^{i} \cdot q\right]$

$3 I_{n+1, A}=I_{n, A}+P_{n, A}^{N_{c}}+Q_{n, A}^{N_{c}}+D_{A} \cdot \sum_{i=1}^{N_{c}-1} P_{n, A}^{i}+D_{A} \cdot \sum_{i=1}^{N_{c}-1} Q_{n, A}^{i}$

$4 Q_{n+1, A}^{1}=0$ (no quarantine the first day, you need the test results)

$\forall 1 \leq i \leq N_{c}-1, Q_{n+1, A}^{i+1}=Q_{n, A}^{i}+P_{n, A}^{i} \cdot \alpha_{n, A}$

The model is a discretized version of a Susceptible Infectious and Recovered (SIR)-type model ${ }^{7}$

We have chosen $R_{0}=2.2 .^{8}$

We estimated the initial model settings using data published by Johns Hopkins University for France ${ }^{9}$ and data collected by the Toulouse Virology Laboratory.

Without containment the prevalence of infection is $8.3 \%$ on March 17 and $97.5 \%$ on May 11 (Fig. 1a). Containment began on March 17 in France and is scheduled to end on May 11. Fig. 1b, c, d, e showed predictions of new cases per day depending on the SARS-CoV-2 seroprevalence before and after the containment phase. Fig. 1b indicates that the seroprevalence before March 17 was $8.3 \%$, and $17.5 \%$ after containment. There was an infection rebound on May 29. However, if the seroprevalence at the beginning of containment was $15.44 \%$ (Fig. 1c), the seroprevalence on May 11 would be $29.1 \%$ and there was an infection rebound. If $31.95 \%$ of the population contracted SARS-CoV-2 before March 17 (Fig. 1d), then $49 \%$ would be infected, immunized or dead on May 11 and the rebound would be smaller. Lastly, when the seroprevalence before containment was $40.05 \%$ (Fig. 1e) there was almost no rebound. The seroprevalence on May 11 was $56.7 \%$. This is why we conclude that the seroprevalence after the containment phase should be between $49 \%$ and $56 \%$ in order to avoid a rebound.

In Fig. 2a we assumed that the containment did not end completely on May 11, but was abolished gradually from May 11 to June 30 , to be totally relaxed from July, 1 . We considered that this progressive phase consisted of a relaxation of $50 \%$ of the restrictive containment measures. Seroprevalence on June 30 was $31.7 \%$ and 

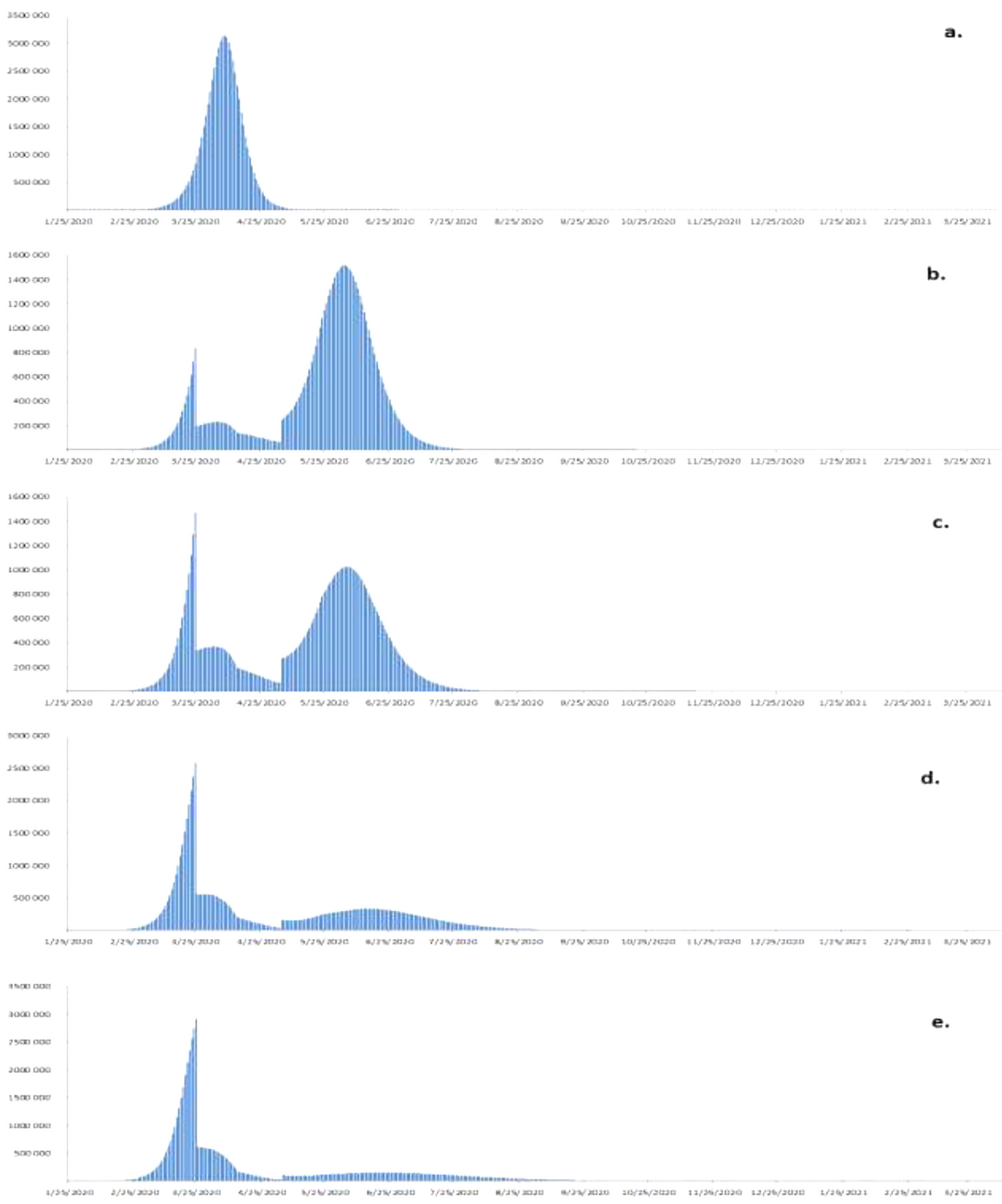

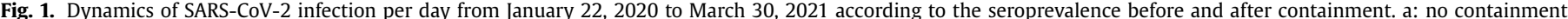

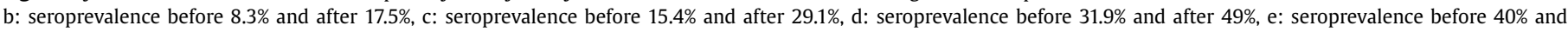
after $56.7 \%$. 

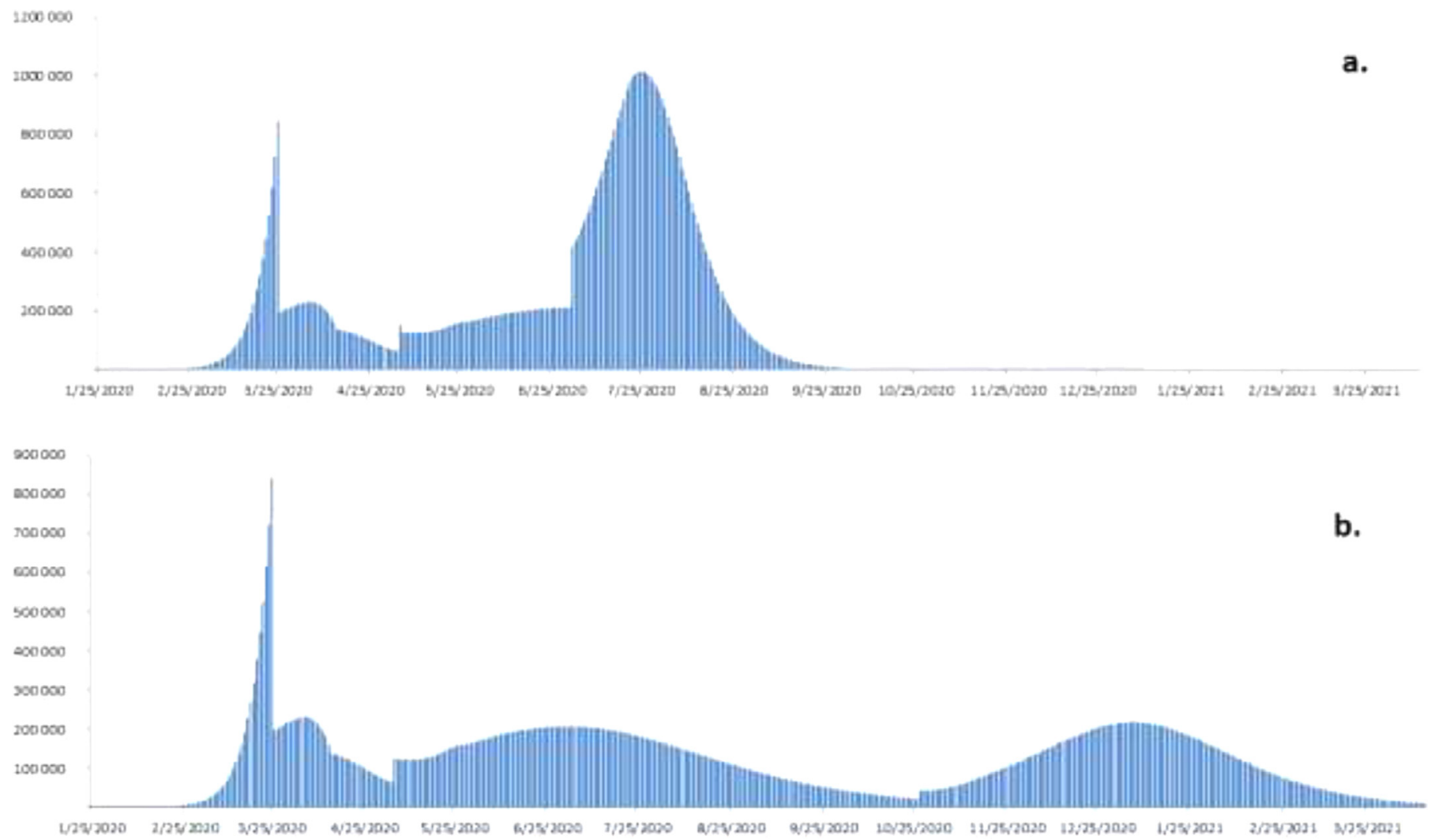

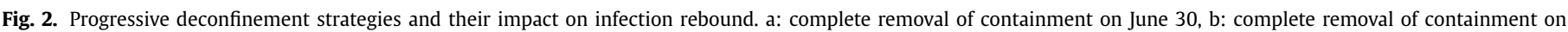
October 25.

leaded to a rebound at the end of July. The ideal situation is that shown in Fig. $2 \mathrm{~b}$, with a progressive deconfinement phase lasting longer, from May 11 to October 25, at which time seroprevalence reached 51.2\%. Relaxation of all restrictions after this date did not lead to a rebound.

Our data indicate that seroprevalence must reach approximately $50 \%$ after total deconfinement on May 11 or a gradual exit phase over several months starting on May 11 if an infection rebound is to be avoided (Fig. 1d, e and Fig. 2b). While the seroprevalence in France before the confinement phase was not measured (March 17) it is probably possible to determine the proportion of the population who came into contact with the virus at the end of the confinement phase. This should provide a basis for estimating the size of any infection rebound. It remains highly unlikely that the case shown in Fig. 1e, with about $50 \%$ of seroprevalence, will apply. It will therefore be a question of adapting the deconfinement strategy to reach $50 \%$ seroprevalence gradually and so avoid a rebound. This may require wearing masks for several months while waiting for vaccine.

The predictive power of the model may be hampered by the way in which casualties are measured, as can the strategy used to detect the number of positive cases. Postprocessing the data to handle such biases will be the topic of future reports.

\section{Acknowledgements}

The English text was edited by Dr Owen Parkes.

\section{References}

1. Perlman S.. Another Decade, Another Coronavirus. N. Engl. J. Med. 2020. https: //doi.org/10.1056/NEJMe2001126.
2. WHO Virtual press conference on COVID-19-11 March 2020 https://www.who.int/docs/default-source/coronaviruse/transcripts/ who-audio-emergencies-coronavirus-press-conference-full-and-final-11mar2020 pdf?sfvrsn=cb432bb3_2 (2020).

3. Saglietto A., D'Ascenzo F., Biondi Zoccai G., Maria de Ferrari G.. COVID-19 in Europe: the Italian lesson. Lancet 2020.

4. Legido-Quigley H., et al. The resilience of the Spanish health system against the COVID-19 pandemic. Lancet 2020.

5. Wu J.T., Leung K.. Nowcasting and forecasting the potential domestic and international spread of the 2019-ncov outbreak originating in wuhan, china: a modelling study. Lancet 2020;395(3).

6. Chang M.G., et al. Time Kinetics of Viral Clearance and Resolution of Symptoms in Novel Coronavirus Infection. Am.J.Res.Crit.Care Med. 2020.

7. Kermack W.O., McKendrick A.G.. A Contribution to the Mathematical Theory of Epidemics. Proc. Roy. Soc. Lond. A 1927;115:700-21.

8. WHO Report of the WHO-China Joint Mission on Coronavirus Disease.(COVID19). Available at: https://www.who.int/docs/default-source/coronaviruse/ who-china-joint-mission-on-covid-19-final-report.pdf (2019).

9. Johns Hopkins database: https://github.com/CSSEGISandData/COVID-19 verified on $03 / 28 / 2020$.

Chloé Dimeglio*

UMR Inserm, U1043; UMR CNRS, U5282, Centre de Physiopathologie de Toulouse Purpan (CPTP), Toulouse 31300, France CHU Toulouse, Hôpital Purpan, Virology Laboratory, 31300 France

Jean-Michel Loubes, Benjamin Deporte Université de Toulouse, Institut de Mathématiques de Toulouse, Toulouse 31400, France

Martine Dubois UMR Inserm, U1043; UMR CNRS, U5282, Centre de Physiopathologie de Toulouse Purpan (CPTP), Toulouse 31300, France CHU Toulouse, Hôpital Purpan, Virology Laboratory, 31300 France

Justine Latour, Jean-Michel Mansuy CHU Toulouse, Hôpital Purpan, Virology Laboratory, 31300 France 
Jacques Izopet

UMR Inserm, U1043; UMR CNRS, U5282, Centre de Physiopathologie de Toulouse Purpan (CPTP), Toulouse 31300, France

CHU Toulouse, Hôpital Purpan, Virology Laboratory, 31300 France

*To whom correspondence should be addressed. E-mail address: dimeglio.c@chu-toulouse.fr (C. Dimeglio)

Accepted 22 April 2020 Available online 29 April 2020

https://doi.org/10.1016/j.jinf.2020.04.031

(c) 2020 The British Infection Association. Published by Elsevier Ltd. All rights reserved.

\section{Early signs that COVID-19 is being contained in Australia}

Dear Editor,

The COVID-19 pandemic is overwhelming many national healthcare networks and crippling many economies. As of 24 April 2020 (11:08AM GMT), a total of 2721,354 confirmed cases, 191,231 deaths and 745,605 recovered cases have been recorded in over 150 countries. $^{1}$ To date, the reported case-fatality varies from 2.3\% (in China) to $7.2 \%$ (in Italy), with substantially higher fatality among older populations, and those with co-morbidities. ${ }^{2}$

Australia has a population of approximately 26 million, of whom $15.4 \%$ are aged 65 years and above. ${ }^{3}$ The first case of COVID-19 infection was reported on 26 January 2020. As of 24 April 2020, there were 6675 known cases, and 78 deaths. Both the federal and state/territory governments have enforced strict public health measures to control this outbreak. ${ }^{4}$ In the present study, we report on the epidemiology of the COVID-19 outbreak in Australia observed thus far, as well as the predicted future numbers of cases, deaths and ICU admissions, and associated ICU costs.

In 2018-2019, total ICU capacity across public and private hospitals in Australia comprised 2229 beds, and the mean cost of each ICU bed-day was AUD $\$ 5040 .{ }^{5}, 6$ We forecasted the number of beds required for COVID-19 patients over time and its associated costs by applying the following conditions: (i) allocation of $10 \%$, $30 \%$ and $50 \%$ of ICU beds for COVID-19; (ii) 3\% (as currently observed in Australia), 5\% (China) and 12\% (Italy) of confirmed cases requiring intensive care; ; (iii) mean ICU stay between 7 and 14 days; and (iv) mean hospital stay prior to intensive care between 7 and 14 days. $^{8}$

Evaluation of temporal changes in trend and dynamic time series forecasting were performed by Box-Jenkins autoregressive integrated moving average and regression models. Predicted models were validated by review of mean absolute percentage errors and $\mathrm{r}$-squared values.

We estimated the mortality rate by dividing the number of deaths on a given day by the number of patients with confirmed
COVID-19 infection (i) on the same day and (ii) seven days before, given that patients who die on any given day were infected much earlier. On this basis, case fatality from COVID-19 infection in Australia is presently between $0.4 \%$ to $3.0 \%$. Fig. 1 depicts the number of new cases observed over time. The number of new cases have decreased since 29 March 2020, with New South Wales, Victoria, Queensland and South Australia all reporting less new cases in the three to five days prior (Supplement Figures $\mathrm{A}$ and $B)$. Hence the rate of rise in incidence has slowed, mindful of the limitations of applying trends to short periods of time. Based on extrapolation of trends prior to 29 March 2020, the Australian healthcare system would have been over-run by over 12,000 confirmed cases by 12 April 2020 (Supplement Figure C). Furthermore, ICU capacity would have been exceeded by mid to end April 2020 (Supplement Figure D). The associated ICU costs would have amounted to between AUD $\$ 8.82$ million and $\$ 34.38$ million if capped at the current maximum number of ICU beds. Notably, Australia has successfully averted these outcomes through timely implementation and strict enforcement of bans on travel and social gatherings, as well as concerted diagnostic and management strategies.

The results of our analysis suggest that Australia is on its way joining China and South Korea in 'flattening the curve'.

\section{Declaration of Competing Interest}

None

\section{Authors contributions}

KLC designed the study and performed the analysis. All authors contributed to manuscript preparation and revision for intellectual content. All authors approved final manuscript version prior to submission.

\section{Funding}

None

\section{Acknowledgment}

None

\section{Supplementary materials}

Supplementary material associated with this article can be found, in the online version, at doi:10.1016/j.jinf.2020.04.042. 


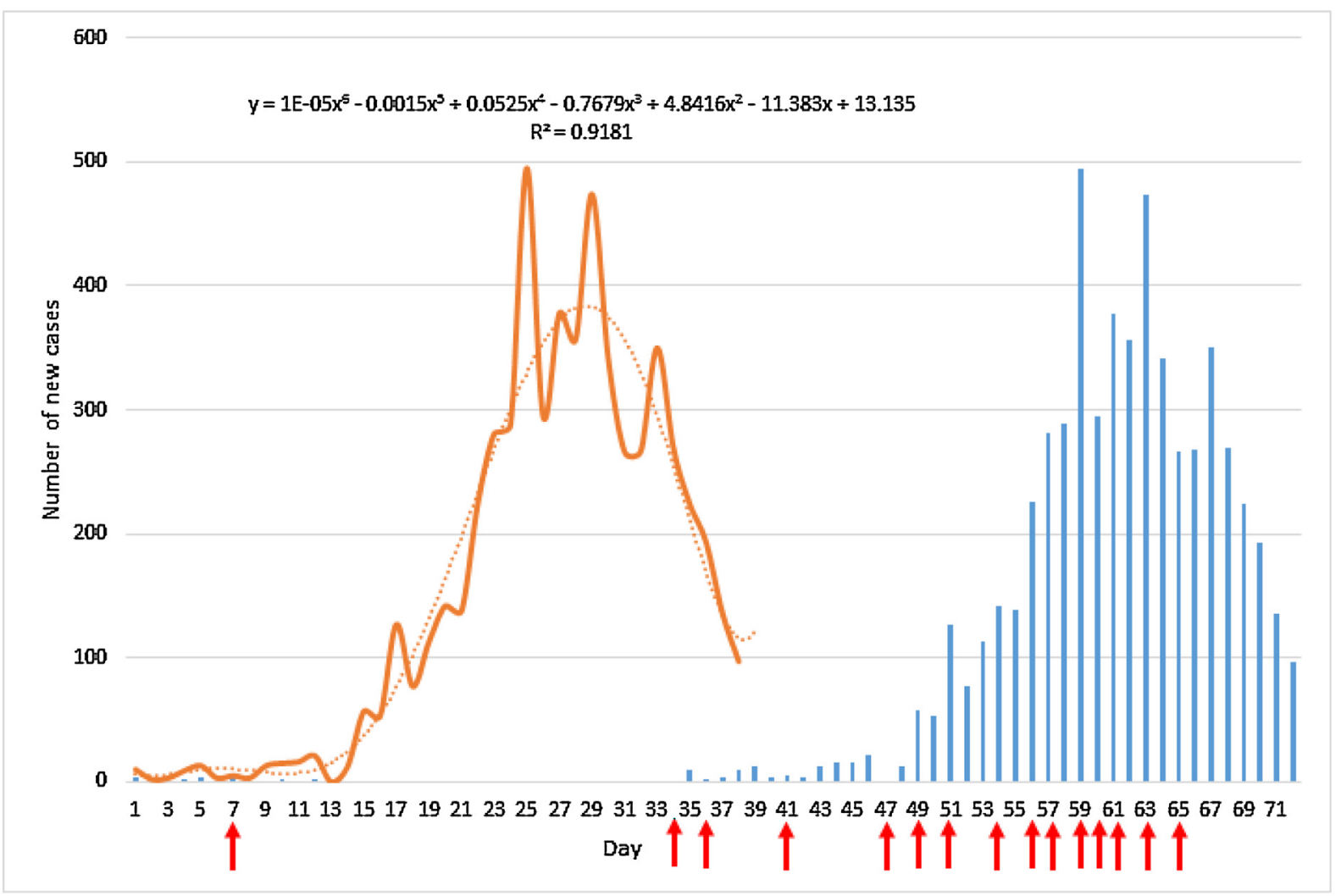

\begin{tabular}{|c|c|c|}
\hline No. & Date & Public health measures \\
\hline 1 & 31 Jan 2020 & $\begin{array}{l}\text { Day } 7 \text { - Foreign nationals returning from China were required to spend a fortnight in a third country } \\
\text { before being allowed into Australia. }\end{array}$ \\
\hline 2 & $27 \mathrm{Feb} 2020$ & $\begin{array}{l}\text { Day } 34 \text { - Australian Health Sector Emergency Response Plan for Novel Coronavirus (COVID-19) } \\
\text { activated. }\end{array}$ \\
\hline 3 & $29 \mathrm{Feb} 2020$ & $\begin{array}{l}\text { Day } 36 \text { - Government extended the enforced quarantine to people returning from Iran, requiring } \\
\text { them to spend a fortnight in a third country before being allowed into Australia. }\end{array}$ \\
\hline 4 & 5 March 2020 & Day 41 - Travel ban on South Korea. \\
\hline 5 & 11 March 2020 & Day 47 - Travel ban on Italy. \\
\hline 6 & 13 March 2020 & Day 49 - Formation of a national crisis cabinet. \\
\hline 7 & 15 March 2020 & Day 51 - All travellers arriving in or returning to Australia must self-isolate for 14 days. \\
\hline 8 & 18 March 2020 & Day 54 - Human biosecurity emergency was declared in Australia \\
\hline 9 & 20 March 2020 & Day 56 - Australia would be closing its borders to all non-residents and non-Australian citizens. \\
\hline 10 & 21 March 2020 & $\begin{array}{l}\text { Day } 57 \text { - Social distancing rule of } 4 \text { square metres ( } 43 \mathrm{sq} \mathrm{ft} \text { ) per person in any enclosed space was } \\
\text { imposed. }\end{array}$ \\
\hline 11 & 23 March 2020 & $\begin{array}{l}\text { Day } 59 \text { - Closure of places of social gathering, including registered and licensed clubs, licensed } \\
\text { premises in hotels and bars, entertainment venues, including but not restricted to cinemas, casinos } \\
\text { and nightclubs and places of worship. Cafes and restaurants are to remain open, but limited to } \\
\text { takeaway only. Similarly, enclosed spaces for funerals and things of that nature will have to follow } \\
\text { the strict four square metre rule. }\end{array}$ \\
\hline 12 & 24 March 2020 & Day 60 - Victoria state closes public schools. \\
\hline 13 & 25 March 2020 & Day 61 - National COVID-19 Coordination Commission (NCCC) was established by the Prime Minister. \\
\hline 14 & 27 March 2020 & $\begin{array}{l}\text { Day } 63 \text { - All States and Territories announced plans in relation to earlier end of Term One in public } \\
\text { schools. The announcements include altering the dates, encouraging parents to keep children at } \\
\text { home and/or having limited supervision/pupil free days in the last week of term for Government } \\
\text { schools, except for the ACT which announced three weeks of pupil-free days. Across all jurisdictions } \\
\text { provisions are still being made during those days for children of 'essential workers', a term loosely } \\
\text { defined and largely any worker who needs to send their child to school, on school sites. }\end{array}$ \\
\hline 15 & 29 March 2020 & $\begin{array}{l}\text { Day } 65 \text { - Two person rule was announced by the Prime Minister, limiting gatherings to maximum of } 2 \\
\text { people. }\end{array}$ \\
\hline
\end{tabular}

Note: Blue bars represent daily observed number of cases in Australia. Brown line denotes smoothed trend line of observed cases. Brown dashed line denotes the projected number of cases.

Fig. 1. Public health measures undertaken to contain COVID-19 in Australia. 


\section{References}

1. The Center for Systems Sciences and Engineering JHU. Coronavirus COVID 19 Global cases. Available at https://gisanddata.maps.arcgis.com/apps/ opsdashboard/index.html\#/bda7594740fd40299423467b48e9ecf6 (Accessed on 31 March 2020)

2. Onder G., Rezza G., Brusaferro S. Case-fatality rate and characteristics of patients dying in relation to COVID-19 in Italy. JAMA 2020 [Epub ahead of print]. doi:10. 1001 /jama.2020.4683.

3. Australian Bureau of Statistics. Population by age and sex, Australia, states and territories. Available at https://www.abs.gov.au/AUSSTATS/abs@.nsf/ featurearticlesbyCatalogue/CCF53AA000E69954CA2582570013F5C6? OpenDocument. Accessed on 31 March 2020.

4. Australian Department of Health. Coronavirus (COVID-19) health alert. Available on https://www.health.gov.au/news/health-alerts/novel-coronavirus-2019-ncovhealth-alert. Accessed on 31 March 2020.

5. Independent Hospital Pricing Authority National pricing model: technical specifications 2019-20. Bull Trimest Plan Fam 2020. https://www.ihpagovau/ sites/default/files/publications/national_pricing_model_technical_specifications_ 2019-20pdf Accessed on 31 March

6. Australian and New Zealand Intensive Care Society. Centre for outcome and resource evaluation report 2018. Avalable athttps://www.anzicscomau/ wp-content/uploads/2019/10/2018-ANZICS-CORE-Reportpdf. Accessed on 31 January 2020.

7. Grasselli G., Pesenti A., Cecconi M. Critical care utilization for the COVID-19 outbreak in Lombardy, Italy: early experience and forecast during an emergency response. JAMA 2020 [Epub ahead of print]. doi:10.1001/jama.2020.4031.

8. Zhou F., Yu T., Du R., Fan G., Liu Y., Liu Z., Xiang J., Wang Y., Song B., Gu X., Guan L., Wei Y., Li H., Wu X., Xu J., Tu S., Zhang Y., Chen H., Cao B. Clinical course and risk factors for mortality of adult inpatients with COVID-19 in Wuhan, China: a retrospective Cohort study. Lancet 2020;395:1054-62.

Ken Lee Chin*

Department of Epidemiology and Preventive Medicine, Monash University, Melbourne Medical School, University of Melbourne Melbourne Medical School, University of Melbourne, Victoria,

Australia

Richard Ofori-Asenso

Department of Epidemiology and Preventive Medicine, Monash

University, Melbourne Medical School, University of Melbourne

Copenhagen Centre for Regulatory Science, Department of Pharmacy, University of Copenhagen, Copenhagen, Denmark

Kaylee A. Jordan

Department of Anaesthesia and Pain Management, Royal Melbourne Hospital, Melbourne, Australia

Daryl Jones Department of Epidemiology and Preventive Medicine, Monash University, Melbourne Medical School, University of Melbourne Austin Health, Melbourne, Australia Department of Surgery, University of Melbourne Victoria, Australia

Danny Liew

Department of Epidemiology and Preventive Medicine, Monash University, Melbourne Medical School, University of Melbourne

*Corresponding author. E-mail address: ken.chin@unimelb.edu.au (K.L. Chin)

Accepted 27 April 2020 Available online 1 May 2020

https://doi.org/10.1016/j.jinf.2020.04.042

(c) 2020 The British Infection Association. Published by Elsevier Ltd. All rights reserved.
Rethinking pandemic preparation: Global Health Security Index (GHSI) is predictive of COVID-19 burden, but in the opposite direction

Dear Editor,

A recent article in Journal of Infection by Lv et al. projected that many countries could face similar COVID-19 situations as witnessed in Hubei in China. ${ }^{1}$ There are many factors that can influence the course of an infectious disease outbreak.

In the wake of the Ebola outbreak in 2014, the Global Health Security Index (GHSI) was developed with the aim of gauging countries' capacity to deal with infectious disease outbreaks. ${ }^{2}$ The GHSI highlights the shortcomings of existing pandemic policies and procedures, with the aim of spurring improvement of future practices. The index ranges from 0 to 100 , and assesses six core elements: prevention, detection and reporting, response, health system, compliance with norms and risk of infectious disease outbreaks. $^{2}$ A higher GHSI indicates better preparedness.

In the present study, we examined the correlation between GHSI and various measures of COVID-19 burden across different countries. We hypothesised that higher GHSI was inversely associated with measures of COVID-19 burden.

Country-level data on COVID-19 as at 11 April 2020 were sourced from the 'worldometer'. ${ }^{3}$ Countries without testing data, or those with no assigned GHSI score were excluded. Furthermore, we included only countries with at least 100 confirmed cases of COVD-19. Data on countries' median age and proportion of females in 2019 were sourced from the United Nations population database. ${ }^{4}$

We analysed the association between GHSI and COVID-19 burden, represented by numbers of tests confirmed cases and deaths per million people per day since the first confirmed case in each country. First, we plotted GHSI against natural log transformed values of these outcomes (to provide more symmetrical distributions). Secondly, we used a generalised linear model (GLM) to determine the association between GHSI and confirmed cases and deaths per million people per day, with adjustment for testing rate, population median age and proportion of females.

We considered GHSI both as a continuous variable and as a categorical variable comprising four quartiles. In the latter analyses, the first (lowest) quarter of GHSI was considered as the reference category.

A total of 100 countries with complete data were included in the analysis (Supplementary Table S1). At the time of the analyses, there were 1,431,533 confirmed COVID-19 cases globally and 82,058 deaths. The median number of tests per million population across the included countries was 2486 (interquartile range [IQR] 623-9515). The countries with the highest and lowest testing rates were Iceland $(84,957$ per million population) and Nigeria ( 24 per million population), respectively. The median number of cases and deaths per million population were 207 (IQR: 35-498) and 3 (IQR: $0 \bullet 8-11)$, respectively.

COVID-19 metrics (log transformed) plotted against GHSI are presented in Fig. 1. These suggest a positive correlation between GHSI and testing rate, as well as cases and deaths per million people per day since the first recorded case. Of note, the US was the highest ranked country in terms of GHSI of all 100 countries analysed yet had the largest number of COVID-19 cases worldwide at the time of analyses. ${ }^{2,3}$ Second-ranked UK was also bearing a large burden of disease. 


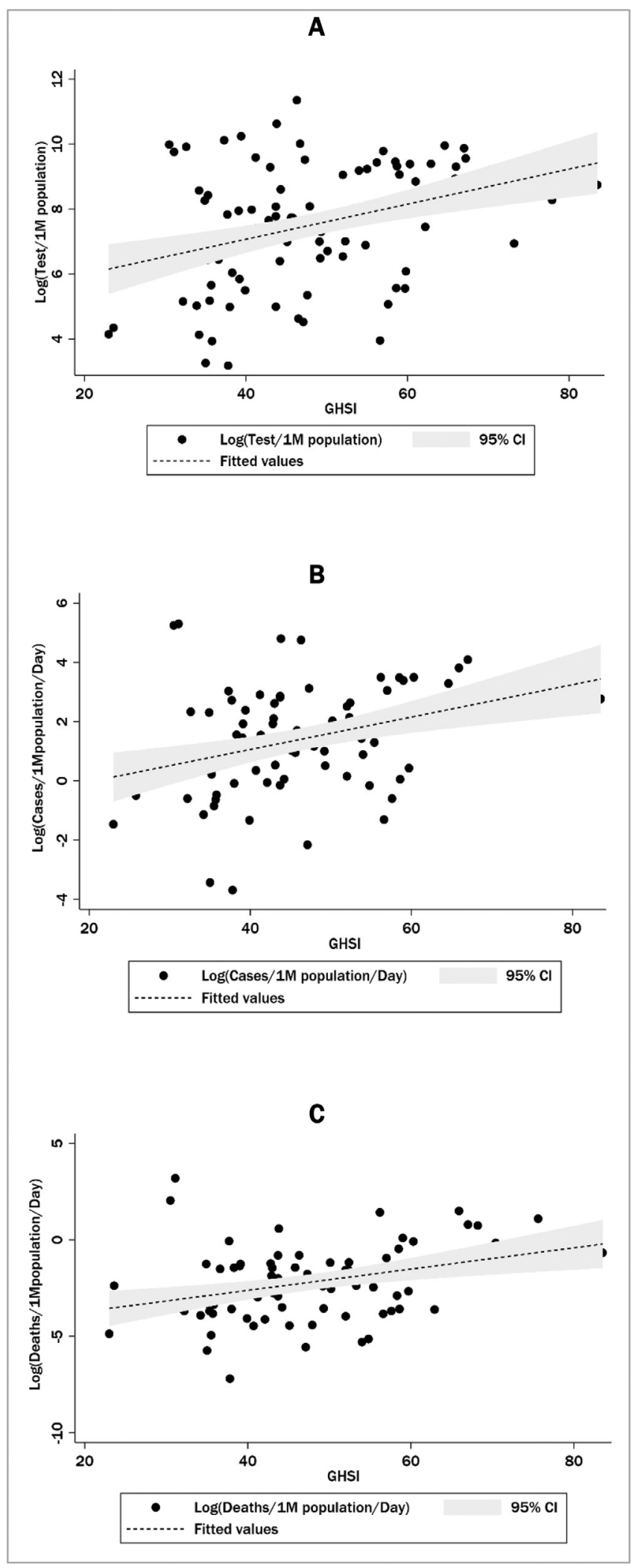

Figure 1. Scatter plot of showing unadjusted correlation between GHSI and testing rate (A), COVID-19 cases (B) and deaths (C) per million people per day.
The results from the GLM model are presented in Table 1. There was no statistically significant association observed between GHSI and testing rate. After adjusting for testing rate, median age and the proportion of females, a positive association was also observed between GHSI and COVID-19 cases and deaths, with the biggest burden borne by countries at the highest quartile of GHSI.

The findings of our study were unexpected. First, no association was noted between GHSI and testing rate, despite that GHSI should serve as a surrogate for healthcare capacity, including COVID-19 testing. Effective pandemic response requires significant investment in testing, with adequate training of healthcare workers in testing, as well as sufficient supply of PPE and testing kits. ${ }^{5}$ In addition, effective and widespread dissemination of information to the general population regarding testing criteria assists case detection. $^{5}$

Secondly, the associations between GHSI and COVID-19 cases and deaths were positive, meaning that the GHSI can reflect a country's capacity to deal with epidemics or pandemics, but in the opposite manner than intended. No doubt there was confounding by increased globalisation among more developed countries (with higher GHSI). Increased exposure to foreigners travelling for the purposes of tourism, business and use of healthcare is likely to increase the risk of new infectious pathogens being introduced. Similarly, mass migration contributes to disruption of local bacterial and viral environments. ${ }^{2}$ Furthermore, the rarity of pandemics in conjunction with false reassurance from a high GHSI may have contributed to more lenient adherence to infection control mechanisms in recent years. ${ }^{6}$

The intent of the GHSI is noble, and the findings of our study should not discourage future endeavours to gauge capacity to respond to pandemics. However, as the world becomes increasingly interconnected, the value of assessing the capacity of countries to manage infectious disease outbreaks individually is redundant. This interconnectedness extends beyond social, political, and business interactions to pathogenic environments. Consequently, identifying and controlling spread of newly arising infectious agents is only as effective as the practices within the poorest performing countries.

The COVID-19 pandemic has revealed insufficiencies in existing knowledge of pandemic preparedness and response. A more integrated global approach is necessary, as is further research into alternative factors related to infection control that have not yet been considered. Development of international response protocols and effective communication channels will permit coordinated global action. Furthermore, establishment of dynamic models and tools will ensure the world is better prepared for future outbreaks.

\section{Acknowledgement}

None

\section{Funding}

None

\section{Conflicts of interest}

None

\section{Authors contribution statement}

All authors contributed to study design, data analysis and manuscript preparation. All authors read and approved final version before submission 


\section{Supplementary materials}

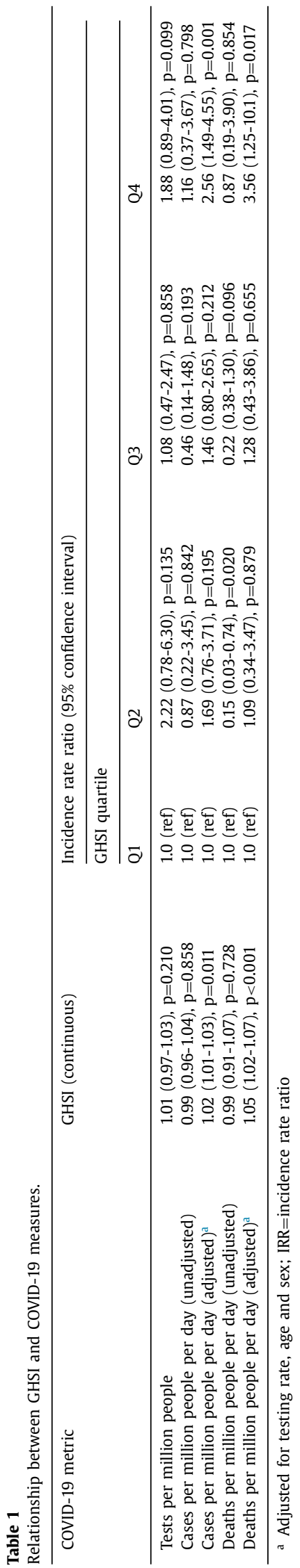

Supplementary material associated with this article can be found, in the online version, at doi:10.1016/j.jinf.2020.05.001.

\section{References}

1. Lv B., Li Z., Chen Y.. Global COVID-19 fatality analysis reveals Hubeilike countries potentially with severe outbreaks. J Infect 2020 Apr 14 pii: S0163-4453(20)30157-2.

2. Nuclear Threat Initiative, Johns Hopkins Center for Health Security, The Economist Intelligence Unit. Global Health Security Index. Available from: https: //www.ghsindex.org/ (Accessed April 13 2020).

3. Worldometers.info. Worldometer COVID-19 Coronavirus Pandemic. Available from: https://www.worldometers.info/coronavirus/ (Accessed April 26, 2020).

4. United Nations, Department of Economic and Social Affairs, Population Division. World Population Prospects 2019 Available from: https://population.un. org/wpp/Download/Standard/Population/ (Accessed April 11, 2020).

5. Krumkamp R., Ahmad A., Kassen A., Hjarnoe L., Syed A.M., Aro A.R., et al. Evaluation of national pandemic management policies $-A$ hazard analysis of critical control points approach. Health Policy 2009;92(1):21-6.

6. World Health Organisation. The world health report 2007 - A safer future: global public health security in the 21st century. Heymann D.L., Prentice Thomson, Reinders Lina Tucker, editors. Geneva: World Health Organisation; 2007.

Tess Aitken

School of Public Health and Preventive Medicine, Monash University, Melbourne, Australia

Ken Lee Chin

School of Public Health and Preventive Medicine, Monash University, Melbourne, Australia

Melbourne Medical School, The University of Melbourne, Australia

Danny Liew

School of Public Health and Preventive Medicine, Monash University, Melbourne, Australia

Richard Ofori-Asenso*

School of Public Health and Preventive Medicine, Monash University, Melbourne, Australia

Department of Pharmacy, Faculty of Health and Medical Sciences, University of Copenhagen, Copenhagen, Denmark

*Address correspondence to: Richard Ofori-Asenso, PhD,

Department of Epidemiology and Preventive Medicine, Monash University, Melbourne, Victoria, Australia, Tel +61411092470. E-mail address: Richard.ofori-asenso@moansh.edu (R. Ofori-Asenso)

Accepted 2 May 2020

Available online 8 May 2020

https://doi.org/10.1016/j.jinf.2020.05.001

(c) 2020 The British Infection Association. Published by Elsevier Ltd. All rights reserved.

\section{Escherichia coli isolated in pigs, Guangdong, China: Emergence of extreme drug resistance (XDR) bacteria}

Dear Editor,

Recently, the emergence of extreme drug resistance (XDR) bacteria coupled with the lack of new drugs in the pipeline had raised public health concern globally. ${ }^{1}$ Escherichia coli (E. coli) is one of the several opportunistic bacteria, which leads to serious economic losses in terms of mortality and morbidity, especially in the pig 
industry. Some strains of the E. coli can cause colibacillosis, severe diarrhea, enteritis, cellulitis, lower productivity, and death in pigs. ${ }^{2}$ For the treatment of these infections, a wide variety of broadspectrum antibiotics as first-line treatment drugs are used to prevent or cure diseases. Bacterial culture and antibiotic sensitivity testing are not always carried out at farm levels for directing antibiotics choices, leading to inappropriate empirical treatment in pig industry. ${ }^{3,4}$ Many bacterial pathogens are exhibiting resistance to increasing numbers of antibiotics making it much more challenging to treat the infections caused by these microbes. ${ }^{3}$

In 2019, a pig farm in Guangzhou, China suffered a severe outbreak of diarrhea among pigs. The owner treated the pigs with antibiotics including Enoxacin, Oxytetracycline, Amoxicillin, Lincomycin, and Flurbenicol, but poor treatment response against diarrhea and large numbers of deaths were noticed which caused huge economic losses. In response to this threat, the diarrhea feces were transported to south China agricultural university for further experimentation. After that, fecal samples were isolated, cultured and identified according to our previous study; ${ }^{5}$ the pathogenic bacterium was confirmed as an E. coli. Antimicrobial resistance testing of the isolates was performed through disk diffusion by using the following drugs: Cefalexin, Cefazolin, Amikacin, Gentamicin, Penicillin, Kanamycin, Ampicillin, Piperacillin, Minocycline, Tetracycline, Doxycycline, Streptomycin, Lincomycin, Vancomycin, Erythromycin. Unfortunately, the above antibiotics showed high resistance. To further confirm our findings, drug resistance genes were screened (bla ${ }_{\mathrm{TEM}}$, bla $\mathrm{SHV}_{\mathrm{H} V}$, qnrA, aac-Im, AphA1, TETA, FloR, and Sul), and the PCR was performed in applied thermal cycler using PCR kits according to the manufacturer's instructions. The result showed that the isolate carried all the above antibiotic resistance genes, which considered as the extreme drug resistance (XDR) bacteria. These results signify that antimicrobial resistance could be reduced by restricting the rational use of antibiotics in intensive farming. Furthermore, the high rate of resistance in pigs is expected because antibiotics continuously used as growth promoters, and for disease prevention and therapy in pig farming in China. ${ }^{6}$ As such, antibiotic resistant strains could readily be spread via direct contact as well as through cross contamination of water, food, and feces, between pigs and with other farm animals, even human present within the study area. ${ }^{6,7}$

Tackling antibiotic resistance is a high priority for WHO. A global action plan on antimicrobial resistance, including antibiotic resistance, was endorsed at the World Health Assembly in May $2015 .^{8}$ China is the world's largest producer and consumer of antibiotics and is the epicenter of antibiotic abuse and bacterial resistance. In the past, the abuse of antibiotics in the population was more prominent; and now, the use of antibiotics in China gradually tends to be "animal use". ${ }^{9}$ At present, the antibiotics are still widely used in animals to prevent and control animal diseases and promote growth, such as bate-lactams, aminoglycosides, tetracyclines, sulfonamides, quinolones, etc. The misuse and abuse of antibiotics can accelerate the development of drug resistance in pathogens. Therefore, China's ministry of agriculture has adopted a comprehensive "antimicrobial-free feed" by 2020 to reduce the harm caused by the overuse of antibiotics. ${ }^{10}$

Due to the misuse and abuse of antibiotics, the emergence of antibiotic resistance is accelerating that makes the prevention and control of pathogens infection difficult. So, the government should make all stakeholders (individuals, policy makers, healthcare industry, scientists, and agriculture sector, etc.) unite to take action to prevent and control the spread of antibiotic resistance to avoid further infection of $E$. coli in animal production and possible animal and public health consequences.

\section{Declaration of Competing Interest}

None of the authors have any conflict of interest.

\section{Acknowledgment}

The study was supported by the Outstanding Young Talents Project of South China Agricultural University.

\section{References}

1. Sorlí L., Luque S., Li J., et al. 2019. Colistin for the treatment of urinary tract infections caused by extremely drug-resistant Pseudomonas aeruginosa: dose is critical. I Infect 2019:79:253-61.

2. John M.F., Eric N., Carlton L.G.. Escherichia coli in postweaning diarrhea in pigs: an update on bacterial types, pathogenesis, and prevention strategies. Anim Health Res Rev 2005;6(01):17-39.

3. Neil S.G.. "Infectious Supercarelessness" in Discussing Antibiotic-Resistant Bacteria. Pathog Immun 2016;1(2):304-7.

4. Emma S., Manal A., Ellie S., et al. Use of whole genome sequencing of commensal Escherichia coli in pigs for antimicrobial resistance surveillance, United Kingdom, 2018. Euro Surveill 2019;24(50):1900136.

5. Zhang H., Li K., Wang Y.J., et al. Investigation and characterization of $\beta$-lactam resistance in Escherichia coli strains isolated from bamboo rats (Rhizomyssinensis) in Zhejiang province, China. J Vet Med Sci 2017:79(10):1633-6.

6. Kittitat L., Jitrapa Y., Waree N., et al. Antimicrobial Resistance in Commensal Escherichia coli Isolated from Pigs and Pork Derived from Farms Either Routinely Using or Not Using In-Feed Antimicrobials. Microb Drug Resist 2018;24(7):1054-66.

7. Rukayya H.A., Evelyn M., Oluwawemimo A., et al. Antimicrobial usage in pig production: effects on Escherichia coli virulence profiles and antimicrobial resistance. Onderstepoort J Vet Res 2019;86(1):1743.

8. World Health Organization (WHO). Antibiotic resistance. [cited 2020 April 16]. https://www.who.int/news-room/fact-sheets/detail/antibiotic-resistance.

9. Zhang O.Q. Ying G.G., Pan C.G., et al. Comprehensive evaluation of antibiotics emission and fate in the River Basins of China: source analysis, multimedia modeling, and linkage to bacterial resistance. Environ Sci Technol 2015;49(11):6772-82.

10. Announcement No. 194 by the ministry of agriculture and rural, China [cited 2020 April 16]. http://www.moa.gov.cn/gk/tzgg_1/gg/201907/t20190710_ 6320678.htm.

Yajing Wang ${ }^{1}$, Jianzhao Liao ${ }^{1}$ College of Veterinary Medicine, South China Agricultural University, Guangzhou 510642, China

Khalid Mehmood University College of Veterinary \& Animal Sciences, Islamia University of Bahawalpur, Bahawalpur, Pakistan

Yung-Fu Chang College of Veterinary Medicine, Cornell University, Ithaca, NY, USA

Zhaoxin Tang*, Hui Zhang* College of Veterinary Medicine, South China Agricultural University, Guangzhou 510642, China

*Corresponding authors.

E-mail addresses: tangzx@scau.edu.cn (Z. Tang), hz236@scau.edu.cn

(H. Zhang)

1 These authors made equal contributions.

Accepted 3 May 2020

Available online 14 May 2020

https://doi.org/10.1016/j.jinf.2020.05.003

(c) 2020 The British Infection Association. Published by Elsevier Ltd. All rights reserved. 